\title{
EL ÁLGEBRA Y SU ENSEÑANZA EN LA ARITHMETICA ESPECULATIVA, Y PRACTICA Y ARTE DE ALGEBRA DE ANDRÉS PUIG (1672)
}

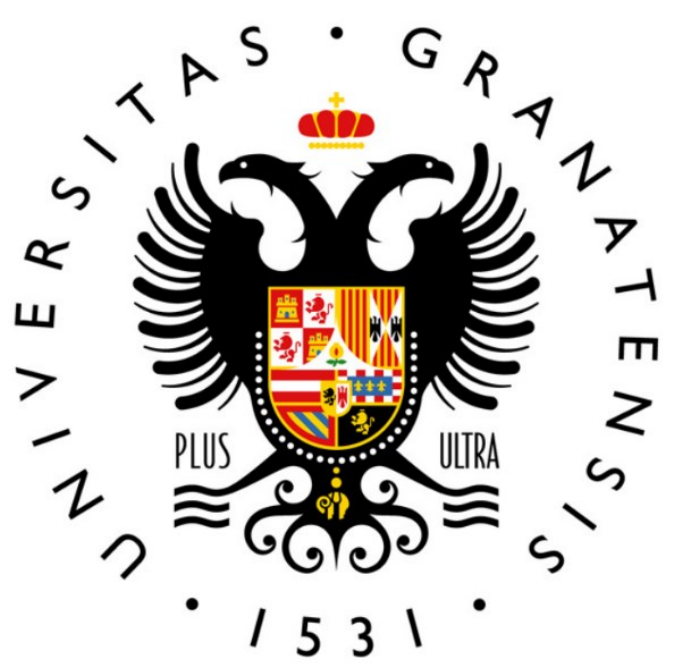

\section{UNIVERSIDAD DE GRANADA}

Trabajo Fin de Máster en Didáctica de la Matemática

Facultad de Ciencias de la Educación

Departamento de Didáctica de la Matemática

Granada, 2020 


\section{EL ÁLGEBRA Y SU ENSEÑANZA EN LA ARITHMETICA ESPECULATIVA, Y PRACTICA Y ARTE DE ALGEBRA DE ANDRÉS PUIG (1672)}

JACINTO RUIZ CATALÁN

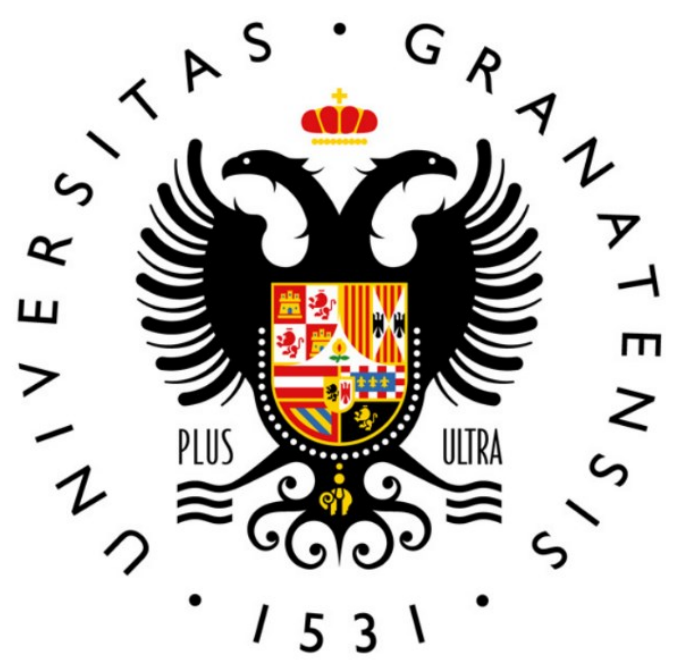

\section{UNIVERSIDAD DE GRANADA}

Trabajo Fin de Máster en Didáctica de la Matemática Facultad de Ciencias de la Educación

Departamento de Didáctica de la Matemática

\section{Dirigido por}

Dr. D. Luis Puig Espinosa 
RESUMEN: En este trabajo se estudia el libro "Arithmetica Especulativa, y Practica, y arte de Algebra" de Andrés Puig, publicado en 1672 y reimpreso con adiciones póstumas en varias ocasiones durante el siglo XVIII, desde el punto de vista de la didáctica de las matemáticas. Se comparan algunos aspectos del álgebra del autor respecto al álgebra española del siglo XVI y del álgebra de su contemporáneo José Zaragoza. Se estudian los dos algoritmos de resolución generales de ecuaciones polinómicas, uno de posible influencia de Viète, y comparándolo con uno de igual influencia, pero de Zaragoza y otro por aproximación con influencia de Nicolás Chuquet. Por último, se analizan las adiciones a la primera impresión, como paratextos. Estas adiciones muestran, entre otras cosas, cómo el autor explica de maneras diferentes (con métodos aritméticos y algebraicos) el mismo problema o cómo resuelve el autor lo que para nosotros sería un sistema de ecuaciones lineales con dos incógnitas pero haciendo uso de una sola incógnita (la cosa).

Palabras clave: Didáctica de las matemáticas, álgebra del siglo XVII, resolución general de ecuaciones, adiciones como paratextos, matemáticos españoles.

\begin{abstract}
This work presents an study of Andrés Puig's book Speculative Arithmetic, and Practice, and Algebra Art, published in 1672 and reprinted with posthumous additions during the XVIII century, from the point of view of the didactics of mathematics. In this case, some aspects of the author's algebra are compared with respect to 16 th century Spanish algebra and the algebra of his contemporary José Zaragoza. The two general algorithms for solving polynomial equations are studied, one with a possible influence of Viète, and comparing it with one of the same influence, but from Zaragoza and another by approximation with influence of Nicolás Chuquet. Finally, the additions to the first impression are analyzed, as paratexts. These additions show the author's approach in different ways (with arithmetic and algebraic methods) the same problem or the method that author uses to solve what for us would be a system of linear equations with two unknowns but making use of a single unknown. (the thing).
\end{abstract}

Key words: Didactics of mathematics, 17th century algebra, general solution of equations, additions as paratexts, Spanish mathematicians. 
Agradezco a mi familia y amigos su paciencia cuando a veces he sido pesado hablando de mi TFM. Pero sobre todo le agradezco a Luis Puig sus consejos, recomendaciones, indicaciones, enseñanzas, su tiempo dedicado a mí y su paciencia durante los meses que hemos estado en contacto, trabajando sobre mi TFM. Partí de casi no saber nada de la historia de los matemáticos españoles y casi nada de investigación. Con su ayuda he conseguido saber un poquito de ambas cosas. El saber un poco de la historia de los matemáticos españoles, y en concreto de Andrés Puig, me ha hecho valorar a estos maestros como correa de transmisión de los conocimientos matemáticos antiguos. En contra de lo que opinaban eminentes historiadores de las matemáticas de finales del XIX y principios del XX, creo que nuestros matemáticos de los siglos anteriores a ellos han sido clave para que se hayan transmitido los conocimientos hasta nuestros días. No todos pueden ser Viète, Descartes o Gauss. Junto a estos eminentes matemáticos deben estar los maestros que sepan transmitir a las siguientes generaciones sus conocimientos, y uno de estos maestros es Andrés Puig. Y para mí, otro de ellos es Luis Puig. Gracias, maestro. 
A mi hijo Alberto

A mi compañera de viaje, Isa 


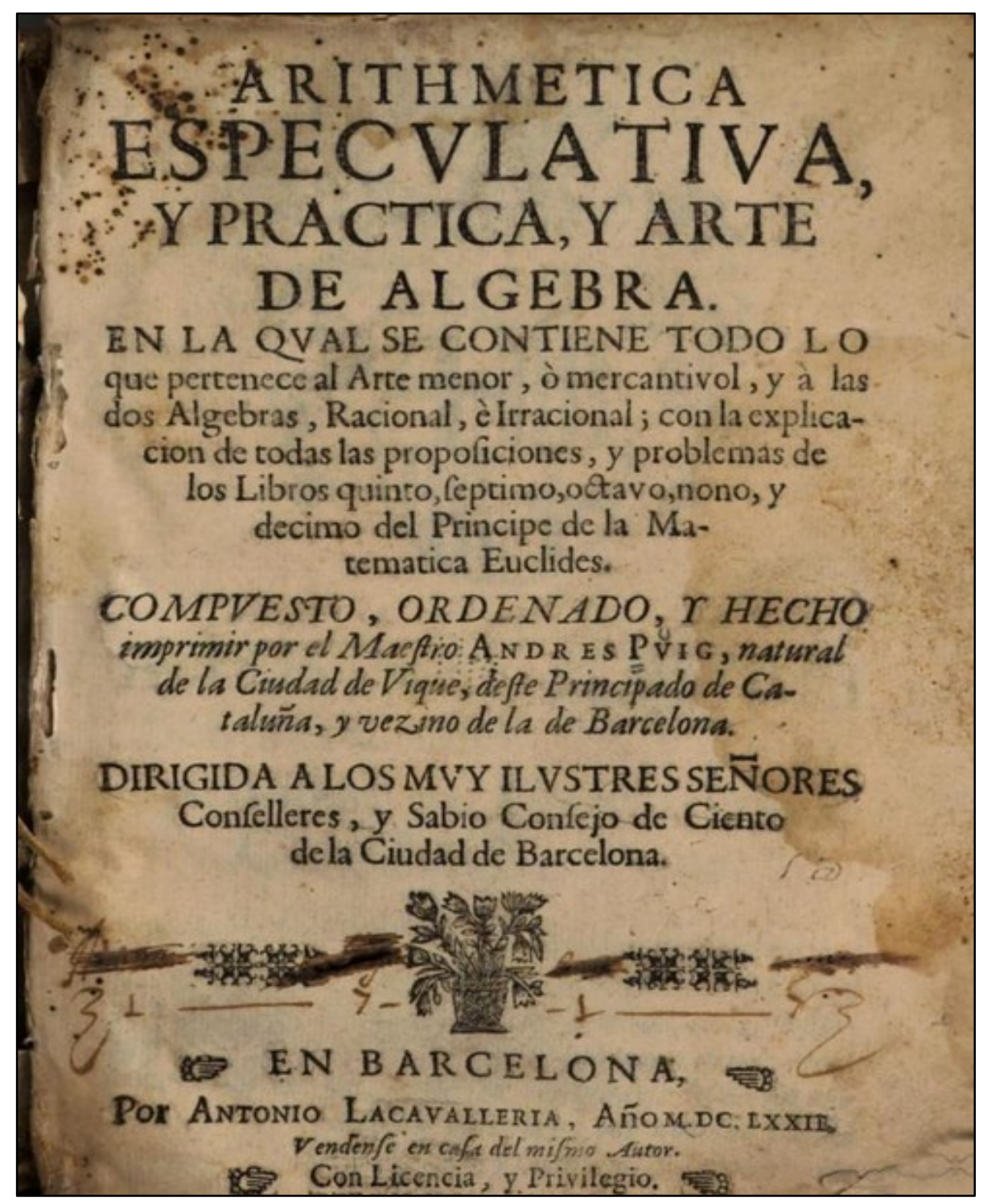

Portada de la Arithmetica de Andrés Puig. Primera impresión de 1672 


\section{ÍNDICE}

1 INTRODUCCIÓN................................................................... 1

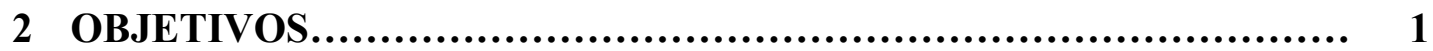

3 MARCO TEÓRICO Y METODOLÓGICO.................................... 2

4 CONTEXTO HISTÓRICO.................................................... 6

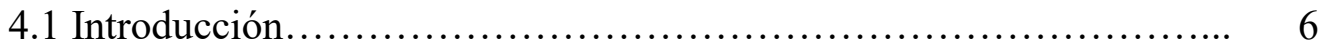

4.2 España y Europa en el siglo XVII................................... 6

4.3 España en el siglo XVII.......................................... 7

4.4 Comienzos del siglo XVIII........................................ 7

4.5 La educación científica.............................................. 7

4.6 La matemática española....................................... 8

5 BIOGRAFÍA DE ANDRÉS PUIG...................................... 8

5.1 Información presente en su obra................................. 8

5.2 Referencias que aparecen en libros de aritmética de los siglos XVIII y XIX.

5.3 Referencias y biografías breves de historiadores que no son de las matemáticas.

5.4 Referencias de historiadores de la ciencia no recientes o matemáticos de finales del siglo XIX y XX ....................................... 10

5.5 Referencias de historiadores de las matemáticas más recientes......... 11

6 CONVENIOS DE TRANSCRIPCIÓN, ESTRUCTURA, IMPRESIONES Y ORGANIZACIÓN DE LA ARITHMETICA............ 11

6.1 Convenios de transcripción........................................ 11

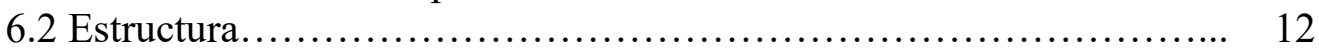

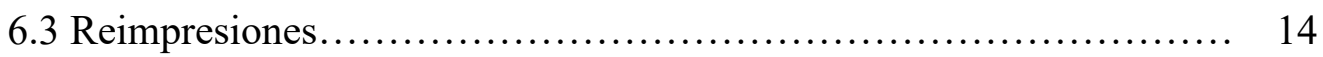

6.4 Organización.................................................... 16

7 EL LENGUAJE ALGEBRAICO DE LA ARITHMETICA .................. 18

8 MÉTODOS DE RESOLUCIÓN DE ECUACIONES POLINÓMICAS... 25

8.1 Método general de cálculo de raíces................................ 25

8.2 Método general de cálculo de raíces aproximadas..................... 31

9 ANÁLISIS DE LAS ADICIONES........................................... 34

10 CONCLUSIONES Y TRABAJO FUTURO............................. 54

11 REFERENCIAS........................................................ 56

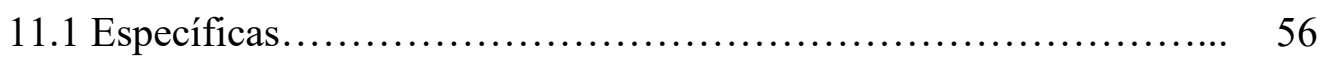

11.2 Generales.................................................... 56

ANEXO I. Resolución de una ecuación por el método general de resolución de ecuaciones de Andrés Puig........................................... 61

ANEXO II. Resolución de una ecuación por el método general de resolución de ecuaciones de Andrés Puig.................................... 63

ANEXO III. Resolución de una ecuación por el método general de resolución de ecuaciones de Andrés Puig................................... 64

ANEXO IV. Resolución de una ecuación por el método general de resolución de ecuaciones de José Zaragoza.................................. 65

ANEXO V. Algoritmo por aproximación de Chuquet con alto nivel de abstracción.

ANEXO VI. Algoritmo por aproximación de Puig con alto nivel de abstracción.

ANEXO VII. Maravillas de Ventallol......................................... 69

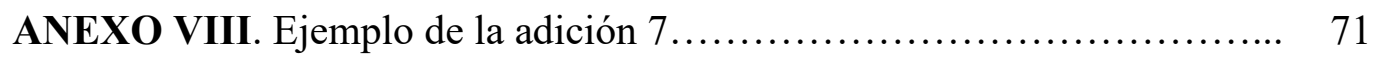


ANEXO IX. Problema de los assentistas de la adición $8 \ldots \ldots \ldots \ldots \ldots \ldots \ldots . \ldots 2$

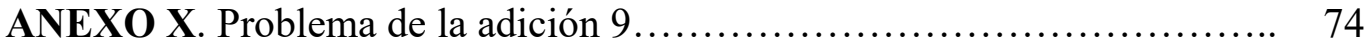

ANEXO XI. Lectura analítica aritmética de la adición $10 \ldots \ldots \ldots \ldots \ldots \ldots . . \ldots 75$

ANEXO XII. Lectura analítica algebraica de la adición 10............... 77

ANEXO XIII. Demostración de la adición 11........................... 79

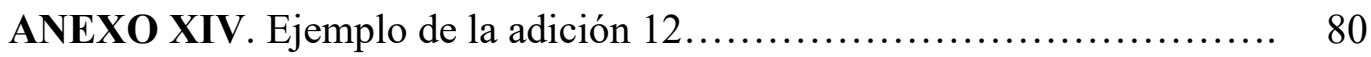

ANEXO XV. Evidencias de la adición 19............................... 81 


\section{FIGURAS}

Figura 1 Potencias, géneros y denominaciones en Andrés Puig................... 19

Figura $2 \quad$ Nombres de los elementos......................................... 21

Figura $3 \quad$ Triángulo de Tartaglia-Pascal..................................... 27

Figura 4 Tabla tipo matriz.................................................. 40

Figura $5 \quad$ Tabla por números................................................... 40

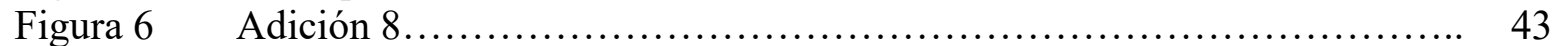

Figura $7 \quad$ Ejemplo décimo....................................................... 44

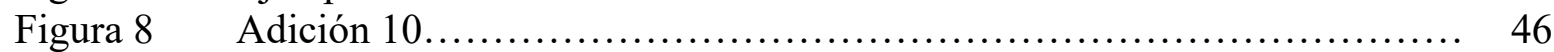

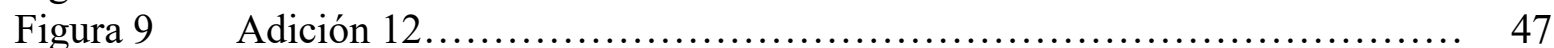

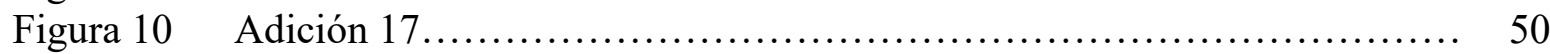

Figura $11 \quad$ Ciclo de ida y vuelta............................................. 55

Figura 12 Algoritmo equivalente a la Regla de los Números Intermedios de Chuquet 67

Figura 13 Algoritmo equivalente a la Regla Media de Andrés Puig................ 68

Figura 14 Primera maravilla de Ventallol (Tolrà, 1619, p. 481).................... 69

Figura 15 Sexta maravilla de Ventallol (Tolrà, 1619, p. 483)....................... 70

Figura 16 Dos maneras de realizar cálculos mercantiles.......................... 71

Figura $17 \quad$ Fórmula del interés para los assentistas.............................. 73

Figura $18 \quad$ Fórmula del interés mejorada...................................... 73

Figura 19 Grafo de la lectura analítica aritmética.............................. 75

Figura 20 Grafo de la lectura analítica algebraica............................ 77

\section{TABLAS}

Tabla 1 Impresiones del libro........................................ 16

Tabla 2 SMS del siglo XVI, de Zaragoza y de Puig....................... 22

Tabla 3 Ecuaciones en el siglo XVI, en Puig y en Zaragoza.................. 24

Tabla 4 Tipología de las igualaciones en Andrés Puig...................... 26

Tabla 5 Tipología de las ecuaciones en José Zaragoza...................... 29

Tabla 6 Relación de la situación de las adiciones.......................... 36 


\section{INTRODUCCIÓN}

En este trabajo estudiamos el libro "Arithmetica Especulativa, y Practica, y arte de Algebra" de Andrés Puig, publicado en 1672 y reimpreso con adiciones póstumas en varias ocasiones durante el siglo XVIII, desde el punto de vista de la didáctica de las matemáticas. En el capítulo 2 presentamos los objetivos del trabajo. En el capítulo 3 exponemos brevemente el marco teórico y metodológico utilizado. En el capítulo 4 expondremos de manera sucinta el contexto histórico. En el capítulo 5 lo poco que sabemos de la biografía de Andrés Puig. En el capítulo 6 describimos el libro como objeto, estableciendo previamente los criterios de transcripción y después las estructura, reimpresiones y organización temática.

Los capítulos 7, 8 y 9 constituyen el centro del estudio. En el capítulo 7 estudiamos el lenguaje o sistema matemático de signos que usa Puig en el libro comparándolo con algunos de los algebristas españoles o que escriben en español del siglo XVI (Marco Aurel, Juan Pérez de Moya y Pedro Núñez) y con su contemporáneo José Zaragoza. En el capítulo 8 estudiamos los Métodos de Resolución de Ecuaciones Polinómicas, y está dividido en dos partes: en la primera, estudiamos el Método General de Cálculo de Raíces y en la segunda el Método General de Cálculo de Raíces Aproximadas. En el capítulo 9 estudiamos todas las adiciones póstumas a la primera impresión de 1672.

En el capítulo 10, presentamos un resumen de los resultados del estudio en forma de conclusiones, y una indicación de una posible continuación del trabajo que queda abierta para su realización futura.

El capítulo 11 recoge las referencias bibliográficas de los textos citados en el trabajo y las referencias bibliográficas de todas las impresiones distintas que hemos localizado del libro objeto de estudio.

Finalmente, en los anexos recogemos dos algoritmos explicativos de los métodos de resolución de raíces aproximadas de Chuquet y Puig y algunos ejemplos explicativos de las adiciones.

\section{OBJETIVOS}

Este trabajo es un estudio de partes del libro "Arithmetica Especulativa, y Practica, y arte de Algebra" de Andrés Puig desde el punto de vista de la educación matemática, que tiene los siguientes objetivos:

- Comparar algunos aspectos del álgebra del autor respecto al álgebra española 
del siglo XVI y a la de su contemporáneo José Zaragoza. En concreto, su lenguaje algebraico y el tipo de ecuaciones que resuelve

- Estudiar los algoritmos de resolución generales de ecuaciones polinómicas

- Analizar las adiciones a la primera impresión para saber cómo Puig explica de maneras diferentes (con métodos aritméticos y algebraicos) el mismo problema. También averiguar qué artificio usa para poder resolver lo que sería para nosotros un sistema de ecuaciones, concibiendo solamente una incógnita (la cosa). Además, analizar los artificios y resultados que obtiene con las adiciones

\section{MARCO TEÓRICO Y METODOLÓGICO}

El estudio de la historia de las matemáticas desde el punto de vista de la educación matemática puede realizarse de formas diferentes y desde planteamientos teóricos distintos.

Así, Gómez (2003, pp. 80-82) distinguió seis enfoques distintos para lo que él llama “investigación histórico-epistemológica":

- El enfoque de la enseñanza desde una perspectiva histórica. Se trata de importar al aula problemas o cuestiones históricas para que los alumnos las resuelvan, con la idea de motivar a los estudiantes

- El enfoque de los obstáculos epistemológicos. Quizás es el enfoque con más impacto. Se trata de determinar concepciones y obstáculos ligados al desarrollo de una noción matemática

- El enfoque del modelo teórico-local. Se trata de poner a prueba los hallazgos teóricos en los Sistemas Educativos, para después de esta experimentación, volver, a base de resultados prácticos, a tener una visión de la problemática de la historia de las ideas que corresponda a los resultados didácticos. Han seguido este modelo en España Puig (1994 y 1998), entre otros

- El análisis de los libros de texto. El investigador puede buscar en ellos información sobre las relaciones del desarrollo de contenidos didácticos con el desarrollo científico y social. También los contenidos relacionados con la enseñanza, actividades, problemas, secuenciaciones, etc. En España hay investigadores en ese campo como Maz (2005) y Gómez (2001)

- El enfoque de la reproducción en los estudiantes de las etapas en la historia. Este enfoque se basa en la idea de que los conceptos matemáticos tienen una evolución histórica que los estudiantes también atraviesan en su proceso de aprendizaje. En este enfoque son cruciales la determinación y caracterización de las etapas y los mecanismos de paso de unas a otras

- El enfoque socio cultural. Aceptando que el conocimiento está profundamente arraigado y conformado por su contexto socio cultural, ofrece otra perspectiva para la investigación histórico-epistemológica

Puig (2019, p. 118) hace una serie de observaciones de lo que él considera que hay que discutir acerca de "qué historia de las matemáticas conduce a una relación fructífera con 
la matemática educativa y cómo superar las dificultades de compatibilizar los intereses de una y otra". Las siguientes son dichas observaciones, que pretenden ser una guía hacia la construcción de un marco de referencia teórico.

Primera observación. Atendiendo a las ideas propuestas inicialmente por Filloy y Rojano (1984, p. 2), “el nuevo acercamiento consiste en realizar análisis de problemas de enseñanza y aprendizaje de las matemáticas con el método histórico-crítico, y después poner a prueba los hallazgos teóricos en los Sistemas Educativos, para después de esta experimentación, volver, a base de resultados prácticos, a tener una nueva visión de la problemática de la historia de las ideas que corresponda a los resultados didácticos”.

Puig complementa esa idea de ida y vuelta considerando un primer movimiento que va de la matemática educativa hacia la historia de las matemáticas. Un segundo movimiento de vuelta con el que los conocimientos adquiridos se incorporan a los diseños de las investigaciones sobre procesos de enseñanza y aprendizaje de las matemáticas.

Estos dos movimientos se pueden insertar dentro del marco teórico y metodológico de los Modelos Teóricos Locales (Filloy, Rojano y Puig, 2008). Pero estos dos movimientos no se quedan ahí sino que el proceso es cíclico y ascendente. En cada ciclo de ida y vuelta se avanza sobre lo aprendido en el ciclo anterior.

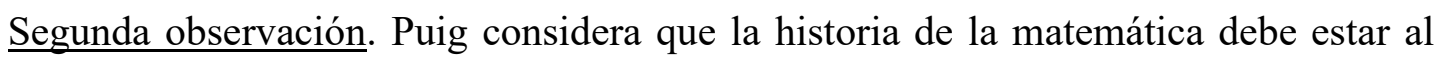
servicio de la matemática educativa (en este tipo de estudios) y advierte del peligro de sólo tomar de la historia lo que ha triunfado, es decir, lo que nos ha llegado a nosotros. Considera que nos interesa saber también aquello que se ha descartado. En sus palabras: “es útil para el presente no sólo lo que conduce al presente, sino también lo que no conduce al presente".

Tercera observación. Puig hace suya la idea de Foucault de tomar los documentos como monumentos. Los documentos históricos han tenido una vida dinámica hasta llegar a nuestros días. Han sido manipulados, fragmentados, alterados, anotados, incrustados en entornos distintos a los originales. En los libros de matemáticas históricos no sólo se resuelven problemas o se demuestran teoremas, sino que se va construyendo el lenguaje de las matemáticas y se van modelando las nuevas prácticas. Y eso es generación de matemáticas también.

Cuarta observación. Puig considera que la idea de Freudenthal de "reinvención guiada" sirve para considerar que lo que se debe llevar a la enseñanza son los procesos que han conducido en la historia a la invención de los conceptos.

Respecto a la idea de "recapitulación” (la ontogénesis repite la filogénesis), Puig 
considera que hay parte de lo que nuestros antepasados matemáticos debían esforzarse en enseñar que ya lo tenemos nosotros asumido culturalmente. Es decir, que hay conceptos, expresiones e ideas que para nosotros son naturales pero que en los textos históricos se explicaban con profusión.

Quinta observación. Puig incorpora el concepto de "desubicación”. Se trata de sacar al estudiante, en este caso, de su zona de confort. La historia de las matemáticas puede desubicar a los estudiantes. Pero hay que tener cuidado de no buscar en los textos históricos solamente lo que ha subsistido sino también las otras ideas, procesos y conceptos que se han quedado en el camino. Desubicarlos para captar su atención, para fomentar la curiosidad por conocer lo que está oculto o es enigmático. Hacerles ver que la historia de la matemática ha estado plagada de errores y pasos falsos, pero que se ha ido perfeccionando y alcanzando niveles cada vez más abstractos.

Pero desubicar a un alumno no es presentarle un enigma irresoluble. Hay que hacer las modificaciones necesarias para que los estudiantes puedan resolverlo. La tarea del profesor debe ser establecer esa distancia que sea lo suficientemente larga como para crear la desubicación, la extrañeza, pero lo suficientemente corta como para que el problema sea resoluble.

El estilo de investigación que lleva años desarrollando Puig (2018a) y otros investigadores podría resumirse en (se cita literalmente):

- El dar sentido al texto convirtiendo el documento en monumento a la manera introducida por Michel Foucault en L'Archéologie du savoir (Foucault, 1969). Citado por Puig (1996, p. 2)

- El tomar los textos como cogniciones petrificadas (Puig, 2006)

- El plantear al texto histórico preguntas que son pertinentes desde el punto de vista de la problemática de la matemática educativa, a la manera formulada originalmente por Eugenio Filloy y desarrollada en Filloy, Rojano y Puig (2008) y Puig (2011)

Sobre este asunto hay una abundante bibliografía desarrollada alrededor del International Group on the Relations between the History and Pedagogy of Mathematics (HPM), fundado hace más de cuarenta años, que no vamos a examinar ni resumir aquí porque hay disponibles excelentes recensiones. Por ejemplo los trabajos producidos por los dos grupos de trabajo de historia del International Congress on Mathematics Education celebrado en 2016 en Hamburgo, editados por Clark, Kjeldsen, Schorcht y Tzanakis (2018) y por Furinghetti y Karp (2018).

Después de las cuestiones de tipo general que hemos expuesto, mencionaremos una 
cuestión muy específica de una parte de la investigación que hacemos en este trabajo, en concreto, la dedicada a las adiciones, porque vamos a tratar las adiciones como un tipo de paratextos.

Según Genette (2001, p. 7) "el texto raramente se presenta desnudo, sin el refuerzo y el acompañamiento de un cierto número de producciones [...]. Este acompañamiento, de amplitud y de conducta variables, constituye lo que he bautizado, [...] el paratexto de la obra". Para Genette "el paratexto se compone de un heteróclito de prácticas y discursos" (2001, p. 8). Genette propone en sus libros alguna organización de tipos de paratextos, como pueden ser los prólogos, prefacios, notas del autor, notas del traductor, subtítulos, adiciones en vida del autor, adiciones póstumas, etc. Los paratextos pueden ser obra del autor pero también del editor. En nuestro caso estudiaremos paratextos relacionados con el autor (como las adiciones póstumas) pero también con el editor (o impresor en la época de que hablamos), como las diferentes impresiones, unas con fecha y otras no, los diferentes impresores y secuencia de impresiones, los prólogos del impresor al lector, etc.

Brizuela (2015) dice:

El paratexto [...] posee, sin embargo, unas características propias e indiscutibles, que tienen una función bien delimitada y específica: hacer llegar al destinatario la intención del autor, sus creencias e ideología, y el propósito con el que ha escrito la obra. (p. 22).

La presencia de paratextos puede tener intenciones diferentes como por ejemplo atraer al lector, publicitar al autor, hacer el texto más comprensible, contextualizar la obra, agradecer a ciertas personas o entidades la ayuda para la edición, etc.

En el caso que nos ocupa, uno de los paratextos que estudiaremos en el capítulo 9, de análisis de las adiciones creemos que pretende hacer el texto más educativo, explicando ciertos aspectos que han podido quedar en las impresiones anteriores un poco más oscuros. También pretende aportar conocimientos previos que el lector debe conocer para poder entender ciertos problemas resueltos anteriormente. Es decir, creemos que el estudio que hacemos de las adiciones, como paratextos, nos hace entender que estamos estudiando un libro que definitivamente se ha enfocado a la enseñanza. Es decir, se trata de un libro de texto del siglo XVII.

Los otros paratextos que hemos estudiado (impresores, diferentes impresiones y fechas, prólogos, dedicatorias, etc.) podemos considerarlos como una manera de entender el contexto en el que se ha impreso el libro, cómo ha sido "la vida" del libro y en resumen, conocer sobre la historia del libro, del autor y de la época.

El estudio de paratextos en libros de matemáticas se ha realizado, aparte de otros, por 
Muñoz y Oller (2018, 2019). Muñoz y Oller (2018) analizan los prólogos de los libros de Pérez de Moya, llegando a conclusiones interesantes acerca de las concepciones matemáticas del autor, de sus intenciones, de su interés por divulgar el conocimiento, etc. Estos mismos autores analizan los prólogos de algunos textos algebraicos del siglo XVI en Muñoz y Oller (2019), donde afirman que "Maz y Rico, en su estudio sobre textos españoles de los siglos XVIII y XIX estudian, por ejemplo, los principios filosóficos y didácticos de los autores o cómo se recoge el interés social de las matemáticas" (p. 54). Es decir, que el estudio de los paratextos nos permite conocer enfoques, a veces relacionados no con el contenido matemático de los textos sino con un contenido más didáctico.

Para este trabajo utilizaremos algunas de las ideas expuestas anteriormente, más concretamente algunas de las ideas expuestas en las observaciones propuestas por Puig y también utilizaremos el concepto de paratexto para caracterizar los elementos que rodean al texto central del libro.

\section{CONTEXTO HISTÓRICO}

\subsection{Introducción}

No es objeto de este trabajo el adentrarse en exceso y pormenorizadamente en la España de la decadencia, es decir en la España del siglo XVII. Simplemente pretendemos contextualizar el personaje y su obra dentro de un entorno político y social que nos permita entender algunos aspectos que de otra forma nos pasarían desapercibidos. Aparte de referirnos a aspectos políticos y sociales, nos referiremos a aspectos educativos, ya que la educación es el objeto principal de este trabajo.

Como el autor vivió durante el siglo XVII, pero su obra se reimprimió también en buena parte del siglo XVIII, hemos considerado incluir también las primeras décadas de este último siglo ya que se produjeron acontecimientos que afectaron a las diferentes reimpresiones del libro que analizamos.

\subsection{España y Europa en el siglo XVII}

Este siglo fue un siglo de tensiones entre las potencias europeas. La Guerra de los Treinta Años (1618-1648) desgastó Europa. La Paz de Westfalia (1648) supuso la pérdida de poder de los Austrias y Habsburgo. Con la Paz de los Pirineos (final de la guerra entre Francia y España), España cedió el Rosellón, la Cerdaña y otros territorios.

Carlos II (1665-1700) no pudo frenar la expansión de Luis XIV de Francia, perdiendo aún más territorios europeos y muriendo finalmente sin descendencia. Esto provocó la 
lucha por el trono español entre Austrias y Borbones, en la llamada Guerra de Sucesión (1701-1713) que se expandió por toda Europa. Esta guerra finalizó con la Paz de Utrecht (1713) que supuso el final del imperio español en Europa, aunque la guerra continuó en España, situando su principal foco en Cataluña.

\subsection{España en el siglo XVII}

Las políticas del valido de Felipe IV provocaron tensiones territoriales, en especial con Cataluña que, tras el levantamiento de 1640, finalizaron con la toma de Barcelona en 1652. Aún con levantamientos territoriales, Felipe IV no abolió los fueros.

\subsection{Comienzos del siglo XVIII}

Tras la muerte de Carlos II se desencadenó la Guerra de Sucesión (1701-1713) entre partidarios del nieto de Luis XIV de Francia, Felipe de Anjou (futuro Felipe V) y el Archiduque Carlos de Habsburgo. Esta guerra civil desencadenó una guerra a nivel europeo. En España, la guerra finalizó poco después de la toma de Barcelona, el 11 de septiembre de 1714, tras un largo sitio. Esto provocó el completo dominio español por parte del borbón Felipe V, que trajo aires centralizadores, perdiéndose los diferentes fueros de las regiones que habían apoyado a Carlos y manteniéndose los de los aliados de Felipe.

Es precisamente en la época convulsa de la Guerra de Sucesión y en los años posteriores cuando más impresiones se hacen del libro de Puig y cuando más cambios hay en impresores y libreros en Barcelona.

\subsection{La educación científica}

Atendiendo al criterio propuesto por Maz (2005) para agrupar libros de texto españoles producidos a lo largo de la historia, en el que se agrupan según los cambios políticosociales, y concretando aún más con Gómez (2011, pp. 12-15), nuestro libro estaría enmarcado en el periodo del libro impreso, que comienza con la implantación de las normas dictadas por el Concilio de Trento en 1546 y finaliza con la expulsión de los jesuitas en 1767.

La educación institucionalizada, que llegaba a pocas personas en esta época, se iniciaba en las escuelas de primeras letras, donde se aprendía lo básico (leer, escribir, contar y religión). A partir de los 8 o 10 años, los niños entraban en escuelas donde se les enseñaba gramática, retórica y humanidades con el objetivo de que aprendieran latín. Estas escuelas estaban generalmente organizadas por la Compañía de Jesús, alguna por universidades e incluso particulares. Era una manera de ascender socialmente ya que la gente con poder adquisitivo tenía sus instructores particulares. 


\subsection{La matemática española}

El siglo XVI es un siglo de auge matemático, con bastantes profesores de matemáticas en las universidades. Pero llega el siglo XVII y la ciencia y la matemática en particular se quedan ancladas en el pasado, sin recibir influencia de las nuevas ideas que están apareciendo en Europa, salvo lo que aportan algunos jesuitas, como José Zaragoza. Una institución tan potente en el siglo XVI, como fue la Academia de Matemáticas, fundada por Felipe II, fue desplazada y absorbida por el Real Colegio Imperial de Madrid, en el que había cátedras de matemáticas, pero un tanto diluidas respecto a lo que fue la Academia de Matemáticas.

Echegaray (1866) y Rey Pastor (1926) tienen una visión muy negativa de la matemática del siglo XVII, pero hoy en día se cree que era una visión exagerada (por lo negativo) y se está releyendo esa época y rescatando del olvido a algunos matemáticos que sí aportaron cosas interesantes. Ahí tenemos a José Zaragoza, por ejemplo.

\section{BIOGRAFÍA DE ANDRÉS PUIG}

Se sabe muy poco de la vida de Andrés Puig y sólo tenemos noticias de un libro suyo, que es el que analizamos en este trabajo. Mucha de la información que se conoce del autor proviene de él mismo, que refiere en su propio libro. A continuación, detallaremos la información y referencias a su persona y a su obra que hemos podido encontrar.

\subsection{Información presente en su obra}

En la portada de su libro figura como "Maestro ANDRES PUIG, natural de la Ciudad de Vique, deste Principado de Cataluña, y vezino de la de Barcelona”. Se trata de la ciudad de Vich, provincia de Barcelona. Por lo tanto, nació en Vich y vivió en Barcelona, al menos en la fecha en que se publicó el libro.

En la primera impresión de su Arithmetica (de 1672) dice, en la página 448: “desta regla me diò algunos principios, un grande Mathematico Valenciano, en la misma Ciudad de Valencia en el año de 1652. que se llamava Iuan Sarrano, al qual siempre hè reconocido por mi Maestro destos principios”. Es decir, que al menos vivió un tiempo en Valencia y aprendió del maestro Juan Serrano.

En la impresión de 1711 se dice que hay unas adiciones póstumas, por lo que en esa fecha debe haber fallecido ya. Por lo tanto, lógicamente, Andrés Puig seguramente nació a principios del siglo XVII y murió o a finales del XVII o a principios del XVIII. Antes de 1600 es improbable que naciera (por la fecha en que escribió el libro) y en 1711 ya había muerto. 


\subsection{Referencias que aparecen en libros de aritmética de los siglos XVIII y XIX}

Hemos consultado sobre todo algunos libros de aritmética de la época como ejemplo y hemos encontrado tres referencias de Andrés Puig en libros de aritmética práctica para comerciantes y mercaderes.

Se le cita como metrólogo, en concreto Guardamino (1757, p. 88) lo califica como "insigne metrólogo". Y lo alaba cuando habla de él:

En Valencia, Mallorca, Cataluña, y señaladamente en el Reyno de Aragon, hay gran variedad de Mensuras; y por lo mismo Geronimo Cortès (à quien siguen Corachan, el Padre Tosca, y otros, à excepción de Andrès Puig, que haviendo antecedido à los citados Authores, y siendo, en mi dictamen, el que mejor escribió de la materia de que se trata, no toca a Aragon [...].

García Caballero (1731, p. 30) también cita a Andrés Puig en su faceta de metrólogo, diciendo: "[...] como se verifica del balance, y cotejo, que de ellas hizo Oberto, según refiere Andrès Puig en su libro de Arithmetica [...]”.

Que Andrés Puig era conocido en el ámbito matemático de la época y posteriormente, lo puede corroborar también la cita que hace de él Poy y Comes (1819, p. 47):

Algunos dicen que la prueba del nueve es falsa, á lo que replica el Maestro Andres Puig en su lib. II de Aritmética práctica, cap. 4. pág. 73, diciendo, entre otras cosas; No hay que maravillar, que ya es propio de la ignorancia decir mal de lo que no se entiende.

\subsection{Referencias y biografías breves de historiadores que no son de las matemáticas}

En cuanto a su profesión, podemos deducir que era maestro, pero no sabemos si de primeras letras o de otro tipo, aunque según el nivel de su libro no debería ser de primeras letras sino más avanzado, aunque sin llegar al nivel universitario si nos atenemos al contenido de su libro y a los datos de que disponemos. Seguramente diera clases a comerciantes, mercaderes y otras personas en niveles no universitarios. En Torres Amat (1836, p. 504) aparece como "maestro de aritmética en Barcelona", aunque las referencias a las impresiones de su libro contienen alguna imprecisión.

En Salarich e Ylla-Català (1983, p. 299) se dice que se estableció en Barcelona y fue profesor. Pero al citar la obra creemos que hay un error ya que indica la fecha de 1670 como la primera impresión, y luego reimpresiones de 1672, 1711, 1715 y 1745. Nosotros sólo hemos encontrado ejemplares de primera impresión con fecha de 1672. De hecho, casi todas las fuentes indican 1672 como fecha de la primera impresión. Hay otra fuente que también habla de una impresión de 1670. Se trata de Espino (2013, p. 39), que hace una relación de los libros presentes en una biblioteca militar del siglo XVII, en la que figura el libro de Puig, pero también indica que esa información proviene de un 
documento notarial que relaciona los libros de la biblioteca. Pensamos que es posible que el oficial de notarías pudiera haberse equivocado en la fecha y el error se ha ido perpetuando en documentos posteriores.

Una cita más extensa aparece en Bernat (2010, p. 203), donde se dice que trabajó como profesor en Barcelona y que su libro tuvo mucha difusión. Además, se indica algo de su contenido, que estaba escrito en lenguaje retórico (más propio de aritméticas del siglo XVI que del XVII) y que trataba también de los irracionales (algo poco habitual en los libros de su época).

León y Sanz (1994, p. 34) citan el libro de Andrés Puig como muy utilizado por constructores en el siglo XVIII:

La "Aritmética especulativa y práctica" de Andrés Puig se imprimió en Barcelona en 1670 y 1672, pero en el siglo XVIII se hicieron dos nuevas ediciones en 1715 y 1745 , siendo por tanto un nuevo caso de relación de la matemática de esta centuria con la anterior....Puig mantiene la sistematización de la matemática como "cuadrivium" sin incluir la arquitectura como harían ya otros autores contemporáneos y aún anteriores; sin embargo, su amplia exposición de los temas desarrollados no dejaría de interesar a los constructores, lo que motivaría sus ediciones en el siglo XVIII.

Agustí i Cullell (1983, p. 5) también lo cita:

[...] allí estudià el 1662, amb Juan Serrano, Andreu Puig, natural de Vic, mestre d'aritmètica a Barcelona, on publicà l'obra Arithmetica Especulativa y Practica, y arte de algebra en la qual se contiene todo lo que pertenece al arte menor o mercantil, y a las dos Algebras Racional e Irracional, $1^{\mathrm{a}}$ Imp. $1672,3^{\mathrm{a}} 1745,4^{\mathrm{a}} 1770,486$ pàgs. Aquesta obra tracta "la resolució d'equacions de grau superior al $2^{\circ}$, que així apareixen per primera vegada a Espanya".

Aunque esta información hay que tomarla con reservas ya que al menos hay un error cuando dice que es la primera vez que aparece en España la resolución de ecuaciones de grado superior a dos (sabemos que el libro de José Zaragoza es de 1669 y que ahí resuelve también ecuaciones de grado superior a dos).

\subsection{Referencias de historiadores de la ciencia no recientes o matemáticos de finales del siglo XIX y XX}

Sánchez Pérez (1935), en su artículo sobre la ciencia española en el siglo XVII cita a Andrés Puig, pero dice no saber nada de él, salvo que vivió en el siglo XVII.

Lo cita también Menéndez y Pelayo en su "Inventario bibliográfico de la ciencia española. Tomo III" (1953, p. 207).

Rodríguez Vidal (1980), en su "Nómina de matemáticos españoles del siglo XVII" refiere datos de Puig que ya aparecen en otras fuentes, como que publica su libro en 1672, que su última impresión conocida es en 1745, que estudia en 1652 con Juan Serrano en Valencia. Y que debería catalogarse como matemático nacido en el reinado de Felipe IV 
y pasa con vida al siglo XVIII, aunque esto último no es del todo seguro ya que en 1711 se publica una impresión con adiciones póstumas.

No lo citan Echegaray (1866), Rey Pastor (1926), López Piñero (1983) y Dou (1990), entre otros.

\subsection{Referencias de historiadores de las matemáticas más recientes}

Peralta (1999, p. 86) cita a Puig y Serrano: "Tampoco aparece estudio alguno sobre las ecuaciones de grado superior al segundo hasta 1672, año en que ve la luz Aritmética especulativa y práctica y arte de álgebra, de Andrés Puig y Juan Serrano”. Y esto no es correcto porque en realidad, el libro es de autoría exclusiva de Andrés Puig (según aparece en la portada). Además, afirma que es el primer estudio que aparece en España de las ecuaciones de grado superior a dos. Esto último es incorrecto también ya que Zaragoza saca su libro en 1669, donde resuelve ecuaciones de grado mayor que dos.

Recasens (2007) cita a Andrés Puig como una de las dos excepciones a la generalidad de aritméticas publicadas en España en el siglo XVII, que son de un nivel básico. Por una parte, cita a José Zaragoza y por otra a nuestro autor. De la Arithmetica de Andrés Puig dice, entre otras cosas que:

Lo que distingue esta Aritmética de Puig de las otras de su época es que, por una parte incluye el estudio de cuestiones irracionales del libro décimo de Euclides y por otra proporciona un método numérico para el cálculo aproximado de raíces de polinomios de grado superior a dos que es igual al de Zaragoza, sin embargo Puig utiliza una notación que es más propia del siglo XVII y usa un estilo narrativo un tanto confuso. (p.424).

Hay que notar que este texto contiene una imprecisión, cuando dice que los métodos de Zaragoza y Puig son iguales ya que no son exactamente iguales como veremos en el apartado en el que analizamos el método general de resolución de ecuaciones de Puig. Y también contiene una errata, cuando habla de que la notación de Puig es propia del siglo XVII, y creemos que se refiere al siglo XVI.

\section{CONVENIOS DE TRANSCRIPCIÓN, ESTRUCTURA, IMPRESIONES Y ORGANIZACIÓN DE LA ARITHMETICA}

En este capítulo estableceremos los convenios de transcripción que utilizaremos a la hora de analizar el libro. También analizaremos la estructura, tanto de la primera impresión como las adiciones y modificaciones que se realizan en las impresiones posteriores ya que el análisis de las adiciones es una parte importante de este trabajo. Finalmente describiremos la organización en libros y el contenido matemático de cada uno.

\subsection{Convenios de transcripción}


Barroso y Sánchez (1993, p. 161) dicen que "Si el criterio principal de transcripción de textos antiguos o clásicos debe asentarse en el respeto a la realidad grafemática, [...], conviene marcar los límites de la modernización o ajuste sin dañar el valor representativo u otros valores de los grafemas". Nosotros vamos a intentar seguir las indicaciones de estos autores a la hora de transcribir textos originales de la época. Seguiremos la idea de Nebrija cuando dice "escrivo como pronuncio", citada por Barroso y Sánchez (1993, p. 173). En concreto, acordamos transcribir el texto tal y como se nos presenta originalmente salvo en estos casos:

- Usaremos la grafía $v$ cuando suene como uve y $u$ cuando suene como $\mathrm{u}$

- Usaremos la grafía s tanto para la ese corta como para la ese larga $f$

- Completaremos las palabras abreviadas con un símbolo parecido al de la ñ encima

- Utilizaremos la modernización de los nombres de personas. Por ejemplo, transcribiremos Andres Pvig como Andrés Puig

- Respetaremos la falta de tildes o su uso diferente al actual

- Respetaremos las demás grafías, como por ejemplo la doble ese cuando aparezca

\subsection{Estructura}

La impresión que vamos a analizar en este apartado es la de 1672, que es la primera, en un tomo de $4^{\circ}$ en pergamino. El libro consta de cubierta, 5 páginas en blanco, portada, otra página en blanco, 2 páginas de dedicatoria, 3 páginas de aprobación, 4 páginas de prólogo al lector, 4 páginas con sonetos y décimas, una página con erratas, 576 páginas numeradas con el texto, 7 páginas para las tablas de contenidos, 6 páginas en blanco y contracubierta. En la portada aparece el título de la obra, después figura el autor: “COMPUESTO, ORDENADO, Y HECHO imprimir por el Maestro ANDRES PUIG, natural de la ciudad de Vique, deste Principado de Cataluña, y vezino de la de Barcelona”.

Seguidamente la dedicatoria: "DIRIGIDA A LOS MUY ILUSTRES SEÑORES Conselleres, y Sabio Consejo de Ciento de la Ciudad de Barcelona”.

Por último, aparece dónde se ha impreso y el impresor: "En BARCELONA, Por Antonio Lacavalleria, AÑO MDCLXXII. Vendese en casa del mismo Autor. Con Licencia, y Privilegio".

Luego una página en blanco y en las siguientes dos páginas está desarrollada la dedicatoria (se numeran cada dos páginas, es decir, por folios).

Después dos páginas de aprobación del "Doctor D. Daniel Sayol, Canonigo de la Santa Iglesia Catedral de Barcelona", por encargo del "Vicario General y Oficial del Obispo de Barcelona”. Existe una errata de impresión ya que la fecha del imprimatur (visto bueno 
de la Iglesia) es del 30 de junio de 1761, cuando debe tratarse de 1671.

Luego otra página de aprobación del "Doctor Iuan Carbonell, Cavallero del Consejo de su Majestad, en el Civil de la Real Audiencia del Principado de Cataluña”. Con fecha 19 de agosto de 1671, y por encargo del "Consejo de su Majestad y su Canciller en este Principado de Cataluña”. Como vemos, hay dos aprobaciones, una por parte de la Iglesia y otra por parte del Rey.

Seguidamente hay un prólogo del autor al "curioso Lector", de 4 páginas. El autor habla de la importancia de la aritmética como "el principio y fundamento de todas las cosas", atendiendo a los antiguos filósofos. Divide la Arithmetica entre Especulativa y Practica, y esta última entre arte menor y mayor, y el arte mayor en Algebra Racional y Algebra Irracional. Define al Algebra Racional como una serie de reglas generales con las que se enseña a responder cuestiones cualesquiera que puedan ser numéricas. El Algebra Irracional la define como aquella en la que se explican todas las proposiciones del libro X de Euclides.

El autor glosa sobre el aprecio que se le tuvo a esta ciencia en Roma, creando una diosa llamada Numeria. También habla de la utilidad de la Arithmetica como manera de evitar las diferencias y discordias de los reinos, provincias y naciones del mundo. Dada la importancia de la Arithmetica, es por ello que era lo primero que enseñaban Pitágoras, Nicómaco, Platón y Aristóteles. También indica la importancia que tiene para otras ciencias como la Geometría, la Música, la Astronomía, la Geografía, la Artillería, la Arquitectura e Ingeniería, etc. Dice el autor que, por su enorme importancia, la Arithmetica debería ser considerada como una de las más grandes creaciones de Dios. Y el hombre, al saber contar, como un ser elegido y diferente a los animales. En cuanto a las motivaciones para crear este libro, el autor dice que "el fin principal ha sido encaminado al aprovechamiento de todos en general, y de cada uno en particular".

Seguidamente encontramos 4 páginas con sonetos y décimas. El primero del Doctor Gerónimo Sastre, Capellán Mayor del Tercio de Toledo. Los otros tres son de "maestros de escribir y contar", colegas de Andrés Puig.

Por último, antes del texto en sí, hay una página con las erratas comentadas por el propio autor.

Luego está el texto propio, dividido en seis libros, en 576 páginas numeradas. Y después 7 páginas sin numerar donde están las tablas de los contenidos de cada uno de los libros en que está dividido el texto.

Finalmente 6 páginas en blanco y la contracubierta. 


\subsection{Reimpresiones}

Encontramos dos impresiones de otro impresor, una de 1711 y otra de 1715 . Una cuarta impresión de impresor diferente, sin fecha (dos reimpresiones diferentes). Y una impresión de 1745 (dos diferentes).

Impresión de 1711 de Figuerò: Se trata de una segunda impresión. En la portada ya no aparece Cataluña sino Cathaluña. Esta impresión contiene unas adendas póstumas del autor, señaladas con un símbolo en forma de mano apuntando. Está dedicada "AL MAGNIFICO MAGISTRADO DE LA LONJA DEL MAR DE ESTA EXCELENTISSIMA CIUDAD DE BARCELONA". El impresor es "Rafael Figuerò, Impressor del Rey nuestro Señor". Luego pone "Vendese en la misma casa, à los Algodoneros". Se entiende que Figuerò vende el libro en su casa, en la calle Algodoneros.

Indica que son cónsules "Francisco Barenys Dr. En Medicina, y Pablo Llescà Mercader”. El Consulado del Mar era una institución encargada de la regulación del comercio, que ejercía como tribunal de conflictos que surgían en las relaciones comerciales.

Como defensores, indica que son "Francisco Galceras Mercader, y Gabriel Font Mercader". En estos nombres y en los de los cónsules, la última palabra de cada nombre es la profesión, no el segundo apellido.

El impresor habla en el prólogo, entre otras cosas, de los reyes (desde Martín, Alonso, Juan, Fernando, Carlos V, Juana, Felipe II y III, y últimamente Carlos II). Hay que notar que Felipe II y III son los respectivos Felipe III y IV de Castilla. También cita a Carlos II como de amable memoria. $\mathrm{Y}$ es que en estos años es cuando se está en plena guerra de sucesión. Felipe V litiga contra el Archiduque Carlos por el trono. Según Camprubí i Pla (2013), Rafael Figuerò sirvió a la causa del Archiduque Carlos y fue nombrado impresor Real. Junto a su hijo tuvieron privilegios reales que perdieron al perder la guerra de Sucesión frente a los partidarios del borbón Felipe V.

Las aprobaciones son "del Canonigo de la Santa Iglesia de Lerida", en fecha de imprimatur de 23 de abril de 1711 y otra de otro canónigo en fecha de imprimatur de 22 de Julio de 1709. La primera, encargada por parte de la Iglesia y la segunda por parte del Rey.

También hay una dedicatoria del impresor al lector donde se habla brevemente del autor, de lo conocida que es la obra y de las adiciones. Esta dedicatoria es añadida en esta impresión de Figuerò, escrita por el impresor, y permanecerá tal y como está en las 
sucesivas impresiones, aun siendo impresas por otros impresores.

Resumiendo, salvo las páginas en blanco, el libro consta de portada, 4 páginas de dedicatoria del impresor, una página de aprobación, una página de prólogo del impresor para el lector, 548 páginas del texto y 6 páginas de tablas.

Impresión de 1715 de Figuerò: Tercera impresión. El impresor es también el de la segunda, Rafael Figuerò. La portada es similar a la de la segunda, pero cambiando la fecha y donde se vende el libro, que ahora es à la Boria (el Barrio de la Bòria es una antigua barriada de Barcelona). El traslado de la imprenta de la calle Algodoneros a la Boria se debió a que una bomba incendió la imprenta durante el sitio de Barcelona en 1714 (Camprubí i Pla, 2013, p. 67). A la única copia digitalizada que hemos localizado y que hemos consultado le faltan las páginas que hay entre la portada y el texto en sí.

Se trata de una copia casi idéntica a la versión de 1711 (salvo que es otra composición). Consta de portada, texto de 548 páginas y 7 páginas de tablas.

Impresión de Giralt sin fecha: Cuarta impresión. El impresor es en este caso Joseph Giralt. Pone que es impresor y librero y que se vende en casa de Pablo Campis Impresor. Esta impresión no tiene tampoco dedicatoria en la portada, pero sí una dedicatoria del impresor al lector, idéntica a la de 1711 de Figuerò. También aparece la fecha de los imprimatur, que es de 21 de junio de 1715, y la firma de quien los encarga, en nombre de la Iglesia y en nombre del Rey. Pero faltan los informes de los encargados de redactarlos, algo raro ya que lo habitual es que aparezca los informes firmados por los redactores y además las firmas de los que encargan dichos informes.

En cuanto a la fecha de impresión, no aparece en esta ocasión. En el Boletín bibliográfico español y estrangero del año 1846, en la página 167 figura una reseña de este libro, que se vende en la "librería europea", en la calle de la Montera número 12 (hay que suponer que de Madrid). En esta reseña aparece la fecha de 1715, en la imprenta de P. Giralt. Es curioso que, en este mismo boletín, pero en su edición de 1842, página 191, aparece el mismo libro, pero pone que no figura el año de edición. $\mathrm{O}$ bien desde el año 1842 hasta el 1846 se ha encontrado una edición fechada o bien en la edición de 1846 se supuso la fecha de impresión como la que pone de imprimatur.

El texto consta de portada, una página de dedicatoria del impresor al lector (la misma de Figuerò) con imprimatur, 497 páginas de texto y 6 páginas con las tablas.

De esta impresión tenemos conocimiento de dos composiciones distintas, aunque con texto muy similar. Pone Vendese en su misma Casa. En esta composición, las páginas son 548 y las tablas 7 páginas. 


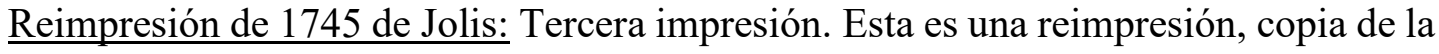
tercera de Figuerò de 1715, y por eso indica que es la tercera impresión en vez de la cuarta. El impresor presentó para la licencia la tercera de 1715 de Figuerò y un certificado de que es una copia de ella.

En las letras ya vemos un cambio, incluso ya no se pone el símbolo $v$ como $u$, entre otras "modernidades". El impresor es "Juan Jolis Impressor, en la calle de los Algodoneros". Y pone que se vende en su misma casa.

La dedicatoria del impresor al lector es la misma que en las reimpresiones anteriores. Aparece una página con la "LICENCIA DEL REAL CONSEJO” (que no aparece en la reimpresión de 1715 ya que entre 1715 y 1745 ya no se necesitan los dos imprimatur sino una licencia real y una fijación de tasa que se tramitan en Madrid). Aparece también una fe de erratas y una tasación de 6 maravedís por pliego, que es el precio al que debe venderse el libro. Y se fecha esta tasación en Madrid a 11 de diciembre de 1745. La tasa de los libros desapareció en 1762, con el reinado de Carlos III.

Resumiendo, el libro consta de portada, una página de dedicatoria del impresor al lector, una página con licencia, fe de erratas y tassa, 486 páginas de texto y 6 páginas de tablas. Hay otra impresión similar a esta en cuanto al contenido (aunque no figura en la portada el año de impresión), salvo que se utilizan algunas modificaciones en cuanto a la grafía. Por ejemplo, ya no se usa la ese larga. Esto nos puede hacer pensar que pueda ser incluso una impresión posterior a la de 1745, aunque no podemos saberlo. En la Tabla 1 se muestra un resumen de las diferentes impresiones y reimpresiones que hemos encontrado:

Tabla 1. Impresiones del libro

\begin{tabular}{llll}
\hline Año & Impresor & Impresión & Composiciones \\
\hline 1672 & Antonio Lacavalleria & Primera & Única \\
\hline 1711 & Rafael Figuerò & Segunda & Única \\
\hline 1715 & Rafael Figuerò & Tercera & Única \\
\hline & Joseph Giralt & Cuarta & Dos distintas \\
\hline 1745 & Juan Jolis & Tercera & Única \\
\hline & Juan Jolis & Tercera & Única \\
\hline
\end{tabular}

\subsection{Organización temática}

El texto consta de 6 libros. Resumiremos a continuación el contenido de los libros aritméticos ya que sólo las adiciones serán objeto de nuestro estudio. Nos centraremos más en la parte algebraica, exceptuando el álgebra irracional, que tampoco es objeto de nuestro estudio.

\section{Libro primero. Trata de Arithmetica espuculativa (pp. 1-58)}

Se divide en 19 capítulos. Y trabaja en la aritmética, utilizando los Elementos de 
Euclides como base. Se establecen algunas definiciones, operaciones básicas con números, primos y compuestos, mínimo común múltiplo, máximo común divisor, proporcionalidad, fracciones, operaciones con fracciones.

\section{Libro segundo. Trata de Arithmetica Practica. (pp. 59-163)}

Consta de 17 capítulos. Se enseñan las reglas de la suma, la resta, la multiplicación y la división. Se explican las fracciones y sus operaciones. Junto a las explicaciones hay muchos ejercicios explicados. Hay ejemplos de conversión de monedas, operaciones con diferentes tipos de medidas, etc.

Libro tercero. Trata de la Regla de Tres. Compañias, arrendamientos, testamentos, alligaciones, baratas y cambios. (pp. 164-266)

Consta de 14 capítulos. Se explica la regla de tres simple y compuesta, se establecen muchas tablas de conversión de medidas entre diferentes ciudades, multitud de ejemplos. Muchos ejemplos de Regla de Compañias (repartos proporcionales), testamentos, Regla de Alligacion (mezcla), Regla de Cambios (cambio de moneda).

Libro cuarto. Trata de progresssiones, una, y dos falsas posiciones, extracciones de diferentes raizes, con muchas demandas, y questiones por ellas absueltas, y otras reglas extraordinarias. (pp. 267-366)

Consta de 12 capítulos. Se definen las progresiones (aritmética y geométrica), sus propiedades y características, falsa posición (regula falsi), doble falsa posición, fracciones, raíces cuadradas, raíces cúbicas, raíz cuarta, raíz quinta e infinidad de ejemplos.

\section{Libro quinto. Trata de Algebra Racional. (pp. 367-480)}

Consta de 11 capítulos. En ellos se define y divide el álgebra, se definen y declaran los caracteres (polinomios) y dignidades (potencias) que se utilizan, operaciones con caracteres, operaciones con fracciones de caracteres, abreviar caracteres (simplificar fracciones algebraicas), raíz cuadrada de caracteres. También se explica la regla del álgebra para ecuaciones hasta de segundo grado, que es la igualación (posición, reducción, división y extracción de raíces), con más de 100 ejemplos. En el capítulo 9 se establece la regla general del álgebra y se aplica a muchas ecuaciones de grado superior al 2. Se expone también ejemplos de cómo resolver también las ecuaciones de primer y segundo grado con esta regla general del álgebra. En el capítulo 11 se enseña otra regla general (por aproximación), que dice que es menos dificultosa. Explica lo que llama Regla Media. Y se completa con algunos ejemplos.

\section{Libro sexto. Trata de Algebra Irracional. (pp. 481-576)}


Consta de 34 capítulos. Se define el álgebra irracional, las cantidades conmensurables e inconmensurables, las superficies conmensurables e inconmensurables, operaciones con raíces cuadradas, operaciones con raíces cúbicas, resolución de ecuaciones irracionales y bastantes ejemplos.

\section{EL LENGUAJE ALGEBRAICO DE LA ARITHMETICA}

Puig (2003, p. 106) indica como una característica de "lo algebraico":

El uso de un sistema de signos al resolver problemas que permite expresar el contenido del enunciado que es preciso para resolverlo (su 'estructura') desprendido de lo que no es preciso. Con ese sistema de signos, además, se puede operar en el terreno de la expresión sin recurrir al del contenido.

Nosotros, atendiendo a esta consideración, vamos a estudiar el lenguaje algebraico o Sistema Matemático de Signos (SMS) utilizado por Andrés Puig en su obra, comparándolo con sus predecesores y con sus contemporáneos. Además, analizaremos qué tipos de ecuaciones y estrategias de resolución utiliza.

El siglo XVII es un siglo de avances importantes en el álgebra, pero para España, es un siglo oscuro en muchos aspectos, también en el álgebra. El siglo anterior, el XVI tuvo algebristas destacados e innovadores en cierta medida, pero en el siglo XVII hubo poco que destacar hasta la publicación de la Arithmetica Universal de Zaragoza en 1669.

El álgebra comienza a entrar en su etapa simbólica, según las etapas propuestas por Nesselman (1842), ya en el siglo XVI, con Viète, completándola con Descartes. Es decir, casi un siglo antes que Andrés Puig, Viète ya utilizaba un lenguaje casi simbólico. Pero Andrés Puig, como veremos a continuación usa un sistema de signos anclado aún en la etapa sincopada. El hecho de que Andrés Puig, casi un siglo después que Viète, utilice un simbolismo más atrasado seguramente se deba a que los libros de álgebra que se usaban en España en esa época utilizaban ese simbolismo sincopado, excepto el utilizado por Zaragoza, que es distinto.

A partir de ahora, analizaremos el simbolismo y el álgebra de Andrés Puig en paralelo al álgebra del siglo anterior (que inspira la suya) y al álgebra contemporánea a él en España. Para realizar este estudio seguiremos las indicaciones propuestas por Puig (2018b), que señala la Arithmetica Algebraica de Marco Aurel (1552) como referencia del álgebra española del siglo XVI y la Arithmetica Universalis de José Zaragoza (1669) como la referencia del siglo XVII.

Siguiendo a Puig (2018b), el álgebra de Zaragoza es la primera que contiene algunas de las ideas innovadoras de Viète (1591). Por ejemplo, ya introduce el término de "álgebra 
especiosa", utilizado por Viète. Pero, sobre todo para lo que estudiamos en este capítulo, ya usa un sistema de signos de tipo simbólico, incluso más adelantado que el de Viète.

Para poder comparar los diferentes "estilos algebraicos", tomaremos como referencia unos aspectos clave que nos pueden servir de comparativa, que son los propuestos por Puig (2018b):

1. La forma en que se construyen los nombres de las especies de números

2. El carácter sincopado o simbólico del sistema de signos y el tipo de signos usados para representar las especies de números

3. El concepto de exponente o algún precursor suyo

4. La forma y el número de las formas canónicas de las ecuaciones y de su generalización

5. La forma y el número de los algoritmos de resolución de las ecuaciones

6. La forma de la "regla única del álgebra" o algún precursor suyo

Andrés Puig, en el libro quinto de la Arithmetica, titulado "Trata de Algebra Racional", que es donde comienza la parte de álgebra, empieza definiendo conceptos. Define lo que es el Álgebra y en las partes en que él la divide. Y después construye dos progresiones, una aritmética que comienza por el 0 y otra geométrica que comienza por el 1 . La aritmética es de distancia 1 y la geométrica de razón 2. Esta última la pone como ejemplo ya que podría ser de razones superiores. A los elementos de la progresión geométrica les llama potencias (exceptuando los dos primeros). Y dice que el segundo término lo va a llamar raiz de todos los demás términos que le siguen "porque de su continua multiplicacion se forman todos los demás” (Puig, 1672, p. 369). Los términos de la progresión aritmética sirven para denominar a los caracteres. Y en medio de estas dos progresiones, escribe las abreviaturas de los caracteres, que son una especie de símbolos para denominar a las diferentes potencias. Es decir, el sistema consta de una raíz, sus potencias, los caracteres y sus denominaciones, tal y como aparecen en la Figura 1.

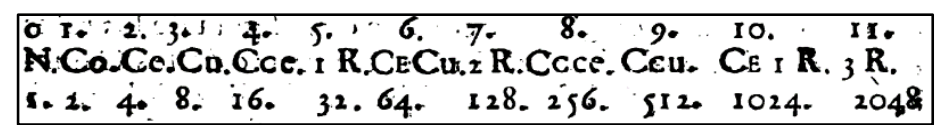

Figura 1. Potencias, géneros y denominaciones en Andrés Puig

La raíz no tiene por qué ser siempre 2. Puede ser cualquier otro número. Por ejemplo, si la raíz es 3, la progresión geométrica sería $1,3,6,9$, 12, etc.

Aparte de esta nomenclatura, Andrés Puig utiliza otros términos sinónimos. Para los caracteres utiliza también dignidades o géneros. En general, la progresión aritmética sirve como denominación de los caracteres. Las denominaciones sirven además "para manifestar quantas proporciones se contienen entre cada una de las dichas potencias" 
(Puig, 1672, p. 369). Y en esta frase se encierra el concepto de exponente, aunque no se exprese con esa palabra. Ya lo apunta Puig (2020) en su borrador para el artículo "Sobre el concepto de exponente y el término 'exponente' en la Arithmetica Universalis de Joseph Zaragozà, posibles fuentes y otros textos anteriores". Según ha analizado Puig (2020) en su estudio, Zaragoza (1669) es el primer matemático que utiliza el término "exponente" en España, aunque no con el significado de "número de veces que una cantidad aparece cuando se multiplica por sí misma reiteradamente" sino "como el lugar que una potencia tiene en la progresión geométrica que la genera”. Además, añade que ni Marco Aurel (1552), ni el alemán Rudolff (1525), ni Pérez de Moya (1558, 1562), ni Rocha (1565), ni Tolrà (1619) lo nombran, pero le dan el significado de "posición en la progresión”. En cambio, Stifel (1544) y Peletier (1554) (que copia a este último) lo nombran y además con el significado de "número de veces". Núñez (1567), Pérez de Moya (1573) y Puig (1672) tampoco nombran la palabra "exponente” pero sí le dan el significado de "número de veces".

Respecto a los géneros, caracteres o dignidades de números, comienza por el número, que es N. o n. y que puede ser un entero o una fracción. Al número lo relaciona con el punto en la geometría. También dice que puede que no se nombre con N. ni con n., pero que es un número simple. Al segundo carácter le llama cosa, raiz o lado. Le llama raiz, como se ha dicho antes, porque los demás se obtienen de su multiplicación. Al contrario del número, cuyo valor es conocido, el valor de la raiz no está determinado hasta que se manifieste en una igualación (ecuación).

Lado es por tomarse por aquella linea, ò lineas, terminativas del quadrado que tras desde caracter se sigue [...]. Cosa, porque obrando con ella en las igualaciones, por occasion de buscar, y hallar algun numero, ò cantidad demandada fingimos, ser el numero que se busca. (Puig, 1672, pp. 370-371).

Aparentemente cosa, raíz y lado son sinónimos para Andrés Puig. Pero vemos un matiz que ya lo apunta Puig (2011) cuando explica la aparición del término cosa en el libro de al-Khwārizmī.

$\mathrm{Si}$ "cosa" y "raíz" fueran la misma cosa, hubiera sido innecesario que apareciera la cosa en escena [...]. Si al - Khwārizmī explica el cálculo con la cosa y no el cálculo con la raíz, es porque cosa y raíz no son conceptualmente iguales. (p. 90).

Puig (1998, p. 7) dice que cuando al-Khwārizm̄̄ aborda la resolución de un problema concreto utiliza el término cosa, que nunca aparece en los enunciados. Es decir, que la raiz sería como un marco o concepto y cosa sería la instanciación concreta de ese concepto en un número, aunque desconocido. La raiz es un tipo de genero, y la cosa es 
un objeto desconocido y que puede tomar la forma de un tipo de genero, dependiendo del problema a resolver. De hecho, $a l-K h w \bar{a} r i z m \bar{l}$, resuelve algunos problemas en que la cosa es de tipo raiz y otros de tipo censo. Es decir, que la cosa no es de un tipo concreto hasta que se instancia en un problema. Y el hecho de que con el paso de los años se identifique cosa y raiz puede que se deba a que la mayoría de los problemas son de cálculo de raices y no de censos u otros generos. Con el paso del tiempo esa diferencia entre cosa y raiz ha desaparecido y en Andrés Puig ya son dos términos sinónimos. De hecho, sólo utiliza el término raiz al principio, cuando define los conceptos iniciales. Después, usa el término cosa tanto para explicaciones como para resolver problemas. Resumiendo, los nombres

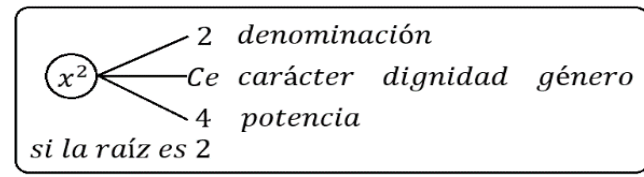

Figura 2. Nombres de los elementos que Andrés Puig le da a cada elemento de su álgebra son los que aparecen en la Figura 2.

Para formar los nombres de los caracteres, utiliza el sistema multiplicativo, propio de los algebristas españoles, italianos y alemanes en el siglo XVI. En cambio, Zaragoza utiliza el sistema aditivo, al igual que Viète, los algebristas árabes medievales y Leonardo de Pisa (Fibonacci). Es decir, que para nombrar cada carácter se sirve del producto de otros anteriores. El proceso lo explica entre las páginas 370 y 372. Comienza por el primer carácter (el numero), luego la raiz, que es de donde parte la serie de potencias. El "Censo, ó quadrado, cuya raiz, ó lado es la cosa, porque como procede de la multiplicacion de la cosa por si misma [...]" (Zaragoza, 1669, p. 371). Esta palabra ya la introdujo Gerardo de Cremona en el siglo XII, al traducir del árabe al latín el libro de álgebra de al Khwārizmī como traducción de la palabra árabe $m \bar{a} l$, que significa "cantidad de dinero" o "tesoro" y que es la que se usa en el álgebra árabe medieval para nombrar la "especie de número" que es el producto de multiplicar una raíz por sí misma. Aunque otro traductor, Gerardo de Chester la tradujo como substancia. Después el Cubo, cuya raiz Cubica es la cosa. Luego el censo de censo ò quadrado de quadrado. Para la quinta potencia introduce el término relato. Y los relatos los va numerando según van apareciendo. Al tratarse de un sistema multiplicativo, las potencias primas no las puede obtener de manera multiplicativa, por lo que se acuña esta nueva palabra. Este término ya aparece en las obras de los algebristas españoles del siglo XVI, y según Molina Sangüesa (2016a y 2016b), en los italianos como Pacioli y los alemanes como Rudolff (pero con el nombre de sursólido). Pero también en algunos algebristas del XVI, como Marco Aurel, que también usa el término sursólido. Hay que decir también que Marco Aurel utiliza un sistema multiplicativo. Por lo tanto, para Andrés Puig, la quinta potencia es el primer 
relato. Después viene el Censi cubo. Y al llegar a otra potencia prima, introduce un segundo relato (bisursolido en notación alemana). Después el censo de censo, el Cubo de cubo, el Censo de primer relato, el tercero relato. Y hasta ahí llega nombrando. Para seguir nombrando las siguientes potencias, explica la siguiente regla:

Si la suma de las denominaciones de los caracteres que se huvieren de multiplicar, fuere numero primo, empeçando del 5. assi como 5.7.11.13.17.\&cc. todos seran numeros relatos...Pero siendo la suma num. compuesto, tomaràs dos qualesquiera numeros, que multiplicados el uno, por el otro monte el num. de la tal suma, y hallados estos dos numeros, ellos nos enseñaràn la dignidad, ò grado del tal caracter. (Puig, 1672, p. 380).

Este método, en principio correcto, es ambiguo en el punto en el que dice "tomaràs dos qualesquiera números”, ya que un número compuesto puede constar de diferentes parejas de números. Andrés Puig, a la hora de trabajar con los caracteres, los abrevia (usando las dos primeras letras de cada palabra o un número y una $\mathrm{R}$ para los relatos). No se trata de usar símbolos sino abreviaturas. Es decir, sigue siendo sincopado. Por lo que el sistema multiplicativo para obtener los caracteres es igual al utilizando en el siglo anterior (salvo diferencias nominales). Por el contrario, José Zaragoza sustituye los caracteres abreviados por una letra (generalmente la $\mathrm{Z}$ ) con exponente numérico, que como ya señala Puig (2018b), toma de Descartes.

Tabla 2. SMS del siglo XVI, de Zaragoza y de Puig

\begin{tabular}{|c|c|c|c|c|c|}
\hline & \multicolumn{3}{|c|}{ Siglo XVI } & \multicolumn{2}{|c|}{ Siglo XVII } \\
\hline & $\begin{array}{l}\text { Marco Aurel } \\
(1552)\end{array}$ & $\begin{array}{l}\text { Juan Pérez de } \\
\text { Moya (1562) }\end{array}$ & $\begin{array}{l}\text { Pedro Núñez } \\
\text { (1567) }\end{array}$ & $\begin{array}{l}\text { José } \\
\text { Zaragoza } \\
(1669)\end{array}$ & $\begin{array}{l}\text { Andrés Puig } \\
\text { (1672) }\end{array}$ \\
\hline $\begin{array}{l}\text { Construcción } \\
\text { de caracteres }\end{array}$ & Multiplicativo & Multiplicativo & Multiplicativo & Aditivo & Multiplicativo \\
\hline $\begin{array}{l}\text { Exponente y } \\
\text { función }\end{array}$ & $\begin{array}{l}\text { No aparece. } \\
\text { Como posición } \\
\text { en una } \\
\text { progresión }\end{array}$ & $\begin{array}{l}\text { No aparece. } \\
\text { Primero como } \\
\text { posición y } \\
\text { luego como } \\
\text { número de } \\
\text { veces }\end{array}$ & $\begin{array}{l}\text { No aparece. } \\
\text { Como número } \\
\text { de veces }\end{array}$ & $\begin{array}{l}\text { Sí aparece. } \\
\text { Como } \\
\text { posición en } \\
\text { una } \\
\text { progresión }\end{array}$ & $\begin{array}{l}\text { No aparece. } \\
\text { Como número } \\
\text { de veces }\end{array}$ \\
\hline $\begin{array}{l}\text { Símbolos } \\
\text { para los } \\
\text { caracteres }\end{array}$ & $\begin{array}{l}\text { Cita: Cosa, } \\
\text { censo, cubo,... } \\
\text { primo relato o } \\
\text { sursólido, etc... } \\
\text { Trabaja con } \\
x \text { f... }\end{array}$ & $\begin{array}{l}\text { Cita: Cosa, } \\
\text { censo, cubo,..., } \\
\text { primer relato... } \\
\text { Cita: } \boldsymbol{x} \text { z ... } \\
\text { Trabaja con: co, } \\
\text { ce, cu, } 1 \mathrm{R}, \ldots\end{array}$ & $\begin{array}{l}\text { Cita: Cosa, } \\
\text { censo, } \\
\text { cubo,..., relato } \\
\text { primo... } \\
\text { Trabaja con: } \\
\text { co, ce, cu, Re. } \\
\text { p }^{\circ} . .\end{array}$ & $\begin{array}{l}\text { Cita: Cosa, } \\
\text { censo, cubo, } \\
\text { censo censo, } \\
\text { cubo censo, } \\
\text { cubo } \\
\text { cubo,... } \\
\text { Trabaja con: } \\
Z^{1}, Z^{2} \ldots\end{array}$ & $\begin{array}{l}\text { Cita: Cosa, } \\
\text { censo, } \\
\text { cubo,..., } \\
\text { primer } \\
\text { relato... } \\
\text { Trabaja con: } \\
\text { Co, Ce, Cu, } \\
1 \mathrm{R} . .\end{array}$ \\
\hline $\begin{array}{l}\text { Símbolo } \\
\text { igual }\end{array}$ & ygual a & yg. à & ygual a & $\Omega$ & ig. à \\
\hline $\begin{array}{l}\text { Símbolos } \\
\text { para la } \\
\text { adición y } \\
\text { sustracción }\end{array}$ & $+y-$ & p y m & $\bar{p}$ y $\bar{m}$ & $+y-$ & p y m \\
\hline
\end{tabular}

Andrés Puig utiliza simbología italiana para los signos de suma y resta, es decir, utiliza 
la "sincopación" p. y m. En cambio, Zaragoza utiliza simbología de influencia alemana, es decir los símbolos actuales para la suma y la resta. Hay que decir que no todos los algebristas españoles del siglo XVI utilizaron los símbolos italianos. Por ejemplo, Marco Aurel usó simbología alemana para la suma y la resta.

En cuanto al signo igual, Marco Aurel (y otros) utiliza ygual a, y Puig ig.à. En cambio Zaragoza utiliza el símbolo “ $\Omega$ ”, que le parece más fácil de escribir que el símbolo “=”. Por lo que podemos concluir que el sistema de signos de Andrés Puig, como el del siglo XVI en España, es sincopado y el de Zaragoza ya se acerca en bastantes aspectos al simbólico (por influencia de Descartes). En la Tabla 2 hay una comparativa de los diferentes SMS analizados.

Las seis canónicas, de la tradición de $a l-K h w \bar{a} r i z m \bar{l}$, están incluidas en ellas, pero de otra manera diferente a las originales ya que Aurel no indica que las igualaciones contengan la cosa o la raiz o el numero sino que habla de la "diferencia de nombres igualmente distantes". En nuestra simbología serían estas cuatro (con $n, m \geq 0$ ):

$$
a x^{n+2}+b x^{n+1}=c x^{n} \quad a x^{n+2}+c x^{n}=b x^{n+1} \quad b x^{n+1}+c x^{n}=a x^{n+2}
$$

Más estas tres:

$$
a x^{2 n+m}+b x^{n+m}=c x^{m} \quad a x^{2 n+m}+c x^{m}=b x^{n+m} \quad b x^{n+m}+c x^{n}=a x^{2 n+m}
$$

Y una que generaliza (en realidad son tres) las tres anteriores:

$$
a x^{n+1}=b x^{n} \quad a x^{n+2}=b x^{n} \quad a x^{n+3}=b x^{n} \quad a x^{n+4}=b x^{n}
$$

Los algoritmos de resolución de las formas canónicas son los propios del álgebra medieval, es decir que cada forma tiene su sistema de resolución.

Zaragoza (1669, pp. 330-340) establece sólo una forma canónica general y un solo algoritmo de resolución, que es el de Viète (1600), aunque Zaragoza no lo dice. La forma canónica general sería muy parecida a una ecuación polinómica actual. Por ejemplo, una de grado cinco sería algo así como: $1 Z^{5}+a Z^{4}+b Z^{3}+c Z^{2}+d Z^{1} \Omega$ e. Y tiene esta forma porque es a la que se le puede aplicar el algoritmo de Viète. La Regla Única del Álgebra consta de los siguientes pasos:

- Igualacion

- Reduccion de la igualacion

- Reduccion de los quebrados à enteros

- Reduccion por represion de Caracteres

- Reduccion del numero à la una parte

- Reduccion del Caracter maior à unidad

- Valor de la letra

Además, en la página 340 presenta una regla particular para las ecuaciones cuadráticas generalizadas, del tipo $\pm 1 Z^{2 n} \pm b Z^{n} \Omega e$, cuya solución la da en una fórmula $x^{n}=$ 
$\frac{\sqrt{b^{2} \pm 4 c} \mp b}{2}$. Donde el primer \pm corresponde al signo de $1 Z^{2 n}$ y el segundo $\mp$ corresponde al sino opuesto de $b Z^{n}$.Ahora veremos cómo organiza Andrés Puig sus igualaciones y los algoritmos de resolución que implementa. Todo esto lo desarrolla en el libro quinto. En el capítulo sexto, "Regla de Algebra, que es la igualación”, indica las etapas o fases de la resolución.

- Posicion

- Reduccion:

- Con enteros

- Con raices

- Con quebrados

- Division

- Extraccion de raiz

Luego indica los diferentes algoritmos para resolver las seis ecuaciones canónicas tradicionales árabes medievales y establece unas generalizaciones basándose en estas formas canónicas. Las formas generales serían en simbología actual (con $m, n \geq 0$ ):

$a x^{2 n+m}+b x^{n+m}=c x^{m} \quad b x^{n+m}+c x^{m}=a x^{2 n+m} \quad a x^{2 n+m}+c x^{m}=b x^{n+m} \quad a x^{m}=b x^{n}$

En el capítulo noveno establece una Regla General del álgebra que tiene esos pasos, que son diferentes a los que ha dicho antes para las ecuaciones de segundo grado, aunque el esquema general es igual, porque la forma canónica a la que hay que llevar la ecuación para resolverla es distinta. Explica cómo resolver ecuaciones de cualquier grado, con términos aditivos y sustractivos (incluso el término de mayor grado). Con estas etapas:

- Posicion

- Reduccion. Se pasa el término independiente a un miembro y el resto al otro miembro de la ecuación. Por supuesto, el término independiente tiene que ser positivo

- Division. La ecuación se manipula para que el término de mayor grado tenga coeficiente la unidad

- Extraccion de raices. Utiliza una adaptación del algoritmo de cálculo de raíces que se lo enseña su maestro Juan Serrano y que posiblemente tenga su origen en Viète

Tabla 3. Ecuaciones en el siglo XVI, en Puig y en Zaragoza

\begin{tabular}{|c|c|c|c|}
\hline & Siglo XVI & Andrés Puig (1672) & José Zaragoza (1669) \\
\hline Formas canónicas & $\begin{array}{l}8 \text { clásicas y sus } \\
\text { generalizaciones }\end{array}$ & $\begin{array}{l}6 \text { clásicas y sus } \\
\text { generalizaciones }\end{array}$ & \multirow{3}{*}{ Una sola general } \\
\hline Generalización & En lenguaje natural & En lenguaje natural & \\
\hline $\begin{array}{l}\text { Forma canónica } \\
\text { única general }\end{array}$ & & Una general & \\
\hline $\begin{array}{l}\text { Algoritmo para las } \\
\text { formas canónicas }\end{array}$ & $\begin{array}{l}\text { Uno por cada } \\
\text { forma canónica }\end{array}$ & $\begin{array}{l}\text { Uno por cada forma } \\
\text { canónica }\end{array}$ & \multirow{2}{*}{$\begin{array}{l}\text { Uno general y una fórmula } \\
\text { para cuadráticas } \\
\text { generalizadas (Regla Unica } \\
\text { del Algebra) }\end{array}$} \\
\hline Algoritmo general & & $\begin{array}{l}\text { Uno general (Regla } \\
\text { general) y otro } \\
\text { aproximado (Otra regla } \\
\text { general) }\end{array}$ & \\
\hline
\end{tabular}


En el capítulo undécimo establece otra regla general. Explica otro algoritmo de resolución de cualquier ecuación, pero de manera aproximada. Con un método de bisección, inspirado en un método similar de Chuquet (Marre, 1884), de quien Estienne de la Roche (1520) lo copió. La Tabla 3 resume la comparación entre las diferentes álgebras analizadas.

\section{MÉTODOS DE RESOLUCIÓN DE ECUACIONES POLINÓMICAS}

\subsection{Método general de cálculo de raíces}

Este método general de resolución de ecuaciones polinómicas es una extensión del tradicional algoritmo de cálculo de raíces. Su uso para resolver ecuaciones polinómicas lo describe Andrés Puig (1672) entre las páginas 447 y 468, en el capítulo noveno del libro quinto: “CAPITULO NONO. En el qual con regla general se enseña responder, y hazer qualquier demanda, ò question, que por Arithmetica se puede hallar". El autor dice que este método se lo enseñó su maestro Juan Serrano, matemático valenciano, en 1652 en la ciudad de Valencia. No hemos podido encontrar ninguna información de Juan Serrano ni nada escrito por él, por lo que lo único que tenemos es lo que dice Andrés Puig.

Antes de pasar a explicar su método, el autor indica que hay que aplicar al problema enunciado verbalmente la regla del álgebra, es decir, 1) traducir el problema a una ecuación, 2) transformar la ecuación a una ecuación en forma canónica y 3) resolver la ecuación en forma canónica. Para ello utilizando los pasos que él llama posición, reducción, división y extracción de raíz. El paso 2) es el que él llama "reducción" y lo que quiere es preparar la ecuación para poder aplicar su método de extracción de raíces. La "reducción", por tanto, ha de ser ahora distinta a la que ha expuesto para el caso de las ecuaciones de segundo grado, en el que las transformaciones que usaba eran similares a las clásicas del álgebra árabe medieval al-jabr y al-muqābala, porque la forma canónica a la que hay que reducir la ecuación obtenida en el paso 1) es ahora distinta. La ecuación debe quedar con todos los términos con la incógnita en un miembro y el término independiente en el otro. Por supuesto, el término independiente debe ser positivo. Una vez hecho esto, el término de mayor grado debe tener coeficiente 1 y todos los demás coeficientes deben ser enteros. Para conseguir esto, aplica de manera indirecta un cambio de variable si es necesario. El procedimiento está descrito con varios ejemplos, en las páginas 448 a 451.

Una vez preparada la ecuación, indica que si la ecuación tiene sólo un término con 
incógnita (igualación simple), es sencillo resolverla. Simplemente se calcula la raíz adecuada del término independiente, aplicando el cálculo de raíces descrito en los capítulos de aritmética. Por ejemplo, para resolver $x^{3}=125$ simplemente calcula la raíz cúbica de 125.

Las igualaciones compuestas (que constan de más de dos términos) las divide en aquellas con todos los coeficientes de los términos la unidad y las que los coeficientes son variados. Y otra subdivisión es si los términos están todos sumados (composición con afirmación) o hay algunos restados (composición con negación). Todas las igualaciones están catalogadas en la Tabla 4.

Tabla 4. Tipología de las igualaciones en Andrés Puig

\begin{tabular}{|c|c|}
\hline \multicolumn{2}{|c|}{ Igualación simple } \\
\hline Forma & Ejemplo \\
\hline$x^{n}=c$ & $x^{4}=16$ \\
\hline \multicolumn{2}{|c|}{$\begin{array}{l}\text { Igualación compuesta (puede faltar alguno de los términos intermedios) } \\
\text { Si todos los términos van sumados se llama composición con afirmación y si alguno va restado es } \\
\text { composición con negación }\end{array}$} \\
\hline \multicolumn{2}{|c|}{ Con coeficientes la unidad (al menos uno positivo) } \\
\hline Forma & Ejemplo de composición con afirmación \\
\hline \multirow{3}{*}{ $\pm x^{n} \pm x^{n-1} \pm \cdots \pm x=c$} & $x^{2}+x=42$ \\
\hline & Ejemplo de composición con negación \\
\hline & $x^{2}-x=30$ \\
\hline \multicolumn{2}{|c|}{ Con coeficientes no unitarios (al menos uno positivo) } \\
\hline Forma & Ejemplo de composición con afirmación \\
\hline \multirow{3}{*}{ $\pm x^{n} \pm a_{n-1} x^{n-1} \pm \cdots \pm a_{1} x=c$} & $x^{3}+3 x^{2}+4 x=46690$ \\
\hline & Ejemplo de composición con negación \\
\hline & $10 x-x^{2}=24$ \\
\hline
\end{tabular}

En el Anexo I realizamos el estudio completo del método de Puig con un ejemplo.

Este método permite resolver, considerando las manipulaciones necesarias para convertirla en canónica y teniendo en cuenta que sólo se encontrarán soluciones positivas, cualquier ecuación polinómica, incluso aquellas con términos restando o términos con coeficientes distintos a la unidad. Puig lo explica con varios ejemplos. En concreto, resuelve, con explicación, 11 ecuaciones polinómicas variadas. La de mayor grado que explica es la de cuarto grado (es de suponer que por no complicar en exceso los cálculos). Los coeficientes de los términos, salvo el independiente que lo sitúa a la derecha del igual y positivo, son tanto positivos como negativos (por supuesto, todos no pueden ser negativos porque entonces no tendría solución positiva). Todas las ecuaciones las analiza ya con el coeficiente del término de mayor grado siendo la unidad (positiva o negativa), pero previamente ha explicado cómo conseguir modificar la ecuación para que así sea. Las 11 ecuaciones analizadas son:
$x^{2}+x=42$
$x^{4}-2 x^{3}=864$
$x^{2}+4 x=60$
$10 x-x^{2}=24$
$x^{2}-x=30$
$x^{3}+x^{2}+x=14424$




$$
\begin{array}{llrl}
x^{3}+3 x^{2}+4 x & =46690 & x^{3}+10000 x^{2}=5773824 & x^{3}-x^{2}-x=77615 \\
x^{3}-5 x^{2}+6 x & =9660 & x^{4}+x^{3}=1375640 &
\end{array}
$$

Por lo tanto, podemos afirmar que Andrés Puig aplica un método general de resolución de ecuaciones polinómicas, siempre que la o las soluciones sean positivas. Es importante hacer notar que este método, aparte del factor de tanteo que representa el seleccionar los diferentes dígitos, aumenta en complejidad y laboriosidad conforme se aumenta el valor de la solución a obtener y conforme aumenta el grado de la ecuación. Por lo que se hace engorroso para esos casos. Por eso mismo, Andrés Puig opta por el otro método general por aproximación que analizamos también en este trabajo.

Para el caso de términos que van restados, en lugar de restar al término independiente y los sucesivos residuos las cantidades que corresponden, se las suma. Y para los términos que tienen un coeficiente diferente a la unidad, multiplica todo el desarrollo del término por dicho coeficiente antes de sumarlo o restarlo. En el Anexo II estudiamos otro ejemplo de este tipo.

Hay un caso especial que señala Andrés Puig. Se trata del caso en que el término de mayor grado está restando. En ese caso, indica que la ecuación tiene dos soluciones (para una ecuación de segundo grado). Explica que teniendo una de las soluciones, la otra se puede hallar fácilmente restando la que hemos hallado al numero de las cosas, es decir, al coeficiente de la $x$ o también dividiendo el término independiente entre la solución que ya tenemos. Como ya conocemos, en las ecuaciones de segundo grado, el producto de las soluciones es igual al coeficiente de la $x$. Por supuesto, no resuelve ecuaciones con soluciones negativas ni nulas.

En el Anexo III podemos ver exactamente las operaciones y signos que emplea Andrés Puig en una de las ecuaciones a resolver. Andrés Puig utiliza el desarrollo de binomios para obtener los diferentes factores. Ya apunta en la página 332 su uso mediante el empleo de un triángulo (semejante al de Tartaglia, Figura 3) y de cómo obtiene los diferentes números a partir de la multiplicación por sí misma diferentes veces de la cosa más un número. Y dice: “[...] de la continua multiplicacion de 1.cosa mas 1.numero, nacen los numeros que en la dicha tabla se contienen [...]" (Puig, 1672, p. 332).

Ahora pasaremos a realizar una comparación entre el método empleado por Puig en su libro de 1672 con el empleado por José Zaragoza en su Arithmetica Universal de

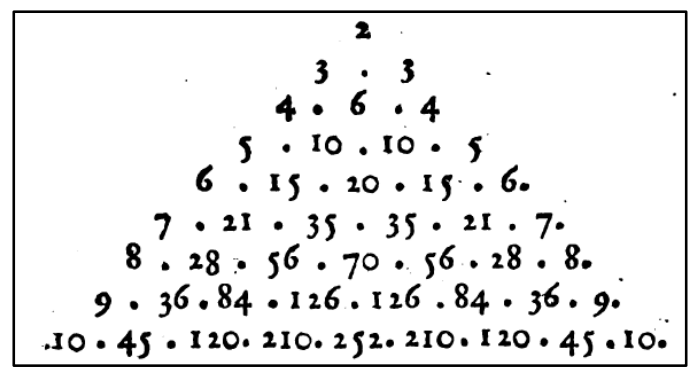

Figura 3. Triángulo de Tartaglia-Pascal 
1669. Zaragoza (1669), en la página 290 explica cómo obtiene un triángulo parecido, componiéndolo mediante el desarrollo teórico del binomio en las sucesivas potencias. Ese triángulo aparece en el libro segundo, página 161, y lo utiliza para el cálculo de las sucesivas raíces. Cuando hace el desarrollo binomial en la página 290, dice que "Con esta multiplicacion continua, se va formando aquella misteriosa Tabla triangular, que en el lib. $2^{\circ}$. cap. 15 . sirve, para sacar todas las raizes".

En el libro segundo de la Arithmetica Universal de Zaragoza de 1669, de la página 153 a la 264, es donde desarrolla su método general para resolución de ecuaciones polinómicas. Lo explica con mucho detalle y ejemplos, mucho más que Andrés Puig. De hecho, Zaragoza le dedica 112 páginas frente a las 25 que utiliza Puig. Zaragoza aplica su método para resolver ecuaciones polinómicas de manera general a partir de la página 194 (en las páginas previas utiliza el método para resolver raíces). Zaragoza explica al menos 28 ejemplos de ecuaciones frente a sólo 11 que explica Puig. En cuanto al detalle de las explicaciones que da cada autor, Puig es bastante escueto en las explicaciones y en la manera de presentar los cálculos. En cambio, Zaragoza explica mucho mejor qué operaciones está haciendo y organiza los datos de manera más entendible para el lector. En concreto, Zaragoza organiza las sucesivas potencias que van a servir para la obtención de los divisores y los restadores en tablas separadas, de forma que se ve muy claro para qué utiliza cada cosa.

El método es muy parecido al de Andrés Puig, salvo en un detalle de cálculo y en la organización de las operaciones. Se trata del punto en donde se debe estimar el valor que hay que darle al siguiente dígito. Andrés Puig sólo utiliza como divisor del residuo el factor de mayor peso, pero Zaragoza, según el coeficiente de cada uno de los términos de la ecuación y de sus signos decide qué factores del desarrollo de los binomios va a utilizar para la obtención de los divisores, pero por término general utiliza todos los factores del desarrollo de la potencia de mayor peso excepto el más pequeño. Es decir, el método de Zaragoza es más preciso que el de Andrés Puig porque utiliza más términos en algunos casos para obtener los divisores (aunque a costa de tener que realizar más cálculos). Zaragoza confecciona tablas adicionales para el cálculo de los divisores y del valor de los factores, lo que permite tener mejor organizada la información y que el lector pueda entender mejor cada uno de los puntos del procedimiento. Ambos autores creemos que toman indirectamente sus métodos de Viète, aunque Viète utiliza para la obtención de los divisores todos los términos excepto el de menor peso. 
En cuanto al tipo de ecuaciones que resuelven Puig y Zaragoza, Puig no organiza los tipos tan minuciosamente como lo hace Zaragoza. De hecho, hay casos posibles que se pueden dar y que Puig no analiza en ningún ejemplo de los que explica. Zaragoza, para cada tipo posible establece la casuística de resolución adoptada. Podríamos resumir la tipología empleada por Zaragoza en la Tabla 5.

Tabla 5. Tipología de las ecuaciones en José Zaragoza

\begin{tabular}{|c|c|}
\hline \multicolumn{2}{|c|}{ Capítulo VIII, p. 194: Conposicion de muchas especies con unidad, y afirmacion } \\
\hline Forma & Ejemplo \\
\hline$x^{n}+x^{n-1}+\cdots+x=c$ & $x^{5}+x^{4}+x^{3}+x^{2}+x=105025640$ \\
\hline \multicolumn{2}{|c|}{ Capítulo IX, p. 201: Conposicion de muchas especies con numero, y afirmacion } \\
\hline Forma & Ejemplo \\
\hline$a_{n} x^{n}+a_{n-1} x^{n-1}+\cdots+a_{1} x=c$ & $20 x^{3}+1000 x^{2}+10000 x=5157160000$ \\
\hline \multicolumn{2}{|c|}{ Capítulo X, p. 210: Conposicion de muchas especies con negacion directa } \\
\hline Forma & Ejemplo \\
\hline$a_{n} x^{n} \pm a_{n-1} x^{n-1} \pm \cdots \pm a_{1} x=c$ & $20 x^{3}+100 x^{2}-2000 x=664960000$ \\
\hline \multicolumn{2}{|c|}{ Capítulo XI, p. 219: Conposicion con negacion directa, y diminucion } \\
\hline Forma & Ejemplo \\
\hline $\begin{array}{l}\text { Igual que el anterior pero los términos restados } \\
\text { hacen que la solución tenga un número menor de } \\
\text { dígitos }\end{array}$ & $x^{3}-219 x^{2}-218=440$ \\
\hline \multicolumn{2}{|c|}{$\begin{array}{l}\text { Capítulo XII, p. 229: Negacion inversa del quadrado, y el cubo (el coeficiente del monomio de mayor } \\
\text { grado es negativo y tiene más de una solución. Al menos un coeficiente positivo) }\end{array}$} \\
\hline Forma & Ejemplo \\
\hline $\pm a_{3} x^{3} \pm a_{2} x^{2} \pm a_{1} x=c$ & $500 x^{2}-x^{3}-26200 x=88000$ \\
\hline \multicolumn{2}{|c|}{ Capítulo XIII, p. 242: Negacion inversa de las otras potestades (Al menos un coeficiente positivo) } \\
\hline Forma & Ejemplo \\
\hline $\pm a_{n} x^{n} \pm a_{n-1} x^{n-1} \pm \cdots \pm a_{1} x=c$ & $195 x^{3}-x^{4}=120$ \\
\hline
\end{tabular}

En el Anexo IV podemos ver cómo soluciona Zaragoza una ecuación sencilla, usando tablas de potencias, lo que hace su método más entendible que el de Puig.

Concluimos que tanto Puig como Zaragoza utilizan el desarrollo de binomios para resolver ecuaciones polinómicas, pero el método de Zaragoza es más claro y por tanto eficaz que el de Andrés Puig a la hora de estimar el valor de las sucesivas cifras de la solución, aunque a cambio de tener que realizar más cálculos.

Hemos podido comprobar que Andrés Puig toma su método de Juan Serrano (como él mismo indica en el texto) y posiblemente Juan Serrano de Viète o de alguien que lo ha obtenido de Viète. Parece ser que José Zaragoza posiblemente lo haya tomado de Viète (1600) o de alguien que lo ha tomado de él, ya que es en cuanto a los cálculos muy parecido (no en cuanto a la organización de las operaciones), aunque Zaragoza no lo diga en su libro.

Nordgaard (1922, pp. 24-32) analiza el algoritmo de Viète, e indica que es una extensión del método hindú del cálculo de raíces. También explica que Viète calcula el número de dígitos que debe tener la solución de la ecuación de una manera sencilla si el 
término de mayor grado es el dominante de la ecuación, pero hay que recalcular si hay otros términos que, por sus coeficientes, hacen que ese dominio no sea tan claro.

En su análisis del algoritmo de Viète, Nordgaard también cita a otros matemáticos que utilizaron dicho algoritmo, pero con alguna modificación. Por ejemplo, los ingleses Thomas Harriot (1560-1621), William Oughtred (1574-1660) y John Wallis (1616-1703) utilizaron el algoritmo de Viète con alguna modificación. Pero también advierte Nordgaard que toma la información de otro autor (De Morgan) y que al menos en Harriot (1631) no ha podido encontrar las modificaciones que cita De Morgan. Nosotros hemos consultado también algunos ejemplos en Harriot (1631) y hemos encontrado al menos una de esas modificaciones en un ejemplo de las páginas 132 a 134. James Hume (1636) simplifica también el método de cálculo para la obtención de los dígitos acortando tanto el divisor como el dividendo para poder estimar los diferentes dígitos de la solución.

En este sentido, Andrés Puig usa también un método para agilizar los cálculos a costa de añadir imprecisión al cálculo de los sucesivos dígitos. El método de simplificación de los cálculos que usa es el de obtener el divisor a partir sólo del factor de más peso del término de mayor grado. Zaragoza, como término general también agiliza el método de Viète considerando el desarrollo del binomio de más peso de la ecuación (excepto el factor de menor peso).

Para poder comparar las simplificaciones de los diferentes autores, usaremos un desarrollo sencillo. Por ejemplo, la ecuación $x^{3}+x^{2}+x=c$. Supongamos que la solución es $N=10 \cdot a+b$. Entonces, $N^{2}=100 \cdot a^{2}+2 \cdot 10 \cdot a \cdot b+b^{2}$ y $N^{3}=1000 \cdot a^{3}+3 \cdot 100 \cdot a^{2}$. $b+3 \cdot 10 \cdot a \cdot b^{2}+b^{3}$. El residuo es $r=c-1000 \cdot a^{3}-100 \cdot a^{2}-10 \cdot a=3 \cdot 100 \cdot a^{2} \cdot b+3 \cdot$ $10 \cdot a \cdot b^{2}+b^{3}+2 \cdot 10 \cdot a \cdot b+b^{2}+b$.

Para el cálculo de $b$, cada autor tomaría como divisor:

\begin{tabular}{ccc}
\hline Viète & Zaragoza & Puig \\
\hline $3 \cdot 100 \cdot a^{2}+3 \cdot 10 \cdot a+2 \cdot 10 \cdot a+1+1$ & $3 \cdot 100 \cdot a^{2}+3 \cdot 10 \cdot a$ & $3 \cdot 100 \cdot a^{2}$ \\
\hline
\end{tabular}

Recasens (2003, pp. 167-170) analiza el cálculo de las raíces de ecuaciones polinómicas en José Zaragoza, desarrollando el binomio. Nosotros hemos utilizado dicho análisis, junto al texto original de Zaragoza para compararlo con el de Puig. Al final de su análisis, Recasens indica que el mismo algoritmo de cálculo se encuentra en Andrés Puig, pero hemos comprobado que no es exactamente el mismo, como hemos visto anteriormente. Recasens, tal y como nosotros notamos, indica que el punto crítico del proceso es el cálculo de la cifra $b$.

El pas en què es calcula la xifra de l'arrel mitjançant una divisió és el punt crucial del 
mètode $\mathrm{i}$, a la vegada, és el punt que arriba a fer impracticable el mètode quan la potència del binomi és massa alta, ja que llavors hi ha massa dificultat en escollir el quotient apropiat per tal que deprés els termes negligits en el desenvolupament del binomi no afectin el dividend sobrepassant-lo. (2003, p. 170).

Conforme aumenta la potencia de los términos de la ecuación, el ajuste del divisor se hace más complejo e inexacto. Además, la presencia de coeficientes en los diferentes términos y signos negativos y positivos hacen aún más complicado dicho cálculo.

\subsection{Método general de cálculo de raíces aproximadas}

En el libro quinto, capítulo undécimo, "en que se declara con exemplos otra regla general, sin tener noticia de la composición de tantos generos, o diferencias de raizes" (Puig, 1672, p. 472), Andrés Puig considera que tiene mucha dificultad el método general que ha explicado anteriormente y que se le ofreció una regla también general, que menciona el agudísimo Estevan de Roca en el capítulo 7 de la primera parte de su aritmética. Dice también que le llama "regla de la Mediacion entre lo mas, y lo menos". Y aunque su autor no la utiliza para este propósito, "servira de luz para la regla que pretendemos, y esta llamaremos Regla Media”. Y a continuación explica su método con ejemplos.

Vamos a detenernos un poco en Estevan de Roca. Antich Rocha (1565), en su Arithmetica se refiere varias veces a él. Lo cita como Estevan de la Rocha o Stephano de la Rocha. Y habla de él como un maestro del que ha obtenido cosas para su libro. Se trata de Estienne de la Roche, que vivió entre los años 1470 y 1530.

De la Roche (1520), en su libro L'arismethique nouvellement composee, folios 28v29r, expone el método que llama la Regle des nombres moyens (regla de los números intermedios) y que es copia literal del método que expone Chuquet en su Triparty. Le Triparty de Chuquet, de 1484, no se llegó a imprimir, pero circuló como manuscrito en su época, con bastante éxito. A finales del siglo XIX, el académico Aristide Marre lo descubrió, transcribió, editó y publicó. La regla de la que hablamos está transcrita en Marre (1884, pp. 101-102). Por lo que podemos concluir que Andrés Puig se refiere al método de Chuquet, que él ha conocido por medio del libro de la Roche, y lo renombra como Regla Media. Veremos a continuación que el método que usa Andrés Puig es, sin embargo, sustancialmente distinto del método de Chuquet, a pesar de que sea similar en su estructura general.

El cambio de nombre tiene su sentido como veremos a continuación. Pasa de ser la "regla de los números intermedios a la regla media". Andrés Puig dice: “[...] y si bien es verdad, que el dicho Autor no trata desta regla para este proposito, con todo nos servirà 
de luz para la regla que pretendemos [...]" (Puig, 1672, p. 472). Pero sabemos que De la Roche (y por tanto Chuquet) utiliza su regla no sólo para resolver raíces de manera aproximada sino también ecuaciones. Y para esto último es para lo que utiliza Puig su regla, aunque sólo para ecuaciones con solución exacta. La palabra intermedio no implica estar en el medio exacto sino entre medias, pero Andrés Puig sí utiliza la palabra medio. Chuquet utiliza su regla para encontrar números entre dos dados.

Analicemos el método empleado por Chuquet en la edición de Marre (1884, pp. 101102). Utiliza dos series de fracciones (progresiones según Chuquet), una ascendente y otra descendente. La serie descendente es $\frac{1}{2}, \frac{1}{3}, \frac{1}{4}, \ldots, \frac{1}{n}$. Y la ascendente es $\frac{1}{2}, \frac{2}{3}, \frac{3}{4}, \ldots, \frac{n-1}{n}$. La regla empleada por Chuquet utiliza que si $a, b, c$ y $d$ son números naturales tales que $\frac{a}{b}<\frac{c}{d}$, podemos encontrar una fracción $\frac{a+c}{b+d}$ que está entre ambas fracciones $\frac{a}{b}<\frac{a+c}{b+d}<\frac{c}{d}$. Es decir, con este método es posible encontrar infinitas fracciones que estén entre dos dadas. Chuquet explica su regla con un ejemplo. Se trata de resolver la ecuación $x^{2}+x=39 \frac{13}{81}$, en contra de lo que afirma Puig de que "[...] el dicho Author no trata desta regla para este propósito [...]" (Puig, 1672, p. 472). Para ello, establece un entorno de enteros donde se encuentre la solución (la amplitud es 1, aunque sería posible aplicar un algoritmo similar con una amplitud diferente). En este caso, establece que el entorno es entre 5 y 6 . Es decir, la solución de la ecuación está entre 5 y 6 . Comienza la regla añadiendo al valor inferior del entorno $\frac{1}{2}$, que es el primer elemento tanto de la serie ascendente como de la serie descendente, es decir $5 \frac{1}{2}$ y comprobando si con este valor de la incógnita nos pasamos de $39 \frac{13}{81}$ o nos quedamos cortos. Si nos pasamos, probamos con el siguiente término de la serie descendente (estableciendo como parte superior del entorno el valor 5 más la fracción probada) y si nos quedamos cortos probamos con el siguiente término de la serie ascendente (estableciendo como parte inferior del entorno el valor 5 más la fracción probada). El proceso se repite hasta que tenemos dos fracciones, que junto al 5, nos delimitan el valor buscado. Una vez que consigue establecer esos valores, el inferior es $5+\frac{a}{b}$ y el superior es $5+\frac{c}{d}$, la regla continúa calculando una fracción entre $\frac{a}{b} \mathrm{y} \frac{c}{d}$ (con el método antes explicado de sumar numerador con numerador y denominador con denominador) y al evaluar $5+\frac{a+c}{b+d}$ en la ecuación se puede comprobar si nos quedamos cortos o nos hemos pasado. Si nos hemos quedado cortos se establece como límite inferior $5+\frac{a+c}{b+d}$ y si nos hemos pasado, se establece este mismo como límite superior. Y el método continúa resituando los límites cada vez en un entorno de menor amplitud respecto al 
valor esperado como solución. El método termina o bien cuando se ha encontrado la solución exacta o cuando ya no deseemos más resolución. Veamos los pasos concretos que da Chuquet en el ejemplo.

La solución está entre 5 y 6 . Comenzamos con 5 y con la progresión descendente. Los límites son $\left\{\frac{1}{2}, \ldots\right\}$. Evaluamos $5 \frac{1}{2} \rightarrow\left(5 \frac{1}{2}\right)^{2}+5 \frac{1}{2}=35 \frac{3}{4}<39 \frac{13}{81} \rightarrow\left\{\frac{1}{2}, \frac{2}{3}\right\}$. Evaluamos $5 \frac{2}{3} \rightarrow$ $\left(5 \frac{2}{3}\right)^{2}+5 \frac{2}{3}=37 \frac{7}{9}<39 \frac{13}{81} \rightarrow\left\{\frac{2}{3}, \frac{3}{4}\right\} . \quad$ Evaluamos $\quad 5 \frac{3}{4} \rightarrow\left(5 \frac{3}{4}\right)^{2}+5 \frac{3}{4}=38 \frac{3}{4}<39 \frac{13}{81} \rightarrow\left\{\frac{3}{4}, \frac{4}{5}\right\}$. Evaluamos $5 \frac{4}{5} \rightarrow\left(5 \frac{4}{5}\right)^{2}+5 \frac{4}{5}=39 \frac{11}{25}>39 \frac{13}{81} \rightarrow\left\{\frac{4}{5}, \frac{3+4}{4+5}=\frac{7}{9}\right\}$. Evaluamos $5 \frac{7}{9} \rightarrow\left(5 \frac{7}{9}\right)^{2}+5 \frac{7}{9}=$ $39 \frac{13}{81}$. Que es el valor exacto. Por lo tanto, la solución exacta es $5 \frac{7}{9}$.

Más adelante, en las páginas 112 y 113 vuelve a aplicar su regla para resolver de manera aproximada, en este caso, la raíz cuadrada de un número que no es un cuadrado. En concreto el número 6. Es decir, que esta regla la aplica no sólo para calcular raíces sino también ecuaciones. En el Anexo V mostramos esta regla con simbología actual y mediante un algoritmo.

Parece ser que esta regla ya era conocida por un matemático español, Juan de Ortega (1512), a principios del siglo XVI, aunque no se sabe con seguridad ya que en su libro figura la aproximación de la raíz de algunos números que coinciden con las aproximaciones dadas por Chuquet pero no el método empleado para llegar a esos valores. Benito, Escribano, Fernández y Sánchez (2012) han realizado un estudio con ordenador para averiguar si las aproximaciones realizadas por Juan de Ortega se podían haber hecho utilizando el algoritmo de Chuquet, y parece que encontraron que era bastante probable que así fuera. La regla utilizada por Chuquet está bien estudiada en Nordgaard (1922, pp. 18-19), que junto con la transcripción de Marre, nos has servido de base para su estudio. En ese texto, Nordgaard analiza varios métodos de aproximación de raíces y de ecuaciones.

La regla que usa Puig conserva el esquema general de la regla de Chuquet, es decir, conserva 1) acotar la raíz entre dos términos enteros, 2) usar progresiones para añadir al valor inicial hasta acotar más estrechamente la raíz, y 3) calcular un valor intermedio entre los extremos del intervalo. Ahora bien, Puig en 1) no acota entre dos enteros consecutivos, en 2) no usa las mismas progresiones que Chuquet y en 3) no calcula el valor intermedio de la misma manera que Chuquet. Puig establece una progresión geométrica de razón dos, comenzando por dos, es decir $2,4,8,16, \ldots 2^{n}$. Según podemos analizar en los ejemplos que expone, se trata de llegar a calcular un entorno entre el que está la solución de una ecuación, establecer un pivote en cada uno de los extremos del entorno y dividirlo por la 
mitad en cada iteración de la regla de manera que nos vayamos centrando alrededor de la solución buscada en entornos de amplitud la mitad cada vez. Por ejemplo, en la página 473 plantea la resolución de la ecuación $x^{2}-2 x=255$. Veamos los pasos que sigue. Aunque Puig se salta alguno, nosotros los expondremos todos para mayor claridad.

Estima un valor para la solución, “[...] y viniendo a la fin, menos de lo que se busca [...]" (Puig, 1672, p. 473), menor del que se busca. En el ejemplo es 14. Prueba con 14: $14^{2}-2 \cdot 14=168<255$. Como se ha quedado corto, prueba sumándole a 14 el primer término de la progresión, que es 2 , obtiene $16: 16^{2}-2 \cdot 16=224<255$. Como sigue siendo menor, le suma a 14 el siguiente término de la progresión, es decir 4, obteniendo 18: $18^{2}$ $2 \cdot 18=288>255$. Ahora se ha pasado, por lo que calcula la media aritmética de los valores en que se ha quedado corto y que se ha pasado, $\frac{16+18}{2}=17$. Prueba con 17: $17^{2}-2$. $17=255 . \mathrm{Y}$ ha encontrado el resultado exacto.

Puig pone algunos ejemplos más, pero en todos ellos existe una solución exacta, por lo que este método lo emplea sólo para resolver ecuaciones con soluciones exactas. De hecho, el mismo Puig indica al final del libro quinto (Puig, 1672, pp. 479-480) que su regla sólo se aplicará cuando el número que se busca esté al menos entre dos números que difieran en dos unidades.

En la actualidad es un método utilizado en diversos campos, como por ejemplo en informática, para insertar elementos en listas ordenadas. En el Anexo VI mostramos esta regla con simbología actual y en forma de algoritmo.

Ponemos concluir que, aunque Andrés Puig dice que toma su método de Estienne de la Roche (y por tanto de Chuquet), ambos métodos difieren bastante. Se parecen en que ambos utilizan alguna sucesión y realizan una serie de cálculos entre dos valores para obtener la solución. La regla de Chuquet utiliza dos sucesiones de fracciones (una ascendente y otra descendente) y una regla para obtener valores intermedios entre dos fracciones (sumando numerador con numerador y denominador con denominador) y la de Puig utiliza una única progresión aritmética de enteros y un procedimiento de cálculo, primero usando los términos de dicha progresión y luego obteniendo la media aritmética entre dos valores enteros o mixtos.

\section{ANÁLISIS DE LAS ADICIONES}

Como ya hemos dicho en el capítulo 3, sobre el marco teórico y metodológico, vamos a considerar las adiciones que aparecen en las impresiones póstumas como lo que Genette (2001) llama "paratextos”, es decir acompañamientos de un texto escrito. 
De las distintas funciones que puede tener el análisis de paratextos, en el caso de estas adiciones póstumas los usaremos para observar de qué tipo son los aspectos que Puig considera que vale la pena mejorar del texto de la edición original, quizá como resultado de los comentarios que recibiera de sus lectores o de la experiencia que tuviera usando el libro en la enseñanza.

Hemos detectado varios casos en los que la adición trata de explicar mejor o de otra manera más comprensible para el lector algún problema o aspecto de la primera impresión. Esto nos da la idea de que el autor pretende hacer más "didáctico" el texto. En otras adiciones hace alguna demostración de alguna regla aparecida sin demostrar en el texto inicial. Hay algún caso en el que en el texto inicial aparecía un problema resuelto de manera aritmética, pero sin sentido y en la adición utiliza el álgebra para dotar de sentido a la resolución aritmética.

Todas las impresiones después de la primera presentan adiciones. Según indica el impresor en la segunda edición, la de Figuerò de 1711, "Esta segunda Impression sale enriquecida con Addiciones posthumas del mismo Autor, las quales van notadas con esta señal ". Son adiciones que seguramente Andrés Puig diera al impresor antes de morir o bien sus herederos las llevaran para la impresión.

Estas adiciones se conservan casi idénticas en todas las demás impresiones posteriores, salvo un pequeño detalle. Se trata de la última página del texto, en que se añade un último ejemplo (el XXI). En la impresión de Figuerò de 1711 añade el ejemplo y termina. Pero en la impresión de 1715, también de Figuerò añade esta frase: "Este Exemplo es el mismo del Libro quarto, Capitulo 12, pagina 341. y se ha vuelto á poner aqui, para que veas, y entiendas de donde sale el artificio de aquel modo de obrar".

En la impresión de 1711 de Figuerò, el ejemplo a que hace referencia este añadido no existe, y por eso no aparece esta referencia. Es decir, que el ejemplo XLII del Capítulo XII del Libro cuarto, que llamaremos "el problema de las gallinas y los huevos", resuelto de manera aritmética sólo está presente en las impresiones posteriores a la de 1711, por lo que se trata de una adición más a partir de la impresión de 1715 en las páginas 341342. Sí aparece este problema, resuelto de manera algebraica como una adición a partir de la impresión de 1711, como el ejemplo XXI del Capítulo XXXIV del Libro sexto.

En las impresiones de Giralt (sin fecha) aparece también esta frase, pero hemos encontrado dos composiciones diferentes, una de 548 páginas y otra de 497 páginas. En la que la primera de ellas, se trata de una impresión con el mismo número de páginas que la de Figuerò de 1715, por lo que entendemos que es una copia exacta. Pero la otra 
impresión de Giralt no es copia exacta sino una nueva composición, aunque con el mismo texto.

En la impresión de 1745 de Jolis, aparece también esta frase, pero hace referencia a la página 286, que es en la que comienza el capítulo y no en la que está el ejemplo. Nos surge además un interrogante. Se trata de que en esta impresión de 1745 de Jolis se dice que es la tercera, pero incluye esta frase al final que aparece por primera vez en la tercera de Figuerò de 1715. Es decir, el impresor Jolis ha tenido que ver que ya había antes una tercera impresión, y ha repetido también tercera impresión, lo cual resulta chocante. Respecto a este asunto tenemos una hipótesis, y es que, en la fecha de la impresión, la autorización para reimprimir se hace a partir de presentar en el Consejo de Castilla un original del que se va a hacer la reimpresión y un certificado del "Corrector" de que la copia es correcta. Seguramente se presentó la tercera impresión de Figuerò de 1715, y al tratarse de una copia exacta, no de una nueva impresión, no tenía sentido que fuera una cuarta impresión sino la reimpresión de la tercera. El resto de adiciones se continúa edición tras edición, todas semejantes a la segunda de Figuerò de 1711.

En la Tabla 6 se enumeran las adiciones que hemos encontrado y dónde irían en la primera impresión.

Tabla 6. Relación de la situación de las adiciones

\begin{tabular}{llll|llll}
\hline$N^{o}$ & $2^{a}$ de 1711 & $1^{a}$ de 1672 & Tipo de contenido & $N^{o}$ & $2^{a}$ de 1711 & $1^{a}$ de 1672 & Tipo de contenido \\
\hline 1 & p. 18 & p. 19 & Matemáticas & 12 & p. 317 & p. 340 & Enseñanza y Mat. \\
\hline 2 & p. 33 & p. 34 & Enseñanza & 13 & p. 317 & p. 340 & Matemáticas \\
\hline 3 & p. 51 & p. 53 & Matemáticas & 14 & p. 317 & p. 340 & Matemáticas \\
\hline 4 & p. 65 & p. 67 & Enseñanza & 15 & p. 318 & p. 341 & Matemáticas \\
\hline 5 & p. 96 & p. 100 & Enseñanza & 16 & p. 319 & p. 341 & Matemáticas \\
\hline 6 & p. 97 & p. 100 & Enseñanza & 17 & p. 327 & p. 351 & Enseñanza \\
\hline 7 & p. 141 & p. 146 & Enseñanza & $N^{o}$ & $3^{a}$ de 1715 & $1^{a}$ de 1672 & Tipo de contenido \\
\hline 8 & p. 194 & p. 210 & Enseñanza y Mat. & 18 & p. 341 & p. 366 & Enseñanza \\
\hline 9 & p. 201 & p. 215 & Enseñanza y Mat. & $N^{o}$ & $2^{a}$ de 1711 & $1^{a}$ de 1672 & Tipo de contenido \\
\hline 10 & p. 259 & p. 279 & Enseñanza & 19 & p. 342 & p. 366 & Enseñanza y Mat. \\
\hline 11 & p. 298 & p. 321 & Enseñanza y Mat. & 20 & p. 547 & p. 576 & Enseñanza y Mat. \\
\hline
\end{tabular}

Manera de referenciar: $\mathrm{N}^{\mathrm{o}}$ Adición, página de la impresión de 1711, página de la impresión de 1672.

Adición $1,18,19$

Puig se da cuenta de un error que ha visto en otros libros, en que se considera el 511 como primo para decir que 130816 es perfecto (y lo mismo ocurre con el 2047 que no es primo y por tanto 2096128 no es perfecto). Dice que este error lo cometen, con los mismos números Estienne de la Roche, el autor de El Dorado Contador, Tartaglia y "otros muchos". Nosotros hemos comprobado que efectivamente el error aparece en Le Triparty de Chuquet (Marre, 1884, p. 68), de donde lo copia Estienne de la Roche en su 
L'arismethique nouvellement composee (de la Roche, 1520, fo. 3r), y en El Dorado Contador (Santa Cruz, 1603, fol. 5v y 6r). Tartaglia dice al comienzo de La Seconda Parte del General Trattato di Numeri et Misure que 130816 es perfecto (Tartaglia, 1556, fol. 1v.) y en el Libro IX explica cómo hallarlos y da una lista de los que para él son los primeros veinte (el último, un número de 24 dígitos), entre los que están los ocho primeros números perfectos, acompañados de otros doce erróneos (Tartaglia, 1556, fol. 146r$146 v)$.

Con esto parece querer decir que tiene muchos conocimientos sobre la materia y que incluso es capaz de corregir a grandes maestros. Por ejemplo, en la adición 3 habla de las "siete maravillas" de Ventallol, añadiendo una más a las expuestas por dicho autor, diciendo que podría considerarse la "octava maravilla". Creemos que estos comentarios están encaminados a "venderse", ya sea como "maestro", como "experto" o simplemente para vender mejor su libro.

Características de la adición: contenido matemático, corregir autores, aritmética.

\section{Adición 2, 33, 34}

En esta adición se plantea una nueva forma de crear una serie de números con una cierta proporción dada. Aquí es pertinente señalar qué es lo que entiende Puig por "proporción”. El concepto de proporción en Puig es similar al de "razón” en Euclides. Pero en realidad Euclides, en sus Elementos, en el libro V, en las definiciones habla de "guardar la misma razón” y no de "razón” como un número. Es decir, lo propio sería hablar de la razón no como un valor o cantidad sino como una manera de relacionarse dos magnitudes. Respecto a la "proporcionalidad" de que habla Puig en el texto, ese concepto corresponde al concepto de "proporción" en Euclides. En el mismo libro V, en la definición 6, dice Euclides: "Llámense proporcionales las magnitudes que guardan la misma razón". De esta manera, cuando nos refiramos a la razón entre dos números o magnitudes $a$ y $b$ no lo haremos con $\frac{a}{b}$ sino como $a: b$, tal y como indican Fernández y Puig (2002). Y cuando hablemos de proporción entre dos razones $a: b$ y $c: d$, lo haremos como estos autores indican, es decir como $a: b:: c: d$ ( $a$ es a $b$ como $c$ es a $d)$.

En la época de Andrés Puig muchos autores utilizaban "proporción” por "razón” y "proporcionalidad" por “proporción”. Clavius, en su famosa edición comentada extensamente de los Elementos de Euclides (Clavius, 1574), que es precisamente la que cita Puig, indicaba esta diferente forma de llamar a los mismos conceptos. El propio Puig lo advierte en el capítulo XVII del libro primero (Puig, 1672, p. 51): "Nota, que lo que aqui llamamos proporcion, llaman algunos razon: y lo que llamamos proporcionalidad, 
llaman proporcion; nombrese como cada uno quisiere, que no està la dificultad en el nombre".

Hay que señalar que Andrés Puig utiliza la edición de Clavius de Euclides, que introduce modificaciones y comentarios. Esto lo refiere Puig al final del libro primero. Clavius (1538-1612) fue un jesuita alemán, matemático y astrónomo, muy famoso por elaborar el cambio del calendario juliano al gregoriano, lo que le llevó a enfrentarse incluso con algunos matemáticos importantes como fue Viète. Entre otras cosas, editó los libros de Euclides, comentándolos. Obra que fue muy famosa en su época y se estudió en todos los colegios jesuitas. Hubo reediciones hasta 1691.

Cuando Puig se quiere referir a la cantidad que representa una razón habla de “denominación de una proporción”. Eso lo aclara en el capítulo IX del libro primero, donde también refiere que Euclides lo llama "cantidad de proporción”. Y esto aparece como una definición en los Elementos, en concreto en la definición 5 del libro VI que según parece no es original de Euclides sino una adición de Teón de Alejandría (padre de la famosa Hipatia), lo que los expertos lo consideran como una torpeza al añadir algo que ya aparece en la proposición 5 del libro VIII.

La manera original del ejemplo que luego resuelve de manera diferente en la adición está basada en la proposición 2 del libro VIII de los Elementos de Euclides: "Hallar tantos números como uno proponga continuamente proporcionales, los menores en una razón dada". El problema original a resolver es: "Demos, que en la proporcion de 4. à 3. que son los menores en aquella proporcion, queremos hallar tres numeros continuos proporcionales" (Puig, 1711, p. 32). Puig quiere, sabiendo que 4 y 3 guardan razón, obtener otros tres números en proporción continua teniendo esa misma razón. Y para ello "cuadra" ambos números, obteniendo 16 y 9. Entre ellos pone el producto de los primeros, es decir, 16, 12 y 9, que son los tres números continuos proporcionales pedidos. Y continúa con el proceso para obtener un cuarto, un quinto, etc.

Si utilizamos simbología actual lo podemos entender mejor: partimos de dos números en razón $a: b$. Ahora multiplicamos la razón por el primer número $a^{2}: a b$, por lo que la razón no cambia. Después hacemos lo mismo pero por el segundo $a b: b^{2}$ por lo que la razón sigue igual. Como ambas razones deben ser iguales entre sí, son una proporción $a^{2}: a b:: a b: b^{2}$. Que si escribimos en forma de proporción continua sería $a^{2}: a b: b^{2}$.

Es decir, que en el ejemplo original utiliza el concepto de razón (“proporción” en Puig). En cambio, en la adición usa el concepto de "denominación de la proporcionalidad", es decir de la fracción como valor de la razón. Y hace estas 
operaciones: $\frac{4}{3}=1 \frac{1}{3}$ que es la "denominación de dicha proporcionalidad". Para hallar el primero de los tres números hace $1 \frac{1}{3} \cdot 4=5 \frac{1}{3}$. De esta manera los tres números en continua proporcionalidad serán $5 \frac{1}{3}, 4$ y 3 . Pero quiere tener los números sin fracción, por lo que multiplica los tres números por el denominador del quebrado, obteniendo 16, 12 y 9 .

Características de la adición: enseñanza, variante, menos euclídeo, más fácil, más práctico, aritmética, proporciones, razón.

\section{Adición 3,51, 53}

En esta adición extiende la manera de "componer proporciones" que aparecía en la primera impresión, de forma que se puede hacer con las cantidades y números que queramos. Además, cita lo que él llama "su octava maravilla" (en comparación con las siete de Ventallol), que es que "si los numeros de todas las denominaciones de las proporciones de dichos numeros, se multiplican unos por otros, el producto siempre será la denominacion de la proporcion de los extremos" (Puig, 1711, p. 51). Y esto lo explica, pero no demuestra, con varios ejemplos. Esta “composición de proporciones" la obtiene de la definición 5 del libro VI de los Elementos (que ya hemos visto que es equivalente a la proposición 5 del libro VIII).

Como ya hemos dicho anteriormente, lo que Puig llama "proporción" es lo que nosotros entendemos como estar en razón y lo que denomina "denominación de una proporción" es el valor de la razón. Puig establece una regla general para componer proporciones, que es "multiplicar sus denominaciones, unas por otras".

Uno de los ejemplos es componer las "proporciones" 4:3, 5:3 y 7:2. Según la regla de Puig, se multiplican los valores de sus razones (“denominaciones de las proporciones"), obteniendo la razón 140:18 (es decir, $\frac{4}{3} \cdot \frac{5}{3} \cdot \frac{7}{2}=\frac{140}{18}$ ). De esta forma ya tenemos la proporción compuesta y podemos obtener cuatro términos en continua proporcionalidad, tal y como se explicó en la adición anterior. En la adición, como hemos comentado, además de ampliar esta regla a cualquier número o cantidad de razones, también dice que el producto de las razones será la razón de los extremos. Y utiliza el ejemplo de los números 5, 4, 12, 3,20 y 2. Primero se construyen las razones y sus valores (“denominaciones de las proporciones") $\frac{5}{4}, \frac{1}{3}, \frac{4}{1}, \frac{3}{20} y \frac{10}{1}$. Luego se multiplican $\frac{5 \cdot 1 \cdot 4 \cdot 3 \cdot 10}{4 \cdot 3 \cdot 1 \cdot 20 \cdot 1}=\frac{600}{240}$ que es la razón $5: 2$. Pero no hace demostración alguna de lo que dice. Finalmente añade que podríamos interponer todas las "proporciones" intermedias que quisiéramos, obteniendo el mismo resultado. Andrés Puig apostilla que esto que él expone podría considerarse la octava maravilla en relación a las siete que establece Juan Ventallol (1521) en su libro. 
Hemos consultado la traducción hecha por Tolrà (1619, pp. 481-484) de la aritmética de Juan Ventallol para analizar cuáles son las siete "maravillas" que cita Puig. Se trata de siete identidades algebraicas acerca de las proporciones. En el Anexo VII están descritas.

Características de la adición: contenido matemático, citar otros autores, mostrar que sabe mucho (lo que él propone es de la misma categoría que las siete maravillas de Ventallol, libro famoso en Cataluña), aritmética, proporciones.

\section{Adición 4,65, 67}

En la primera impresión aparece una tabla de multiplicar de los diez primeros números (en forma de matriz 10x10. Figura 4). Puig dice que de los Arithmeticos es llamada Tabla Pitagorica. En la adición aparece una tabla más de multiplicar (Figura 5).

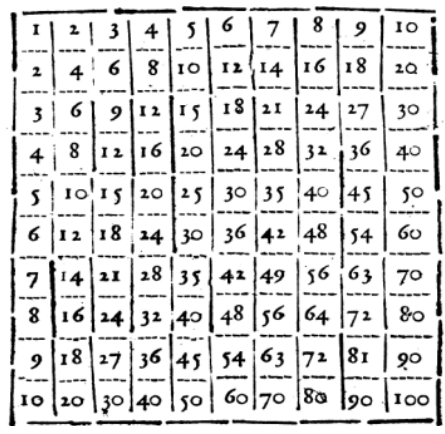

Figura 4. Tabla tipo matriz

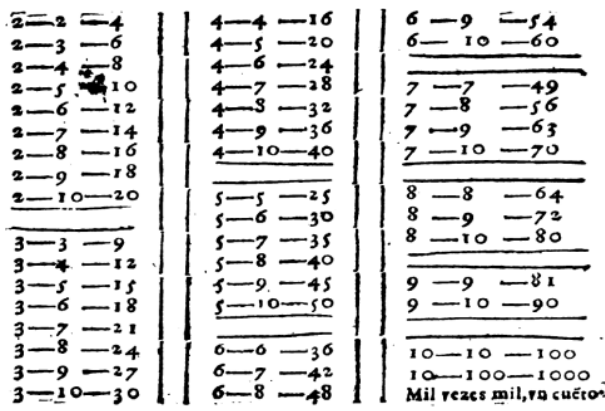

Figura 5. Tabla por números

Esta nueva tabla es más práctica que la anterior porque de un solo vistazo permite obtener el resultado de la multiplicación, sin tener que buscar fila y columna (tal y como aparece en la primera tabla). Está organizada por subtablas, una por cada número, comenzando por el 2 (el 1 no aparece porque no tiene utilidad). Cada subtabla comienza por el producto del número por él mismo. Es decir, que se ahorra los productos anteriores que ya se han calculado en subtablas previas. De esta manera, la nueva tabla contiene los resultados de los productos y es más reducida y rápida para su uso que la organizada en forma de matriz.

Características de la adición: enseñanza, variante, menos ligada a la tradición culta, más fácil, más práctico, aritmética, multiplicación, proporciones.

Adición 5,96, 100

Decía en la primera impresión:

[...] es bien advertir à los principiantes, qual sea el intento principal desta regla, por la dificultad, que siempre ha causado el ver, que multiplicando $\frac{3}{4}$ por $\frac{2}{3}$ monta $\frac{1}{2}$ que es menor que los quebrados que se multiplican. $\mathrm{Y}$ assi digo, que el intento desta regla, es saber quanto valen $\frac{3}{4}$ de un entero, valiendo el mismo entero $\frac{2}{3}$ que realmente es una regla de tres. (Puig, 1672, p. 100).

Como podemos apreciar, el mismo autor indica que esta operación le cuesta bastante 
entenderla a los “principiantes”. Es decir, está dedicada a enseñar a personas no expertas en las matemáticas. Y señala algo que sabemos que cuesta entender a los estudiantes cuando las primeras veces trabajan con las fracciones, que es que el producto de dos fracciones puede dar lugar a una fracción más pequeña. Esta misma dificultad la encontramos cuando hacemos ver a los estudiantes de primeros cursos que el producto de un número por otro número entre 0 y 1 da como resultado un número menor que el inicial. Y lo contrario cuando dividimos. Ya lo indicó Brousseau (1980) cuando dijo que el conocimiento de los números naturales es un obstáculo a la hora de comprender los decimales, debido a que genera que los estudiantes establezcan relaciones entre estos dos tipos de números. Y esto mismo ocurre con las fracciones, que se confunde la multiplicación con el aumento y la división con la disminución. Y según parece, ese problema ya lo habían detectado en época de Puig y seguramente antes.

Para explicar el por qué el producto de dos fracciones puede ser menor que las mismas fracciones, utiliza las fracciones como parte-de. Y pone un ejemplo, que consiste en calcular $12 \cdot 12=144$. Y luego calcular $\frac{3}{4}$ de $12=9 \mathrm{y} \frac{2}{3}$ de $12=8$, que multiplicados da 72 , que es $\frac{1}{2}$ de 144 . Es decir que comprueba con un ejemplo que lo que dice es cierto.

En la adición hace una explicación diferente: "Multiplicar no es otra cosa, que de dos numeros compuestos, tomar el uno tantas veces quantas unidades huviere en el otro" (Puig, 1711, p. 96). Señala que como multiplicar consiste en tomar tantas veces un número como indica el otro, si ese "tantas veces" es menor que la unidad, estamos tomando menos veces de la unidad, por lo que el resultado tiene que ser menor que el original. Aquí, la dificultad es entender que "tantas veces" no es un número entero de veces, por lo que ese concepto debe ser entendido previamente por el alumno. En palabras de Puig: "[...] que aviendo de multiplicar $\frac{3}{4}$ por $\frac{2}{3}$ el numero que se tiene de multiplicar, no se puede tomar una vez entera, porque el multiplicador no llega à uno [...]” (Puig, 1711, p. 96).

Características de la adición: enseñanza, variante, más fácil, aritmética, multiplicación, fracciones.

\section{Adición 6,97, 100}

Esta adición es similar a la anterior, pero con la división. Ahora lo que pretende es explicar y poner algunos ejemplos de división de fracciones. Primero indica que no es necesario reducir a común denominador: "Reduzimos los quebrados, sin hazer mencion de hallar nuevo denominador" (Puig, 1711, p. 97). Para obtener el resultado lo que hace es multiplicar en cruz, tal y como enseñamos a los niños. Y mediante un ejemplo, que es 
dividir $\frac{7}{8}$ entre $\frac{3}{7}$, advierte al lector que el cociente es mayor que lo que se parte. Y aquí tenemos un caso similar al de la adición anterior. Aunque no lo explica con tanto detalle como en el caso de la multiplicación, en realidad el mecanismo explicativo es el mismo.

Dice Puig: "porque el intento desta regla, es saber quanto vale un entero, al respecto que $3 / 7$ del mismo entero valen 7/8" (Puig, 1711, p. 97). Toma las fracciones como operadores sobre enteros. En la adición complementa la explicación anterior con otra diferente. Dice:

Partir [...] no es otra cosa que de dos números propuestos hallar un tercer numero, que nos declare, y manifieste las vezes, que el partidor entre, ò està contenido en el numero que se parte [...], y si el partidor fuesse menor, mayor seria el cociente. (Puig, 1711, p. 97).

Este tipo de división se llama "cuotición", que posibilita la extensión del concepto de división a números que no sean naturales, entre otras cosas.

Características de la adición: enseñanza, variante, más fácil, aritmética, división, fracciones.

\section{Adición 7,141, 146}

En la primera impresión, el autor resuelve un problema mercantil. Se trata de saber el montante de una mercancía en la que hay una mezcla de diferentes medidas y el precio en diferentes monedas. Para calcular el montante total en dinero de toda la mercancía, realiza una serie de multiplicaciones y aplica la regla de tres en sucesivas ocasiones. En la adición explica este mismo problema, pero utiliza fracciones y restos de la división de fracciones. El proceso es más sencillo y mecánico. En el Anexo VIII podemos ver un ejemplo sencillo para comprobarlo.

Características de la adición: enseñanza, variante, más fácil, más práctico, aritmética, cambio de monedas, cambio de unidades de medida tradicionales, fracciones.

\section{Adición 8, 194, 210}

La adición comenta un problema planteado que consiste en un préstamo a cierta cantidad de años vista, y se calcula el tanto por ciento de interés anual que se cobra. Los cálculos no se hacen con la fórmula que conocemos actualmente sino mediante el uso de una regla de tres compuesta y un poco de ingenio. En la adición, Andrés Puig indica que esta manera de reducir muchos pagos a uno sólo se realizaba en:

[...] las Contadurias, y Veedurias de la Corte de Madrid, para pasar, y ajustar las cuentas à los Asentistas de los Exercitos, porque quando los Assentistas pagan de su dinero algunas cantidades, el Rey les paga interès de su dinero todo aquel tiempo que se les tarda en darles los pagamentos en el tiempo concertado [...]. (Puig, 1711, pp. 194-195).

Los assentistas del ejército (eran una especie de contratistas) pagaban los suministros y a los soldados de los ejércitos a cuenta del Rey. Pero en esa época, las arcas estaban 
bastante vacías y el assentista pagaba de su bolsillo y luego le cobraba al Rey con intereses. Refiere que el caso contrario también ocurre, es decir, que el Rey paga por adelantado a los assentistas, por lo que les cobra intereses. Y como son operaciones que se solapan en el tiempo, se suele hacer un solo pago y una sola cantidad. Y a eso se le llama dia fixo. Pero dice que hasta ahora, eso se ha calculado en perjuicio de una de las partes, y que él va a explicar cómo hacerlo para que no haya perjuicio en ninguna de ellas.

Un ejemplo que pone en la primera impresión es el de la Figura 6.

Y lo resuelve de una manera que sería habitual en la época.

Primero hace la siguiente suma

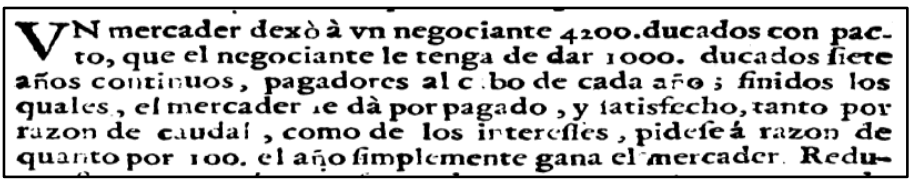

Figura 6. Adición 8 $1+2+3+4+5+6+7=28$. Divide esta cantidad por 7 . Que es el número de pagas. Resulta $\frac{28}{7}=4$. $\mathrm{Y}$ en esos años gana el mercader $7000-4200=2800$ ducados. A continuación, hace una regla de tres compuesta.

Si 4200 ducados ganan en 4 años 2800 ducados

100 ducados ganarán en 1 año .......ducados

$$
\frac{2800}{\frac{4200}{100} \cdot \frac{4}{1}}=\frac{280000}{16800}=16 \frac{2}{3}
$$

El artificio de sumar del 1 al 7 al principio y dividirlo por 7 lo justifica diciendo que el primer año tiene que pagar una anualidad de interés, el segundo tiene que pagar por dos años, el tercero por tres y así sucesivamente. Entonces, si sumamos todas las anualidades que debe y las dividimos por el número de años en que tiene que pagarlas, sale el número de años en los que se pagarían los intereses. Es decir, si debemos 4200 ducados a pagar en 7 años, el primer año deberemos pagar intereses de $7 \cdot \frac{4200}{7}$ ducados, el segundo de 6 . $\frac{4200}{7}$ ducados y así sucesivamente hasta terminar a los 7 años. Es decir, pagaremos de intereses $(1+2+3+4+5+6+7) \cdot \frac{4200}{7}$ ducados $=\frac{28}{7} \cdot 4200$ ducados $=4 \cdot 4200$ ducados. Es decir, que pagaremos intereses como si fuese en un solo pago en 4 años.

En otro ejemplo, que es en el que Puig compara el método de los assentistas y su nuevo método es donde podemos ver que el nuevo método es más exacto que el anterior. En el Anexo IX está este ejemplo resuelto y comparado con lo realizado según el método de los assentistas.

Hay que señalar que la manera en que se calculan actualmente los intereses no es igual a como indica Puig. Ahora se aplican los intereses sobre lo prestado y él aplica los intereses como ya incluidos en lo prestado.

Características de la adición: contenido matemático, enseñanza, corrección del error 
en una regla de cálculo usual, aritmética financiera, interés.

Adición 9,201,215

En esta adición explica la manera de resolver correctamente un problema, que según dice, ha acontecido en Barcelona (dice aqui en Barcelona, por lo que en ese momento vive ahí) y nadie se ha puesto de acuerdo en la manera de resolverlo. Él lo resuelve aquí y dice que lo puede corroborar la persona implicada en el problema (es un problema de un préstamo). La explicación del problema está en el Anexo X.

Características de la adición: contenido matemático, enseñanza, ejemplo de la vida real, aritmética financiera, interés.

\section{Adición 10,259, 279}

Esta adición viene a completar un problema planteado en la primera impresión que consiste en calcular cuánto tiempo tardan en encontrarse dos móviles que viajan en direcciones contrarias (Figura 7).

Actualmente, este tipo de problema se suele resolver con un sistema de ecuaciones, usando la fórmula del movimiento rectilíneo uniforme $v=\frac{e}{t}$.

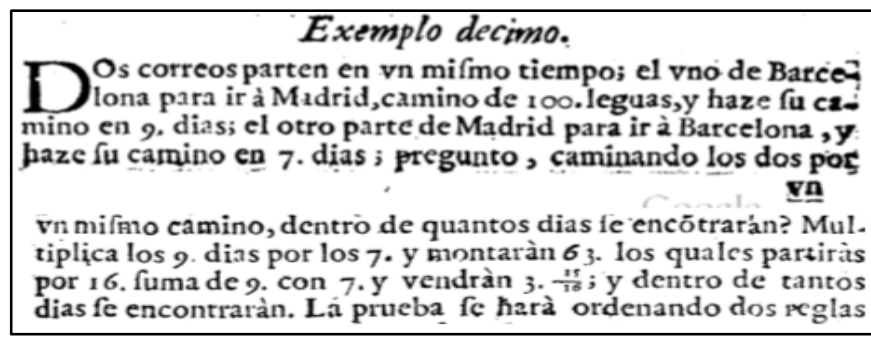

Figura 7. Ejemplo décimo

Pero Puig lo resuelve utilizando una serie de cálculos que son $9 \cdot 7=63 ; 9+7=$ 16; $63: 16=3 \frac{15}{16}$. Y da una prueba de la corrección de los cálculos utilizando dos reglas de tres. Si en 9 días camina 100 leguas, en $3 \frac{15}{16}$ días caminará $43 \frac{108}{14}$ leguas. Y el otro, si en 7 días camina 100 leguas, en $3 \frac{15}{16}$ días caminará $56 \frac{278}{112}$ que sumadas a las anteriores darán las 100 leguas. Pero esto no es más que una comprobación del resultado. No es una demostración de que esa serie de cálculos es la solución del problema. Si examinamos entre qué cantidades está hecha esa serie de cálculos, podemos constatar que carecen de sentido. De hecho, atendiendo a Puig y Cerdán (1991), se ha producido un proceso de traducción de un problema verbal a una serie de operaciones aritméticas, pero lo que hace falta para que ese proceso de traducción pueda desencadenarse es que en el campo semántico del texto del problema sea posible dotar de sentido a dichas operaciones. Y vemos que la primera de las operaciones, $9 \cdot 7$, se hace entre la cantidad "tiempo que tarda el que sale de Barcelona" y la cantidad "tiempo que tarda el que sale de Madrid”, producto que carece de sentido. Sumar esas dos cantidades, que es lo que se hace en la segunda de las operaciones, también carece de sentido. Y, careciendo de sentido ambas, dividir una 
por otra es imposible que lo tenga. Este problema es uno de los típicos estudiados en Puig y Cerdán (1990 y 1991), Filloy, Puig y Rojano (2008) y Puig (2010).

En Puig y Cerdán (1990 y 1991) se analiza la estructura del proceso de resolución de los problemas aritmético-algebraicos de enunciado verbal, utilizando como instrumento de análisis un tipo de diagrama derivado del método de análisis y síntesis, y se constata que hay análisis realizados con este método que no permiten resolver de manera aritmética ciertos problemas, porque esos análisis los abocan a una solución algebraica, pero que esos mismos problemas pueden ser analizados de otra manera que sí que conduce a una solución aritmética. Posteriormente, en Filloy, Puig y Rojano (2008) y Puig (2010) se analiza la estructura del proceso de resolución utilizando como instrumento de análisis un tipo de grafo derivado del método cartesiano, en concreto, del primer paso del método cartesiano que es la lectura analítica del enunciado del problema que lo transforma en una red de cantidades entrelazadas por relaciones. Con este instrumento se hace posible determinar si una lectura analítica concreta de un problema admite o no una solución aritmética, simplemente examinando las propiedades del grafo que representa esa lectura analítica. Igualmente, se constata que de un mismo problema se pueden hacer lecturas analíticas distintas, y que estas lecturas analíticas pueden ser unas aritméticas y otras algebraicas, de manera que los grafos correspondientes serán unos aritméticos y otros algebraicos.

La regla que plantea Puig (1672) para resolver el problema es una regla aritmética, una sucesión de operaciones aritméticas con cantidades conocidas, pero, como hemos visto, esas operaciones carecen de sentido como operaciones entre las cantidades del problema enunciado. Ahora bien, en cualquier lectura analítica del problema, tanto si es aritmética como si es algebraica, todas las cantidades y todas las relaciones entre ellas se obtienen examinando su significado en el contexto de la historia descrita en el enunciado, las operaciones entre las cantidades que se puedan hacer a partir de esas relaciones tienen pues sentido.

Si la lectura es aritmética, hay una manera de recorrer el grafo que la representa, haciendo operaciones siempre entre datos (los iniciales o datos obtenidos a partir de ellos) hasta obtener la incógnita del problema. Todas las operaciones que constituyen la solución del problema, tendrán por tanto sentido como operaciones entre las cantidades del problema.

Si la lectura es algebraica, la situación es distinta. En ese caso, una vez designada una cantidad (o más de una) con una letra, hay una manera de recorrer el grafo que la 
representa, haciendo operaciones entre datos e incógnitas (o, dicho de forma más general, entre expresiones algebraicas) hasta obtener una ecuación, igualando dos expresiones algebraicas distintas de la misma cantidad. Todas las operaciones que se hacen para construir la ecuación tendrán por tanto sentido como operaciones entre las cantidades del problema. Sin embargo, en este caso, no termina ahí la resolución del problema, falta resolver la ecuación, y las operaciones que se hacen para resolver la ecuación, ya no son operaciones que se correspondan con las relaciones obtenidas en la lectura analítica, sino las transformaciones algebraicas y las operaciones del algoritmo o fórmula que resuelven la ecuación. Esas transformaciones y operaciones responden a significados puramente algebraicos entre cantidades abstractas y no tienen por qué tener sentido entre las cantidades concretas del problema.

Es decir, si la regla que da Puig (1672) para resolver el problema es un conjunto de operaciones aritméticas sin sentido entre las cantidades del problema, no puede ser el resultado de una lectura analítica aritmética. Caben dos grandes posibilidades: o bien es el resultado de una lectura analítica aritmética cuya serie de operaciones con sentido se ha transformado a posteriori en la serie de operaciones sin sentido de la regla mediante propiedades aritméticas, probablemente para que la regla sea más concisa; o bien es el resultado de una lectura analítica algebraica, y la regla está construida a partir de las operaciones que resuelven la ecuación o incluso de una simplificación algebraica de ellas.

En el Anexo XI desarrollamos el proceso de análisis del problema haciendo una lectura analítica aritmética, usando para representarla el instrumento de los grafos expuesto en Filloy, Puig y Rojano (2008) y Puig (2010).

Ahora nos planteamos si Puig (1672) pudo llegar a su solución (carente de sentido) por medio de la transformación de otra solución con sentido como la que mostramos en el Anexo XI. No podemos saberlo porque no lo explica en ningún lugar, pero la regla que presenta para resolver el problema en esta adición que aparece en Puig (1715), se corresponde precisamente con la lectura analítica que acabamos de presentar, como veremos a continuación. Otra opción es que echara mano del álgebra para obtener esa regla aritmética a partir de la serie de operaciones que resuelven la ecuación. Aunque eso tampoco podemos saberlo, veremos al examinar la última de las adiciones, que con respecto a otro problema dice que una resolución algebraica explica una regla aritmética, en sus propias palabras, explica "de donde sale el artificio de aquel modo de obrar" (Puig,

G De otra manera Parte las 100. 1eguas por Ios 9. dias que el vno las camima, y hallaràs $\mathbf{x} x$, y tantas leguas camina efte cada dia: Parte afimirmo las dichas 100 . leguas por $105 \mathrm{z}$ dias que el otro las camina, y hallaras 14. 3 , y tantas camina efte otro cada dia: Parte affimifmo las 100 . leguas por 25 . 65 ruma de las leguas que los dos caminan cada dia, y vendrăn
los mirmos 3. dias : 6 que por la otra via has hallado.

Figura 8. Adición 10 
1715, p. 548). Veamos la resolución propuesta en la adición (Figura 8).

La serie de operaciones con que resuelve el problema en la adición son las mismas de la lectura analítica aritmética que hemos presentado, por lo que todas tienen sentido, y Puig (1715) explícitamente indica con qué cantidades está operando cada vez y cuál es la cantidad que resulta.

En el Anexo XII presentamos otra lectura analítica algebraica del problema, que resulta más natural o más habitual una vez se dispone del lenguaje del álgebra simbólica. Como resultado de dicha lectura analítica obtenemos la fórmula $t_{e}=\frac{100}{\frac{100}{9}+\frac{100}{7}}$. Y éstas son las operaciones que Puig (1715) indica en esta adición.

Entonces nos podemos plantear la cuestión de si, en la adición, Puig (1715) está explicando la solución que él habría obtenido de esta resolución algebraica del problema, o bien de la resolución aritmética que hemos presentado antes en la que las operaciones tienen sentido. Pero esta es una cuestión a la que no podemos dar una respuesta con certeza, con los datos que tenemos.

Características de la adición: enseñanza, variante, aritmética, problema de móviles de encontrar, regla intuitiva.

Adición 11, 298, 321

En esta adición demuestra que un número que no es cuadrado no se le puede sacar la raíz cuadrada (en el ámbito de los números naturales). Aquí, Puig se refiere a número en el sentido euclidiano. En el libro VII de los Elementos de Euclides, en la definición 2, define el número como una pluralidad compuesta de unidades. Es decir, que un número es un número natural (excepto el 1 que es el origen de los números). Por lo tanto, lo que quiere demostrar Puig es acerca de los naturales. La demostración la realiza con un ejemplo y por reducción al absurdo. Podemos verla en el Anexo XIII.

Características de la adición: contenido matemático, enseñanza, aritmética, cálculo aproximado, cálculo de la raíz cuadrada.

Adición 12, 317, 340

En esta adición da una solución nueva a uno de los ejercicios de la primera impresión y además indica que hay más soluciones posibles (Figura 9).

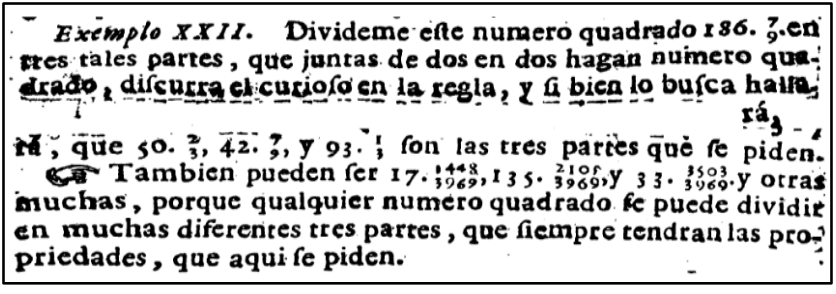

Figura 9. Adición 12

No explica cómo se hace, pero hay algunos ejemplos anteriormente que nos dan idea 
del fundamento de lo que hace. En concreto, en el primer ejemplo del capítulo explica la manera de obtener dos cuadrados cuya suma sea también un cuadrado. Es un típico problema de Diofanto. En el ejemplo segundo hace lo mismo que en el anterior, pero para tres cuadrados. De esta manera puede construir ternas de números cuadrados que sumen otro cuadrado. Ahora, utiliza esto para, mediante el artificio que explica en el ejemplo quinto, donde dice cómo construir una terna de cuadrados que sumen otro cuadrado mediante el uso de otra terna ya conocida, obtener otra solución. El procedimiento lo podemos ver en el Anexo XIV.

Características de la adición: contenido matemático, enseñanza, variante, números cuadrados, aritmética.

\section{Adición 13,317, 340}

Las adiciones 13 a 16 entran en el capítulo XI del libro cuarto, donde se ponen ejemplos de geometría resueltos de manera aritmética. Pero estas 4 adiciones no son en realidad ejemplos sino enunciados de teoremas ya que todos comienzan con un "si... entonces...". Además, se enuncian de manera teórica, aunque se desarrollan genéricamente con un ejemplo. Veamos la primera adición: "Exemplo II. Si sabidas las canas cuadradas, que tiene un campo, quieres saber quantas canas tiene su lado, haràs de esta manera [...]" (Puig, 1711, p. 317).

Ahora pone el ejemplo de un campo de 5625 canas cuadradas y para calcular el lado saca la raíz cuadrada, que es 75 canas (una cana son ocho palmos, o unos $180 \mathrm{~cm}$ ). Y apostilla que donde en geometría se habla de lado del cuadrado, en aritmética se habla de raíz cuadrada.

Características de la adición: contenido matemático, variante, teoremas en vez de problemas, generalización, geometría.

\section{Adición 14, 317, 340}

Esta adición tiene las mismas características que la anterior. El enunciado es el siguiente: "Exemplo IV. Si por la noticia de un lado de un paralelogramo, y de su area, quieres saber el otro lado, aràs assi [...]" (Puig, 1711, p. 317).

Aquí simplemente calcula el lado de un rectángulo conociendo su área y el otro lado.

Características de la adición: contenido matemático, variante, teoremas en vez de problemas, generalización, geometría.

\section{Adición 15, 318, 341}

Esta adición también es del mismo tipo que las anteriores. Dice así: "Exemplo VI. Si por la noticia de la area de un triangulo equilatero (ó de lados iguales, que todo es uno), 
quieres saber su lado, aràs assi [...]" (Puig, 1711, p. 318).

Si el área es $A$ y la longitud del lado es $l$, la fórmula que propone Puig es $\frac{l}{2}=\sqrt[4]{\frac{A^{2}}{3}}$, que es correcta. También advierte que si se sabe por número cuánto mide el lado, no se sabrá por número cuánto mide su área, y viceversa. Ya sabemos a qué se refiere con número Puig, a número natural. Por lo que está diciendo indirectamente que la raíz de 3 no es un número natural. Y dice que estas dos cantidades (lado y área) son inconmensurables entre sí, al igual que lo son el lado del cuadrado y su diagonal.

Características de la adición: contenido matemático, variante, teoremas en vez de problemas, generalización, geometría.

Adición 16,319, 341

Otra adición del mismo tipo que las anteriores. En este caso es: "Exemplo VIII. Si por la noticia de la area quieres saber el diametro del circulo, arás desta manera..." (Puig, 1711, p. 319).

La fórmula que aplica para obtener el diámetro a partir del área es $d=\sqrt{\frac{A \cdot 14}{11}}, \mathrm{Si}$ desarrollamos esta fórmula, obtenemos para el área $A=\frac{11}{14} \cdot d^{2}$. Y si hacemos uso del radio, $A=\frac{44}{14} \cdot r^{2}$, Con lo que está tomando como $\pi$ el valor de $\frac{44}{14}$, lo que se ajusta bastante al valor real de $\pi$. Expresamente, Puig dice que el valor de $\pi$, aunque no utilice el signo ya que se empezó a utilizar en 1706 (Beckmann, 2006, p. 19), es de $3 \frac{1}{7}$.

También indica que para calcular el perímetro (la circunferencia, como le llama Puig), basta con multiplicar el diámetro por el número $3 \frac{1}{7}$ (que como sabemos es la aproximación de $\pi$ ). Para una figura oval (una elipse), se calcula su área multiplicando el largo por el ancho, el producto multiplicado por $11 \mathrm{y}$ dividido por 14 . Es decir, $A=\frac{11 \cdot L \cdot l}{14}$, que si introducimos $\pi$, sería la fórmula $A=\frac{\pi \cdot L \cdot l}{4}$. Normalmente se utilizan los dos radios, entonces $A=\pi \cdot R \cdot r$.

Características de la adición: contenido matemático, variante, teoremas en vez de problemas, generalización, geometría.

Adición 17,327, 351

Esta adición viene a explicar, (aunque no a demostrar) un ejemplo anterior. En concreto, el ejemplo XIII (capítulo XII, libro cuarto). Este ejemplo dice:

Un hombre quiere esmerçar 36. reales en 36. cabeças de volateria, conviene a saber en capones à 4. reales cada uno, en gallinas a 3 . reales cada una, y en mierlas à 6 . dineros cada una; preguntase quantas cabeças comprará de cada especie; para que sean justamente 36 . cabeças, y valgan justamente 36. reales. (Puig, 1711, p. 327). 
El problema consiste en que un hombre quiere invertir 36 reales en 36 aves, sabiendo que los capones valen a 4 reales cada uno, las gallinas a 3 reales cada una y mirlos (Esteve y Belvitges, 1803) a 6 dineros cada uno. Hay que averiguar cuantos animales hay de cada tipo.

En la primera impresión, Puig dice que no se para a explicar la regla para resolver el problema porque "no está fundada en reglas generales, como muchos aritméticos enseñan" (Puig, 1672, p. 351). Y directamente da la solución, que es de 5 capones, 3 gallinas y 28 mirlos.

En la adición indica que los autores que resuelven este problema lo hacen por tanteo, pero que en realidad se trata de una regla general, y verdadera, y que, si se aplica, se puede saber si el resultado es correcto o falso o si tiene varias soluciones. Y pasa a plantear otro problema similar y a resolverlo. Ahora veremos que el proceso de resolución tiene mucho que ver con la resolución de un sistema de dos ecuaciones con tres incógnitas, pero expresamente advierte Puig que "es una regla general en el arte menor sin aver de acudir à la Algebra" (Puig, 1711, p. 327). Por lo tanto, estamos ante un problema que según el propio Andrés Puig es aritmético, pero no sabemos si se trata de un problema que según Puig (2010) tendría una lectura analítica realmente aritmética o requeriría una resolución algebraica. Sea como sea, si en paralelo a los pasos que va dando Puig, se hace la resolución algebraica, se entiende perfectamente el sentido de las operaciones.

Este es el problema (Figura 10):

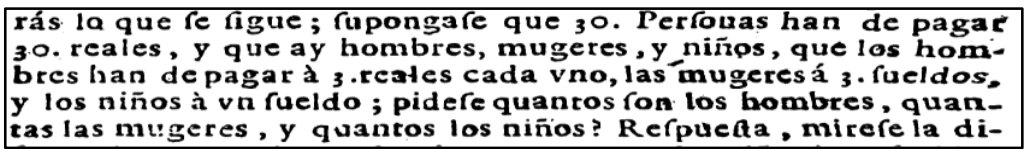
Figura 10. Adición 17

Mirese la diferencia que ay de un sueldo que paga cada niño, à 6. sueldos que paga un hombre, y hallaràs 5. dexalos aparte. Mira assi mesmo la diferencia, que ay de un sueldo à los 3. sueldos que paga cada muger, y hallaràs 2. dexalos también aparte.

Ahora se ha de mirar que si todas las 30. personas fuesen niños, no pagando mas de un sueldo cada uno, solo pagarian 30. sueldos, $y$ quedarian por pagar otros 30.

Los quales dividiràs en dos partes tales, que la una se pueda dividir enteramente por 5. y la otra por 2. que son los dos numeros que dexastes aparte.

Saca 5. de 30. te quedaràn 25. Y como no se pueden partir enteramente por 2. saca otros 5. y te quedaràn 20.

Que partidos por 2. vienen a ser 10. y tantas diràs que son las mugeres.

Y porque el 5. se ha sacado dos veces diràs, que dos son los hombres.

Los que faltan hasta 30. que son 18. son los niños.
$N$ o de hombres $=x$

$N$ o de mujeres $=y$

$N$ o de niños $=Z$

1 real $=2$ sueldos

$\{x+y+z=30$

$\{6 x+3 y+z=60$

$$
\begin{gathered}
6 x+3 y+z=60 \\
-(x+y+z=30) \\
--------- \\
5 x+2 y=30
\end{gathered}
$$

Si $x=1 \Rightarrow 2 y=25$ Si $x=2 \Rightarrow 2 y=20$

$y=\frac{20}{2}=10$ mujeres $x=2$ hombres $10+2=12 \Rightarrow 30-$ $12=18$ niños 
También indica Puig que hay otra solución posible, que es cuando dividimos 30 entre 2 , que le podíamos quitar dos veces 5 y también se podría dividir entre 2, por lo que habría otro resultado posible, que sería 4 hombres, 5 mujeres y 21 niños.

Asimismo, dice que este tipo de problemas no tendría solución si las dos partes que quedan no son divisibles por los números que hemos calculado. Para terminar, plantea y resuelve (sin explicar los pasos) otro ejemplo del mismo tipo.

Características de la adición: enseñanza, variante, más práctico o más rápido, aritmética, problema de reparto, regla explicada con ejemplo.

Adición 18, 341, 366

Esta adición es especial. En la impresión de 1711 de Figuerò no aparece (y debería ir en la página 342). En la impresión sin fechar de Giralt sí aparece. En la impresión de 1715 aparece en la página 341. En las demás impresiones también aparece. Es decir, esta adición aparece en todas las impresiones menos en la primera y en la de 1711 de Figuerò. La adición es: "Exemplo XLII. Un hombre comprò 17. gallinas y 80. huevos por 78. reales, y al mesmo precio comprò 24. gallinas, y 56. huevos por 103. reales; pidese quanto le costò cada gallina, y lo que pagò de cada huevo?" (Puig, 1715, p. 341).

Con ojos actuales, lo primero que intentaríamos es resolver el problema mediante un sistema de ecuaciones, pero Puig lo resuelve en este lugar con proporciones. Indica las operaciones necesarias para llegar a la solución, pero no las fundamenta. Sin una explicación, la resolución es difícil de entender.

Como veremos más adelante, este mismo problema lo tenía ya desde la impresión de 1711 (la adición 20) pero resuelto de manera algebraica. Además, curiosamente esta adición 20 no está colocada en su lugar correspondiente sino al final del libro. Es decir, en la impresión de 1711 aparece la adición 20 pero no la 18. Posiblemente el impresor de la de 1711, Figuerò, tuviera documentos para añadir en las adiciones póstumas de Puig, pero se le pasara añadir la adición 18 y la 20, y cuando el libro estaba ya compuesto encontrara la 20 y la añadió al final o encontrara la 18 y la 20 y decidió añadir sólo la 20.

Pero a partir de esta impresión, en las siguientes ya sí aparece la adición 18 en su lugar, pero la 20 sigue al final del libro, y además con una pequeña aclaración que indica que la 20 "se ha á buelto a poner aqui, para que veas, y entiendas de donde sale el artificio de aquel modo de obrar" (Puig, 1715, p. 548). Es decir, que Puig se da cuenta de que el artificio empleado en la adición 18 no es sencillo de entender y lo "explica" con la resolución algebraica de la adición 20 . Y esto parece que es un ejemplo de creación de un artificio aritmético a partir de una resolución algebraica de un problema ya que el artificio 
empleado carece de sentido si no se ampara en la resolución algebraica.

Características de la adición: enseñanza, variante, más práctico o más rápido, aritmética, proporcionalidad, regla que proviene de la resolución algebraica (pero que se puede pensar aritméticamente).

Adición 19,342, 366

Esta adición es un capítulo completo añadido al final del libro cuarto. Se trata del "Cap. XIII. En el qual se siguen las evidencias" (Puig, 1711, pp. 342-351).

Son 39 identidades algebraicas enunciadas de manera verbal y acompañadas con ejemplos numéricos (son en realidad teoremas). Con estas identidades ya se justifican las transformaciones algebraicas que realiza al resolver ecuaciones en los siguientes dos libros (los de álgebra). De hecho, ya en la primera identidad dice: "Esto aunque parece cosa de poca consideracion, es de suma conveniencia para reducir mucha parte de las igualaciones compuestas, à simple igualacion, como en su lugar se manifestarà" (Puig, 1711, p. 342).

Al final del capítulo hace una introducción de los dos libros siguientes del álgebra, añadiendo que por medio del álgebra se pueden resolver todos los problemas aritméticos. Quizás por eso mismo utilice en ocasiones el álgebra para "explicar" los artificios que se hacen en la aritmética. Seguramente las 39 identidades que expone en el capítulo son un nexo fuerte de enlace entre aritmética y álgebra. En el Anexo XV están descritas todas las evidencias.

Las evidencias 34 a 37 justifican las operaciones realizadas en la cuarta parte de la "regla de Algebra", que es la "extracción de raiz".

Características de la adición: contenido matemático, enseñanza, identidades algebraicas expresadas verbalmente, teoremas, álgebra.

\section{Adición 20,547, 576}

Esta última adición sirve para explicar un problema que debería ir en el libro quinto (de álgebra racional). Puig lo indica expresamente. En las impresiones posteriores a esta, indica que este problema es similar a otro añadido en el libro cuarto, pero que en aquel lugar estaba resuelto de manera aritmética y aquí algebraica. Hay que añadir que esta segunda apostilla no está en la impresión de 1711 de Figuerò porque en aquella impresión tampoco estaba este problema resuelto aritméticamente.

El problema es este: "Exemplo XLII. Un hombre comprò 17. gallinas y 80. huevos por 78. reales, y al mesmo precio comprò 24. gallinas, y 56. huevos por 103. reales; pidese quanto le costò cada gallina, y lo que pagò de cada huevo?” (Puig, 1715, pp. 547-548). 
La resolución algebraica que describe da sentido a las operaciones que hace en su resolución aritmética, por lo que vemos una vez más que el álgebra puede servir para “explicar” la aritmética. En su resolución aritmética no hace más que realizar las operaciones conducentes a resolver la "igualación" que utiliza en su resolución algebraica. Veamos esa resolución algebraica.

\begin{tabular}{|c|c|}
\hline $\begin{array}{l}\text { una gallina vale } 1 . \text { co. de huevos } \\
\text { 17. gallinas valen 17.co.de huevos }\end{array}$ & $\begin{array}{l}1 \text { gallina }=x \text { huevos } \\
17 \text { gallinas }=17 x \text { huevos }\end{array}$ \\
\hline $\begin{array}{l}\text { y 80. huevos mas que comprò con ellas, } \\
\text { son 17. co.p. 80.y esto es lo que vale 78. reales }\end{array}$ & $17 x+80 \rightarrow 78$ \\
\hline $\begin{array}{l}\text { luego las } 24 . \text { gallinas al mesmo } \\
\text { precio valen, 24.co.de huevos }\end{array}$ & 24 gallinas $=24 x$ huevos \\
\hline $\begin{array}{l}\text { y 56. huevos mas que con ellas comprò, } \\
\text { son 24.co.p. 56. y esto es lo que le costò } \\
\text { 103.reales }\end{array}$ & $24 x+56 \rightarrow 103$ \\
\hline \multicolumn{2}{|l|}{$\begin{array}{l}\text { estas quatro cantidades son proporcionales, } \\
\text { y la multiplicacion de la primera por la } \\
\text { quarta, es igual à la multiplicacion de } \\
\text { la segunda por la tercera, las quales } \\
\text { quatro cantidades proporcionales estàn } \\
\text { desta manera, }\end{array}$} \\
\hline \multicolumn{2}{|l|}{$\begin{array}{l}\text { 17.co.p. 80.primera, 78. reales segunda, } \\
\text { 24.co.p.56.tercera, y 103.reales la quarta; }\end{array}$} \\
\hline $\begin{array}{l}\text { y siguiendo la regla hallaràs, que el producto } \\
\text { de la primera por la quarta, } \\
\text { es } 1751 . \text { co.p. } 8240 . \text { que serà igual } \\
\text { al producto de la segunda por la tercera, } \\
\text { que son } 1872 . \text { co.p. } 4368 \text {. }\end{array}$ & $\begin{array}{l}(17 x+80) \cdot 103=1751 x+8240 \\
78 \cdot(24 x+56)=1872 x+4368 \\
1751 x+8240=1872 x+4368\end{array}$ \\
\hline $\begin{array}{l}\text { que siguiendo la igualacion ... hallaràs } \\
\text { que la co.vale 32.y tantos son los huevos } \\
\text { que vale una gallina; }\end{array}$ & $x=32$ \\
\hline $\begin{array}{l}\text { luego las } 17 . \text { gallinas valen } 544 . \text { huevos, } \\
\text { que juntos con los } 80 . \text { que con ellas comprò, } \\
\text { seràn } 624 .\end{array}$ & $\begin{array}{l}17 \cdot x=544 \\
544+80=624\end{array}$ \\
\hline $\begin{array}{l}\text { y partiendo 1872. dineros } \\
\text { (que son los 78. reales que les costaron) } \\
\text { por estas 624. hallaràs 3.y 3. dineros pagò } \\
\text { de cada huevo, }\end{array}$ & $\begin{array}{l}78 \text { reales }=1872 \text { dineros } \\
\frac{1872}{624}=3\end{array}$ \\
\hline $\begin{array}{l}\text { y valiendo cada gallina } 32 \text {. huevos, como } \\
\text { hemos hallado; siguese, que cada una le } \\
\text { costò } 96 \text {. dineros, que son 4. reales ... }\end{array}$ & $\begin{array}{l}32 \cdot 3=96 \\
96 \text { dineros }=4 \text { reales }\end{array}$ \\
\hline
\end{tabular}

Si nos fijamos, los pasos que luego "copia" en la resolución aritmética son:

\begin{tabular}{ll}
\hline $17 \cdot 103=1751$ & $(17 x+80) \cdot 103=1751 x+8240$ \\
$80 \cdot 103=8240$ & \\
\hline $24 \cdot 78=1872$ & $78 \cdot(24 x+56)=1872 x+4368$ \\
$56 \cdot 78=4368$ & \\
\hline & $1872 x+4368=1751 x+8240$ \\
\hline $1872-1751=121$ & $121 x+4368=8240$ \\
\hline $8240-4368=3872$ & $121 x=8240-4368=3872$ \\
\hline$\frac{3872}{121}=32$ & $x=\frac{3872}{121}=32$ \\
\hline
\end{tabular}

Como ya comentamos en la adición 18, allí se resolvía este mismo problema de manera 
aritmética mediante un artificio que precisamente consiste en las mismas operaciones de la resolución algebraica. Las dificultades en explicar la resolución de este (y otros) problemas en el campo de la aritmética quizás sean el motivo por el que Puig no lo hace, y espera a la resolución algebraica para hacerlo. Pero la resolución algebraica tampoco es como la haríamos en la actualidad ya que seguramente nosotros utilizaríamos un sistema de dos ecuaciones lineales con dos incógnitas. Pero para Puig esto no sería posible ya que con el álgebra que utiliza no es posible operar más que con una incógnita (la cosa). Entonces, se tiene que valer de un artificio que consiste en calcular sólo con una variable y pasar la otra en función de esta (utilizar una proporción). En el caso concreto, lo que hace es pasar el valor de la gallina a unidades de huevos (huevos por gallina) y así tiene sólo una incógnita. Pero ni siquiera él podría pensar en este artificio como un cambio de variable (ya que para él sólo tiene sentido una incógnita) sino más bien como una estrategia de resolución. Esto es, $17 x+80: 78:: 24 x+56: 103$, y aplicando una de las reglas de la proporcionalidad, "primera por cuarta es igual a segunda por tercera", obtiene la ecuación $(17 x+80) \cdot 103=78 \cdot(24 x+56)$ a partir de la proporción. Con $x$ como la cantidad de huevos que valen una gallina.

Características de la adición: enseñanza, contenido matemático, variante, más práctico o más rápido, álgebra, cambio de variable.

\section{CONCLUSIONES Y TRABAJO FUTURO}

Hemos podido encontrar poca información del autor, salvo que nació en Vic, estudió con Juan Serrano en Valencia y trabajó en Barcelona, seguramente como maestro de mercaderes y como profesor particular. Sólo tenemos noticias de que escribiera el libro que hemos analizado, que según el número de impresiones y el periodo que abarcan, debió tener relativo éxito.

Según el análisis comparativo que hemos realizado de su lenguaje algebraico, se acerca más al del siglo anterior que el de su contemporáneo José Zaragoza, más moderno. El de Puig es un lenguaje sincopado y el de Zaragoza es simbólico.

Hemos analizado sus dos reglas generales de resolución de ecuaciones polinómicas. La primera, que se la enseña su maestro Juan Serrano y que seguramente tenga influencia de Viète, la hemos comparado con la de Zaragoza, que también seguramente está influida por Viète. Hemos concluido que tanto Zaragoza como Puig simplifican algo sus cálculos respecto a los que realiza Viète, pero Zaragoza es mucho más organizado y explica con mucho más detalle todo el proceso de cálculo que Puig. 
En cuanto a la segunda regla de resolución de ecuaciones polinómicas, en este caso por aproximación, Puig dice que es una modificación de un método que ha aprendido de Esteban de Roca (Estienne de la Roche). Sabemos que este método lo copió de la Roche de Chuquet, ya que lo hemos comprobado. Ambos métodos, el de Chuquet y el de Puig, tienen algunos parecidos, pero no son iguales. Chuquet utiliza su método para resolver raíces de manera aproximada y también ecuaciones polinómicas. Puig, en cambio utiliza su método para resolver ecuaciones, pero siempre de manera exacta, es decir, no utiliza su método para encontrar una solución aproximada de la ecuación, sino que la solución es exacta y el método la encuentra.

Por último, en las adiciones hemos encontrado conexiones entre aritmética y álgebra en algunas de ellas. Por ejemplo, problemas que en la primera impresión se resuelven de manera aritmética y sin explicación, en las adiciones se resuelven además de manera algebraica y se explican. También lo contrario, problemas resueltos de manera algebraica en la primera impresión, en las adiciones se explican procedimientos aritméticos para resolverlos. Otras adiciones muestran identidades, como las conocidas identidades notables, que explican algunas de las operaciones realizadas en la primera impresión, y que quedaban un tanto oscuras. Por ejemplo, muestra las identidades correspondientes a la fórmula para resolver ecuaciones de segundo grado. También hemos visto el artificio que utiliza para poder resolver lo que para nosotros sería un sistema de ecuaciones, pero utilizando sólo una incógnita (la cosa).

Pero aún queda mucho por hacer. Solamente hemos completado una primera parte de la ida de un ciclo de ida y vuelta, tal y como Puig (2019, p.119) indica en su primera observación (Figura 11). Ahora nos queda diseñar una implementación didáctica para aplicar lo que hemos aprendido con el análisis de nuestro texto, implantar en las aulas dicha implementación y ver si se consiguen mejoras en el proceso de enseñanza-aprendizaje. Y así, completaríamos un primer ciclo, que podría continuarse con más ciclos de mejora.

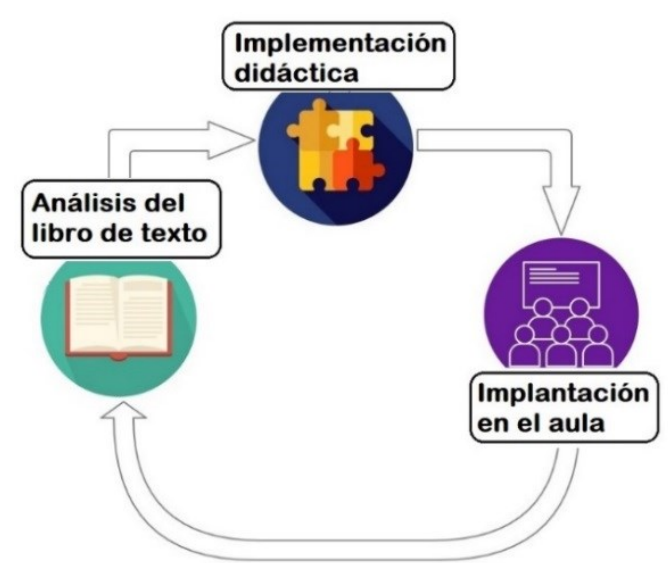

Figura 11. Ciclo de ida y vuelta 


\section{REFERENCIAS}

\subsection{Específicas}

Puig, A. (1672). Arithmetica especulativa, y practica, y arte de algebra. Barcelona: Antonio Lacavalleria.

Puig, A. (1711). Arithmetica especulativa, y practica, y arte de algebra. Segunda Impresión. Barcelona: Rafael Figuerò.

Puig, A. (1715). Arithmetica especulativa, y practica, y arte de algebra. Tercera Impresión. Barcelona: Rafael Figuerò.

Puig, A. (sin fecha a). Arithmetica especulativa, y practica, y arte de algebra. Cuarta Impresión. Barcelona: Joseph Giralt.

Puig, A. (sin fecha b). Arithmetica especulativa, y practica, y arte de algebra. Cuarta Impresión. Barcelona: Joseph Giralt.

Puig, A. (1745). Arithmetica especulativa, y practica, y arte de algebra. Tercera Impresión. Barcelona: Juan Jolis.

Puig, A. (sin fecha c). Arithmetica especulativa, y practica, y arte de algebra. Tercera Impresión. Barcelona: Juan Jolis.

\subsection{Generales}

Agustí i Cullell, J. (1983). Ciencia i técnica a Catalunya en el segle XVIII. La introducció de la máquina de vapor. Barcelona: Institut d'Estudis Catalans.

Aurel, M. (1552). Libro primero, de Arithmetica Algebratica, en el qual se contiene el arte Mercantivol, con otras muchas Reglas del arte menor, y la Regla del Algebra, vulgarmente llamada Arte mayor, o Regla de la cosa; sin la qual no se podra entender el decimo de Euclides, ni muchos otros primores, assi en Arithmetica como en Geometria. Valencia: En casa de Joan de Mey.

Barroso, J. y Sánchez de Bustos, J. (1993). Estado actual de los estudios sobre el Siglo de Oro. En M. García Martín (Ed.), Actas del II Congreso Internacional de Hispanistas del Siglo de Oro (1, pp. 161-178). Salamanca: Ediciones Universidad de Salamanca.

Beckmann, P. (2006). Historia de $\pi$. México: Conaculta.

Benito, M., Escribano, J., Fernandez, E. y Sánchez, M. (2012). Fray Juan de Ortega's approximations, 500 years after. arXiv: 1212.1125.

Bernat, P. (2010). Científics d'Osona. Diccionari històric i bibliogràfic dels cientìfics nascuts o vinculats a Osona. Vic: Patronat d'Estudis Osonencs.

Brizuela, M. L. (2015). Los paratextos en la obra dramática de Calderón de la Barca (Tesis Doctoral). UNED, Madrid.

Brousseau, G. (1980). Problèmes de l'enseignement des décimaux. Recherche en didactique des mathématiques, 1 (1), 11-59.

Camprubí i Pla, X. (2013). L’impressor Rafael Figueró (1642-1726) i la premsa a la Catalunya del seu temps (Tesis doctoral). Universitat de Barcelona, Barcelona.

Clark, K. M., Kjeldsen, T. H., Schorcht, S., y Tzanakis, C. (Eds.) (2018). Mathematics, Education and History: Towards a Harmonious Partnership. Cham, Switzerland: Springer.

Clavius, C. (1574). Euclidis Elementorum libri XV. Roma: Apud Vincentium Accoltum. 
De la Roche, E. (1520). L' arismethique nouvellement composee. Lyon: Costantin Fradin.

Dou, A. (1990). Las matemáticas en la España de los Austrias. En L. Español González (Ed.), Estudios sobre Julio Rey Pastor (1888-1962) (pp. 151-172). Logroño: Instituto de Estudios Riojanos.

Echegaray, J. (1866). Discurso leído por José Echegaray ante la Real Academia de Ciencias. Exactas, Física y Naturales en su recepción pública el once de marzo de 1866. Madrid: Imprenta y librería de don Eusebio Aguado.

Espino, A. (2013). Una biblioteca del Barroco: Las lecturas del sargento mayor Don Juan Garcés, alcaide de San Felipe de Mahón. Revista Atalanta, 1 (1), 25-66.

Esteve, J. y Belvitges, J. (1803). Diccionario Catalán-Castellano-Latino. Tomo I. Barcelona: En la oficina de Tecla Pla Viuda Administrada por Vicente Verdaguer.

Euclides (2007). Elementos. Traducción y notas de María Luisa Puertas Castaños. Barcelona: Gredos.

Fernández Lajusticia, A. y Puig, L. (2002). Análisis fenomenológico de los conceptos de razón, proporción y proporcionalidad. La Gaceta de la RSME, 5 (2), 397-416.

Filloy, E., Puig, L. y Rojano, T. (2008). El estudio teórico local del desarrollo de competencias algebraicas. Enseñanza de las Ciencias, 25 (3), 327-342.

Filloy, E. y Rojano, T. (1984). La aparición del lenguaje aritmético-algebraico. L'Educazione Matematica, 5 (3), 278-306.

Filloy, E.; Rojano, T., y Puig, L. (2008). Educational Algebra. A Theoretical and Empirical Approach. New York: Springer.

Foucault, M. (1969). L'archéologie du savoir. Paris: Gallimard.

Furinghetti, F. y Karp, A. (2018). Researching the history of mathematics education. An international overview. Cham, Switzerland: Springer.

García Caballero, J. (1731). Breve Cotejo y Valance de las pesas y medidas. Madrid: En la imprenta de la viuda de Francisco del Hierro.

Genette, G. (2001). Umbrales. México D.F.: Siglo XXI.

Gómez, B. (2001). La justificación de la regla de los signos en los libros de texto: ¿Por qué menos por menos es más?. En P. Gómez y L. Rico (Eds.), Iniciación a la investigación en didáctica de la matemática. Homenaje al profesor Mauricio Castro. Granada: Editorial Universidad de Granada.

Gómez, B. (2003). La investigación histórica en Didáctica de la Matemática. En E. Castro (Ed.), Investigación en educación matemática: séptimo Simposio de la Sociedad Española de Investigación en Educación Matemática (pp. 79-86). Granada: Editorial Universidad de Granada.

Gómez, B. (2011). Marco preliminar para contextualizar la investigación en historia y educación matemática. Épsilon, Revista de Educación Matemática, 28 (1), 9-22.

Guardamino, D. de (1757). Prontuario, y claves de las correspondencias, que, entre sì, tienen las Monedas, Medidas de Granos, de Palmos, y Peso sutil de Castilla, con las de varios Reynos, y Provincias de la Europa, Señorio de Vizcaya, y demàs Continente de España. Madrid: Antonio Marín.

Harriot, T. (1631). Artis Analiticae Praxis. Londres: Apud Robertum Barker.

Hume, J. (1636). Algèbre de Viète, d'une Méthode nounelle, claire et facile, and Traité de 
la Trigonométric pour resoudre tous Triangles rectilignes et sphériques. París: Louys Boulenger.

León Tello, F.J. y Sanz Sanz, M.V. (1994). Estética y teoría de la Arquitectura en los tratados españoles del siglo XVIII. Textos Universitarios. Madrid: CSIC.

López Piñero, J. M. (1983). Diccionario Histórico de la Ciencia Moderna en España. Barcelona: Ediciones Península.

Marre, A. (1884). Le Triparty en la science des nombres par Maistre Nicolas Chuquet Parisien. Rome: Imprimerie des Sciences Mathématiques et Physiques.

Maz, A. (2005). Los números negativos en España en los siglos XVIII y XIX (Tesis doctoral). Universidad de Granada, Granada.

Menéndez y Pelayo, M. (1953). La ciencia española. Inventario bibliográfico de la ciencia española. Tomo III. Santander: CSIC.

Molina Sangüesa, I. (2016a). La designación terminológica de las potencias de la incógnita: algunas cuestiones sobre el tránsito del álgebra retórica al álgebra sincopada en el Renacimiento hispano. Arbor, 192 (77), 397-411.

Molina Sangüesa, I. (2016b). El legado de al-Khwārizmī: análisis de la traducción e introducción de algunos arabismos en el campo del álgebra hispánica renacentista. Quaderns: Revista de traducció, 23, 79-95.

Muñoz Escolano, J. M. y Oller Marcén, A. M. (2018). Análisis de los prólogos de los textos matemáticos del Bachiller Juan Pérez de Moya. En D. Carrillo, E. Sánchez, J. M. Matos, P. L. Moreno y W. Rodrigues (Eds.), IV Congreso Iberoamericano de Historia de la Educación Matemática. Actas (pp. 235-243). Murcia: Ediciones Electolibris S. L.

Muñoz Escolano, J. M. y Oller Marcén, A. M. (2019). Análisis de los prólogos de los textos algebraicos publicados en España durante el siglo XVI. Historia y Memoria de la Educación, 11, 51-85.

Nesselman, G. H. F. (1842). Versuch einer Kritischen Geschichte der Algebra, 1. Teil. Die Algebra der Griechen. Berlín: G. Reimer.

Nordgaard, M. A. (1922). A Historical Survey of Algebraic Methods of Approximating the Roots of Numerical Higher Equations Up to the Year 1819. New York: Teachers college, Columbia university.

Núñez, P. (1567). Libro de Algebra en Arithmetica y Geometria. Amberes: Herederos de Arnoldo Birckman.

Ortega, J. de (1512). Tratado subtilissimo de Arismetica y de Geometria. Lyon: Joannes Trinxer.

Peletier, J. (1554). L'algèbre. Lyon: Ian de Tournes.

Peralta, J. (1999). El despertar de la matemática española (de la crisis del 98 a la Guerra Civil). Actas del I Simposio "Ciencia y Técnica en España de 1898 a 1945, Cabrera, Cajal, Torres Quevedo" (pp. 58-106). Lanzarote: Amigos de la cultura científica.

Pérez de Moya, J. (1558). Compendio de la regla de la cosa o arte mayor. Burgos: Martin de Bitoria.

Pérez de Moya, J. (1562). Arithmetica practica, y specvlatiua. Salamanca: Mathias Gast.

Pérez de Moya, J. (1573). Tratado de Mathematicas. Alcalá de Henares: Juan Gracian.

Poy y Comes, M. (1819). Elementos de aritmética numérica y literal al estilo del comercio 
para instrucción de la juventud. Barcelona: Oficina de Sierra y Martí.

Puig, L. (1994). El De Numeris Datis de Jordanus Nemorarius como sistema matemático de signos, Mathesis, 10, 47-92.

Puig, L. (1996). Pupils' Prompted Production of a Medieval Mathematical Sign System. En L. Puig y A. Gutiérrez (Eds.), Proceedings of the Twentieth International Conference on the Psychology of Mathematics Education (1, pp. 77 84). Valencia: PME.

Puig, L. (1998). Componentes de una historia del álgebra. El texto de al-Khwarizmi restaurado. En Hitt (Ed.). Investigaciones en Matemática Educativa II (pp. 109131). México, DF: Grupo Editorial Iberoamérica.

Puig, L. (2003). Historia de las ideas algebraicas: componentes y preguntas desde el punto de vista de la matemática educativa. En E. Castro (Ed.), Investigación en educación matemática: séptimo Simposio de la Sociedad Española de Investigación en Educación Matemática (pp. 97-108). Granada: SEIEM.

Puig, L. (2006). Vallejo perplejo. En A. Maz, M., Torralbo y L. Rico (Eds.), José Mariano Vallejo, el matemático ilustrado. Una mirada desde la educación matemática (pp. 113-138). Córdoba: Servicio de Publicaciones de la Universidad de Córdoba.

Puig, L. (2010). Researching (algebraic) problem solving from the perspective of Local Theoretical Models. Procedia Social and Behavioral Sciences, 8, 3-16.

Puig, L. (2011). Researching the History of Algebraic Ideas from an Educational Point of View. En V. Katz y C. Tzanakis (Eds.), Recent Developments on Introducing a Historical Dimension in Mathematics Education (pp. 29-42). Washington, DC: The Mathematical Association of America.

Puig, L. (2018a). Cambios en el álgebra que se enseña en el siglo XVII en España a partir de la Arithmetica Universalis de Joseph Zaragoza. Conferencia: Seminario de Investigación Historia de las matemáticas y educación matemática. Córdoba, Spain.

Puig, L. (2018b). Lo viejo y lo nuevo en la enseñanza del álgebra en el siglo XVII en España: la Arithmetica especulativa, y practica y arte del algebra de Andrés Puig frente a la Arithmetica Universalis de Joseph Zaragozà. Conferencia: Grupo de Investigación "Historia de las matemáticas y educación matemática (HMEM)" del XXIII Simposio de la Sociedad Española de Investigación en Educación Matemática. Gijón, España.

Puig, L. (2019). Observaciones acerca de la historia de las matemáticas en la matemática educativa. En J. M. Marbán, M. Arce, A. Maroto, J. M. MuñozEscolano y Á. Alsina (Eds.), Investigación en Educación Matemática XXIII (pp. 117- 130). Valladolid: SEIEM.

Puig, L. (2020). Sobre el concepto de exponente y el término 'exponente' en la Arithmetica Universalis de Joseph Zaragozà, posibles fuentes y otros textos anteriores. Pendiente de publicación.

Puig, L. y Cerdán, F. (1990). La estructura de los problemas aritméticos de varias operaciones combinadas. Conferencia plenaria invitada en la Cuarta Reunión Centroamericana y del caribe sobre Formación de Profesores e Investigadores en Matemática Educativa. Guerrero, México.

Puig, L. y Cerdán, F. (1991). Acerca del carácter aritmético o algebraico de los 
problemas verbales. En E. Filloy y T. Rojano (Eds.), Memorias del Segundo Simposio Internacional sobre Investigación en Educación Matemática (pp. 35-48). Cuernavaca, Morelos, México.

Recasens, E. (2003). Càlcul d'arrels d'equacions polinòmiques a l'Arithmetica Universal de J. Saragossà. Actes de la VII Trobada d'Història de la Ciència i de la Tècnica (pp. 167-172). Barcelona: Shat.

Recasens, E. (2007). El cultivo de las matemáticas puras en la España del siglo XVII. En V. Navarro y W. Eamon (Eds.), Más allá de la Leyenda Negra: España y la revolución cientifica (pp. 413-426). Valencia: Universitat de València, CSIC, Instituto de Historia de la Ciencia y Documentación.

Rey Pastor, J. (1926). Los matemáticos españoles del siglo XVI. Toledo: Imprenta de A. Medina.

Rocha, A. (1565). Arithmetica. Barcelona: En casa de Claudio Bornat.

Rodríguez Vidal, R. (1980). Notas para una nómina de matemáticos españoles del siglo XVII. En S. Garma (Ed.), El científico español ante su historia: la ciencia en España entre 1750-1850: I Congreso de la Sociedad Española de Historia de las Ciencias (pp. 365-370). Madrid.

Rudolff, C. (1525). Behend und Hubsch Rechnung durch die kunstreischen regeln Algebre so gemeinlicklich die Coss genent werden. Voulfius Strassburg: Cephaleus Joanni Jung.

Salarich i Torrens, M. S. e Ylla-Català i Genís, M. S. (1983). Vigatans il·lustres. Sant Hipòlit de Voltregà: Impremta Planàs.

Sánchez Pérez, J. A. (1935). La Matemática. Estudios sobre la ciencia española del siglo XVII. Asociación de Historiadores de la Ciencia Española (pp. 597-633). Madrid.

Santa Cruz, M. G. de (1603). Libro de Arithmetica Especulativa, y Practica, intitulado El Dorado Contador. Sevilla: Bartholome Gomez, impressor.

Stifel, M. (1544). Arithmetica Integra. Nuremberg: Johann Petreium.

Tartaglia, N. (1556). La seconda parte del general trattato di numeri et misure. Venecia: Curtio Troiano de i Nauò.

Tolrà, J. B. (1619). Arismetica de Ivan Ventallol, traduzida de lengua Catalana en Castellana, por el Doctor Juan Batista Tolra. Va añadido un Tratado de la ARTE MAYOR llamada ALGEBRA o REGLA DE LA COSA compuesto por el mismo Doctor Tolra. Tarragona: Gabriel Roberto.

Torres Amat, F. (1836). Memorias para ayudar a formar un diccionario crítico de los escritores catalanes, y dar alguna idea de la antigua y moderna literatura de Cataluña. Barcelona: Imprenta de J. Verdaguer.

Ventallol, J. (1521). Pratica mercantívol. Lyo: Joan de la Place.

Viète, F. (1591). In artem Analyticem Isagoge. Turonis: Iametium Mettayer Typographum Regium.

Viète, F. (1600). De numerosa potestatum ad exegesim resolutione. Ex opere restitutae mathematicae analyseos, seu, Algebra novâ Francisci Vietae. Parisiis: Excudebat David Le Clerc.

Zaragozà, J. (1669). Arithmetica Universalis, que comprehende el arte menor, y maior, algebra vulgar, y especiosa. Valencia: Geronimo Vilagrasa. 


\section{ANEXO I. Resolución de una ecuación por el método general de resolución de ecuaciones de Andrés Puig}

Se trata de resolver la ecuación $x^{3}+x^{2}+x=16275$.

La solución, en principio debe ser un número de 2 cifras. Hay que advertir que si la solución tiene más de dos cifras, el proceso se convierte en recursivo, de forma que se irán seleccionado de izquierda derecha los dígitos de la solución de dos en dos, y con el primero obtendremos el segundo basándonos en el desarrollo del binomio formado por ambos (como veremos a continuación). Una vez que ya hemos encontrado los dos dígitos más significativos (empezando por la izquierda), esos dos formarán un número y junto al siguiente dígito se formará nuevamente un binomio que nos ayudará a calcular el nuevo dígito. Y así sucesivamente hasta que los encontremos todos.

Sigamos con el ejemplo. La solución la podemos representar por $N=10 a+b$. Entonces,

$$
\begin{gathered}
N^{3}=(10 a+b)^{3}=10^{3} \cdot a^{3}+3 \cdot 10^{2} \cdot a^{2} \cdot b+3 \cdot 10 \cdot a \cdot b^{2}+b^{3} \\
N^{2}=(10 a+b)^{2}=10^{2} \cdot a^{2}+2 \cdot 10 \cdot a \cdot b+b^{2}
\end{gathered}
$$

Los factores están ordenados de mayor a menor peso. Ahora vamos a poner la ecuación, suponiendo que $N$ es la solución de la misma.

$$
\begin{aligned}
& \left(10^{3} \cdot a^{3}+3 \cdot 10^{2} \cdot a^{2} \cdot b+3 \cdot 10 \cdot a \cdot b^{2}+b^{3}\right)+\left(10^{2} \cdot a^{2}+2 \cdot 10 \cdot a \cdot b+b^{2}\right)+ \\
& (10 a+b)=16275
\end{aligned}
$$

Puig hace las siguientes operaciones (con su nomenclatura, por supuesto).

Primero, separa el número 16275 en grupos de 3 en 3, comenzando por la derecha. Se obtienen dos grupos. Con el de la izquierda obtendremos el dígito $a$ y con el siguiente el $b$.

El dígito $a$ se obtiene calculando la raíz cúbica entera. Es decir, $\sqrt[3]{16} \cong 2$.

Al 16275 le restamos los factores que no contienen el dígito $b$ y que posiblemente sean los de más peso (aunque no siempre, pero no se puede restar ningún factor que contenga el dígito $b$ porque aún no se conoce) de cada una de las potencias de la incógnita, obteniendo el primer residuo.

$r_{1}=16275-10^{3} \cdot a^{3}-10^{2} \cdot a^{2}-10 a=10^{3} \cdot 2^{3}-10^{2} \cdot 2^{2}-10 \cdot 2=16275-$ $8000-400-20=7855$

Ahora es el momento de obtener el dígito $b$. Sabemos que el residuo que hemos calculado corresponde a los factores que no hemos restado. Es decir: 
$r_{1}=7855=\left(3 \cdot 10^{2} \cdot a^{2} \cdot b+3 \cdot 10 \cdot a \cdot b^{2}+b^{3}\right)+\left(2 \cdot 10 \cdot a \cdot b+b^{2}\right)+(b)=(3 \cdot$

$\left.10^{2} \cdot 2^{2} \cdot b+3 \cdot 10 \cdot 2 \cdot b^{2}+b^{3}\right)+\left(2 \cdot 10 \cdot 2 \cdot b+b^{2}\right)+(b)$

De todos estos factores, el de mayor peso es el primero. Descartamos el resto y aproximamos $b$ al entero que nos salga de hacer la siguiente división:

$$
r_{1} \cong 3 \cdot 10^{2} \cdot a^{2} \cdot b \Rightarrow b=\frac{7855}{3 \cdot 10^{2} \cdot 2^{2}} \cong 6^{\prime} 55 \cong 6
$$

Es decir, el divisor es solamente el factor de más peso de todos los que tenemos. Hay que notar que a veces el valor de $b$ no es el correcto ya que es posible que el residuo que quede sea demasiado pequeño como para poderle restar más factores. Esto lo avisa Puig que puede ocurrir. En ese caso, se toma un valor inferior. Vamos a comprobar que este es el caso. Sigamos con el proceso.

Ahora, al residuo que tenemos le restamos los demás factores, ya que conocemos $b$. $r_{2}=r_{1}-\left(3 \cdot 10^{2} \cdot 2^{2} \cdot 6+3 \cdot 10 \cdot 2 \cdot 6^{2}+6^{3}\right)-\left(2 \cdot 10 \cdot 2 \cdot 6+6^{2}\right)-(6)=$ $7855-9576-276-6=-2003$

Y claramente nos hemos pasado con el valor de $b$. Por lo tanto, recalculamos con un valor inferior de $b$. Tomamos $b=5$.

$r_{2}=r_{1}-\left(3 \cdot 10^{2} \cdot 2^{2} \cdot 5+3 \cdot 10 \cdot 2 \cdot 5^{2}+5^{3}\right)-\left(2 \cdot 10 \cdot 2 \cdot 5+5^{2}\right)-(5)=$ $7855-7625-225-5=0$

Y la solución de la ecuación es $N=25$. 
ANEXO II. Resolución de una ecuación por el método general de resolución de ecuaciones de Andrés Puig

Resolvamos la ecuación $x^{2}-4 x=165$.

Sea la solución $N=(10 a+b)$ ya que debe tener dos dígitos. Tomamos $\sqrt{1}=a$.

$$
\begin{gathered}
N^{2}=(10 a+b)^{2}=10^{2} \cdot a^{2}+2 \cdot 10 \cdot a \cdot b+b^{2} \\
r_{1}=165-10^{2} \cdot a^{2}+4 \cdot 10 \cdot a=165-100+40=105 \\
b=\frac{105}{2 \cdot 10 \cdot a} \cong 5
\end{gathered}
$$

$r_{2}=r_{1}-2 \cdot 10 \cdot a \cdot b-b^{2}+4 \cdot b=105-2 \cdot 10 \cdot 1 \cdot 5-5^{2}+4 \cdot 5=105-100-$ $25+20=0$

Y la solución es $N=15$. 


\section{ANEXO III. Resolución de una ecuación por el método general de resolución de}

\section{ecuaciones de Andrés Puig}

Resolución de la ecuación del ejemplo sexto, pp. 455-458.

\begin{tabular}{|c|c|}
\hline $\begin{array}{c}\text { Andrés Puig } \\
\text { éfte num. I 44.4. fe componè de r.cu.p.r.ce.p.co.co. }\end{array}$ & $\begin{array}{l}\text { Con simbología actual } \\
\qquad x^{3}+x^{2}+x=14424\end{array}$ \\
\hline 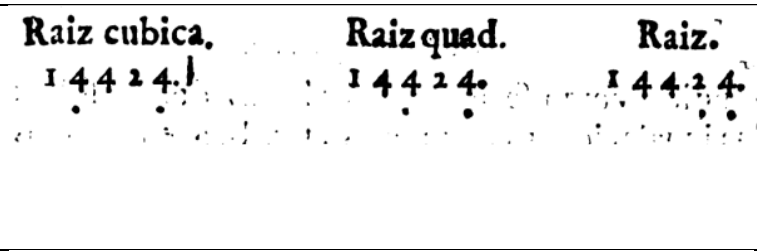 & $\begin{array}{l}\text { Se separa el término independiente en grupos de } 3,2 \\
\text { y } 1 . \\
N^{3}=(10 a+b)^{3}=10^{3} \cdot a^{3}+3 \cdot 10^{2} \cdot a^{2} \cdot b+3 \\
10 \cdot a \cdot b^{2}+b^{3} \\
N^{2}=(10 a+b)^{2}=10^{2} \cdot a^{2}+2 \cdot 10 \cdot a \cdot b+b^{2} \\
N=10 a+b\end{array}$ \\
\hline 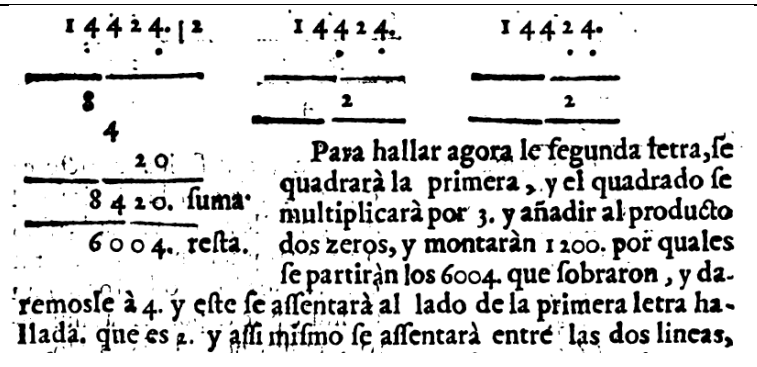 & $\begin{array}{l}\sqrt[3]{14} \cong 2 \\
\text { Los factores mayores de cada una de las potencias: } \\
10^{3} \cdot a^{3}=10^{3} \cdot 2^{3}=8000 \\
10^{2} \cdot a^{2}=10^{2} \cdot 2^{2}=400 \\
10 a=10 \cdot 2=20 \\
\text { Los sumamos: } \\
8000+400+20=8420 \\
\text { Calculamos el primer residuo: } \\
r_{1}=14424-8420=6004\end{array}$ \\
\hline 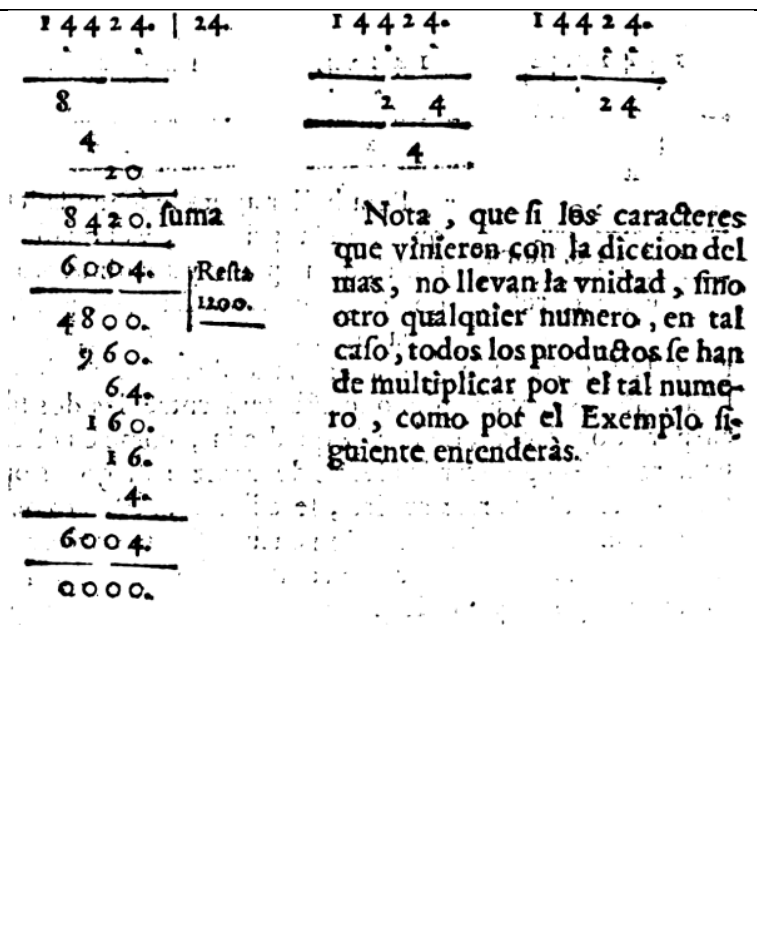 & $\begin{array}{l}b=\frac{r_{1}}{3 \cdot 10^{2} \cdot a^{2}}=\frac{6004}{3 \cdot 10^{2} \cdot 2^{2}}=\frac{6004}{1200} \cong 4 \\
\text { Aquí, aunque no lo diga, ha tenido que recalcular ya } \\
\text { que debería ser } 5 \text { y no } 4 \text {, pero como se pasaría con } 5 \text {, } \\
\text { por eso recalcula y utiliza el } 4 \text {. } \\
\text { Los factores que quedan de } N^{3}: \\
3 \cdot 10^{2} \cdot a^{2} \cdot b=3 \cdot 10^{2} \cdot 2^{2} \cdot 4=4800 \\
3 \cdot 10 \cdot a \cdot b^{2}=3 \cdot 10 \cdot 2 \cdot 4^{2}=960 \\
b^{3}=4^{3}=64 \\
\text { Los factores que quedan de } N^{2}: \\
2 \cdot 10 \cdot a \cdot b=2 \cdot 10 \cdot 2 \cdot 4=160 \\
b^{2}=4^{2}=16 \\
\text { El factor que queda de } N: \\
b=4 \\
\text { Los sumamos: } \\
4800+960+64+160+16+4=6004 \\
\text { Calculamos el segundo residuo: } \\
r_{2}=6004-6004=0 \\
\text { La solución es } N=10 a+b=10 \cdot 2+4=24\end{array}$ \\
\hline
\end{tabular}




\section{ANEXO IV. Resolución de una ecuación por el método general de resolución de} ecuaciones de José Zaragoza

Utilizaremos simbología actual para poder ver mejor la organización de las operaciones y los datos.

Analizaremos el ejemplo $1^{\circ}$ de la página 201 de la Arithmetica de Zaragoza.

La ecuación es $x^{5}+11 x^{3}+100 x^{2}+220 x=34024320$.

La solución tiene 2 dígitos. El primero se obtiene calculando la raíz quinta de 340 por defecto (ya que se separa el término independiente en grupos de 5 dígitos y se toma el de la izquierda). El primer dígito será $\sqrt[5]{340} \cong 3$. Por lo que $a=3$. Vamos a desarrollar los binomios:

$$
\begin{aligned}
& (10 a+b)^{5}+11 \cdot(10 a+b)^{3}+100 \cdot(10 a+b)^{2}+220 \cdot(10 a+b)=34024320= \\
& \left(10^{5} \cdot a^{5}+5 \cdot 10^{4} \cdot a^{4} \cdot b+10 \cdot 10^{3} \cdot a^{3} \cdot b^{2}+10 \cdot 10^{2} \cdot a^{2} \cdot b^{3}+5 \cdot 10 \cdot a \cdot b^{4}+\right. \\
& \left.b^{5}\right)+11 \cdot\left(10^{3} \cdot a^{3}+3 \cdot 10^{2} \cdot a^{2} \cdot b+3 \cdot 10 \cdot a \cdot b^{4}+b^{3}\right)+100 \cdot\left(10^{2} \cdot a^{2}+2 \cdot\right. \\
& \left.10 \cdot a \cdot b+b^{2}\right)+220 \cdot(10 \cdot a+b)
\end{aligned}
$$

\begin{tabular}{|c|c|c|}
\hline $\begin{array}{r}34024320 \\
243 . \\
297 ! \\
900 \\
660 \\
2469360 \\
9330720\end{array}$ & {$\left[\begin{array}{l}+ \\
+\quad 1 Z^{5} \\
+\quad 11 Z^{3} \\
+100 Z^{2} \\
+220 Z^{x} \\
\text { uma. } \\
\text { Refid. }\end{array}\right.$} & $\begin{array}{l}\text { Primero calculamos el primer residuo, restando al término } \\
\text { independiente de la ecuación los factores de mayor peso } \\
\text { de cada uno de los binomios desarrollados. } \\
r_{1}=34024320-10^{5} \cdot a^{5}-11 \cdot 10^{3} \cdot a^{3}-100 \cdot 10^{2} \\
a^{2}-220 \cdot 10 \cdot a=9330720\end{array}$ \\
\hline
\end{tabular}

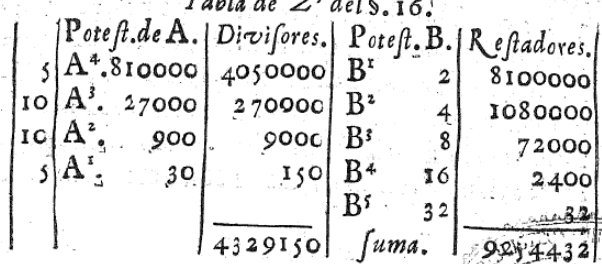

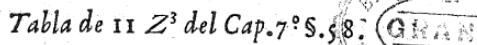

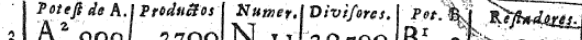

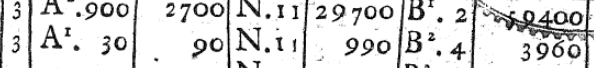

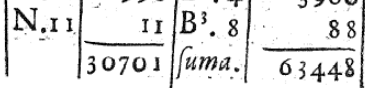

Tabla de $100 Z^{2}$ del Cap. $7^{\circ} 5.58$.

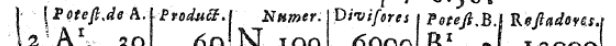

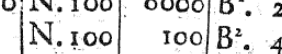
o1vu fuma. $\frac{400}{12400}$

Ahora usaremos las tablas de las potencias para obtener divisores y restadores. Pondremos sólo la primera. El resto se obtienen con los desarrollos de los binomios.

\begin{tabular}{|c|c|c|c|c|}
\hline \multicolumn{5}{|c|}{ Tabla de $x^{5}$} \\
\hline & Pot. Con $a$ & Divisores & Pot. Con $b$ & Restadores \\
\hline 5 & $10^{4} \cdot a^{4}=810000$ & $5 \cdot 10^{4} \cdot a^{4}=4050000$ & $b=2$ & $5 \cdot 10^{4} \cdot a^{4} \cdot b=8100000$ \\
\hline 10 & $10^{3} \cdot a^{3}=27000$ & $10 \cdot 10^{3} \cdot a^{3}=270000$ & $b^{2}=4$ & $10 \cdot 10^{3} \cdot a^{3} \cdot b^{2}=1080000$ \\
\hline 10 & $10^{2} \cdot a^{2}=900$ & $10 \cdot 10^{2} \cdot a^{2}=9000$ & $b^{3}=8$ & $10 \cdot 10^{2} \cdot a^{2} \cdot b^{3}=72000$ \\
\hline 5 & $10 \cdot a=30$ & $5 \cdot 10 \cdot a=150$ & $b^{4}=16$ & $5 \cdot 10 \cdot a \cdot b^{4}=2400$ \\
\hline 1 & & & $b^{5}=32$ & $b^{5}=32$ \\
\hline & & 4329150 & & 9254432 \\
\hline
\end{tabular}

\begin{tabular}{|c|c|c|c|c|c|c|}
\hline \multicolumn{7}{|c|}{ Tabla de $x^{3}$} \\
\hline & Pot. Con $a$ & Productos & Coeficientes & Divisores & Pot. Con $b$ & Restadores \\
\hline 3 & $10^{2} \cdot a^{2}=900$ & 2700 & 11 & $11 \cdot 3 \cdot 10^{2} \cdot a^{2}=29700$ & $b=2$ & $11 \cdot 3 \cdot 10^{2} \cdot a^{2} \cdot b=59400$ \\
\hline 3 & $10 \cdot a=30$ & 90 & 11 & $11 \cdot 3 \cdot 10 \cdot a=990$ & $b^{2}=4$ & $11 \cdot 3 \cdot 10 \cdot a \cdot b^{2}=3960$ \\
\hline
\end{tabular}




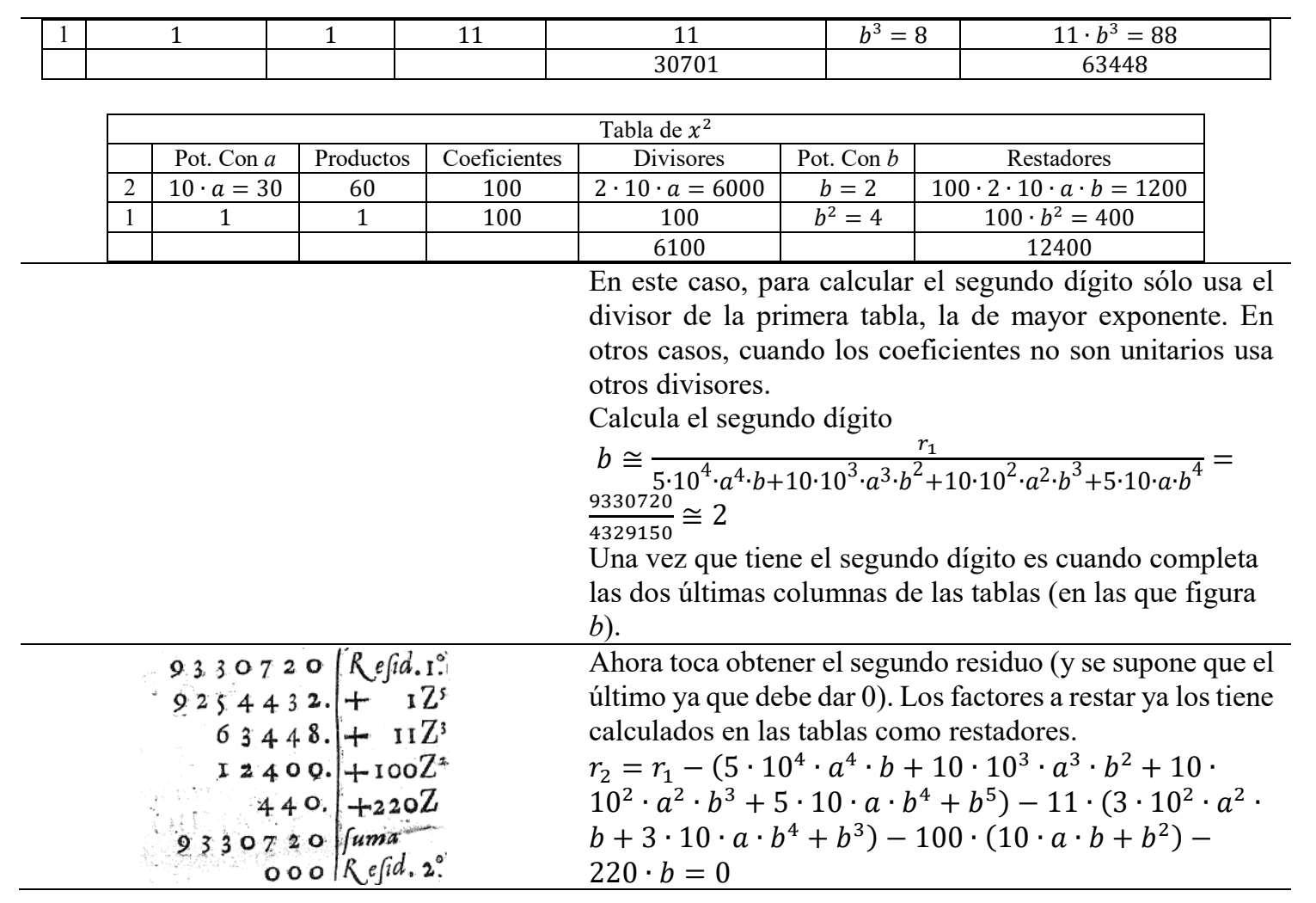

Para calcular el dígito $b$ toma la suma de los divisores de la tabla de la potencia de mayor grado como divisor del residuo, como hemos visto, menos el de menor peso $\left(b^{5}\right)$. Y obtiene que el segundo dígito vale 4. Ahora puede completar la tabla con los restadores, que los utiliza para calcular el siguiente residuo (que en este caso es 0 y termina el proceso). 


\section{ANEXO V. Algoritmo por aproximación de Chuquet con alto nivel de}

\section{abstracción}

Esta regla la podemos mostrar con una simbología actual (Figura 12), en forma de algoritmo a nivel más abstracto e incluyendo las fracciones y operaciones en el propio algoritmo. Vamos a suponer que el valor a evaluar en el problema en cuestión es $S$ y el entorno de la solución es $[A, A+1]$. La asignación de un valor se representa con el operador ":=".

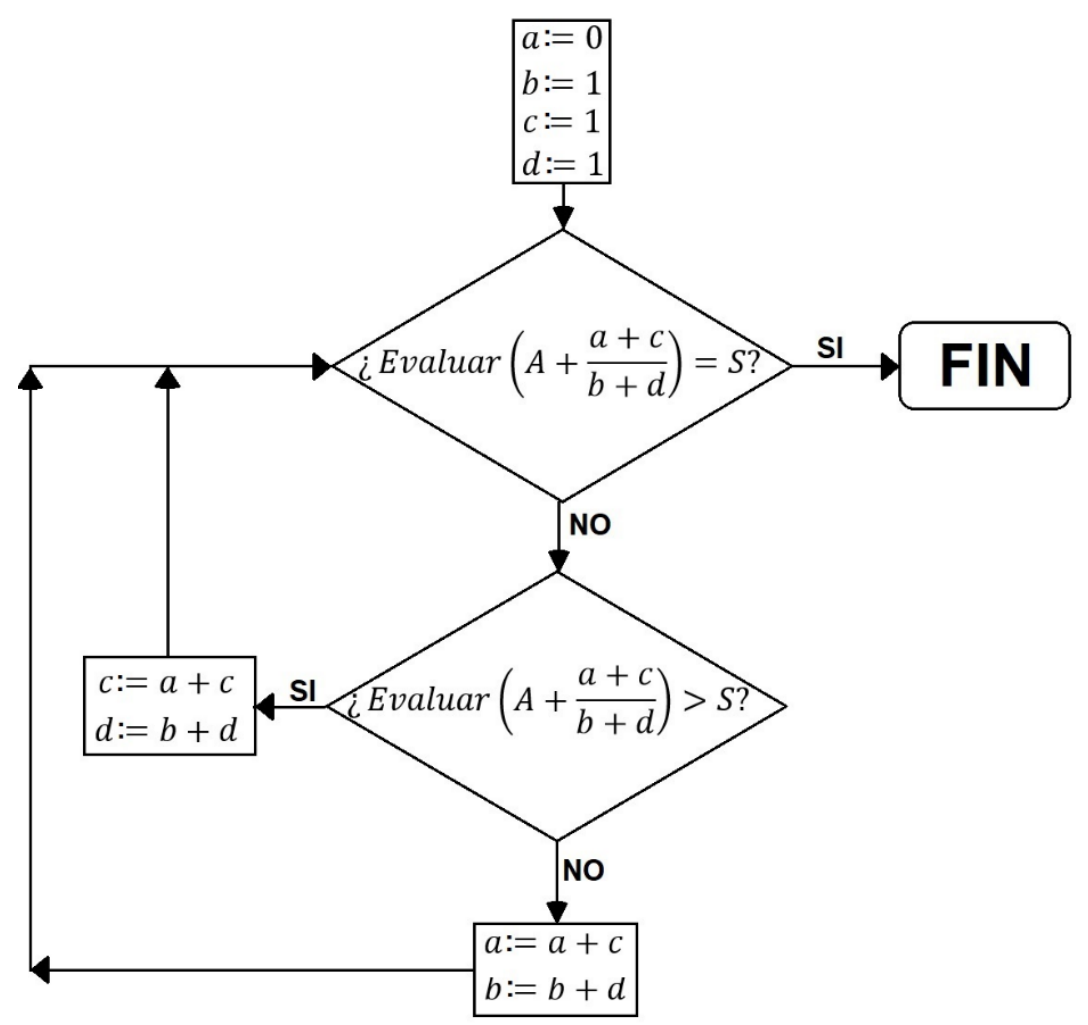

Figura 12. Algoritmo equivalente a la Regla de los Números Intermedios de Chuquet 


\section{ANEXO VI. Algoritmo por aproximación de Puig con alto nivel de abstracción}

Esta regla la podemos mostrar con una simbología actual (Figura 13), en forma de algoritmo a nivel más abstracto. Vamos a suponer que el valor a evaluar en el problema en cuestión es $S$ y el valor por defecto para estimar es $A$. La asignación de un valor se representa con el operador ":=".

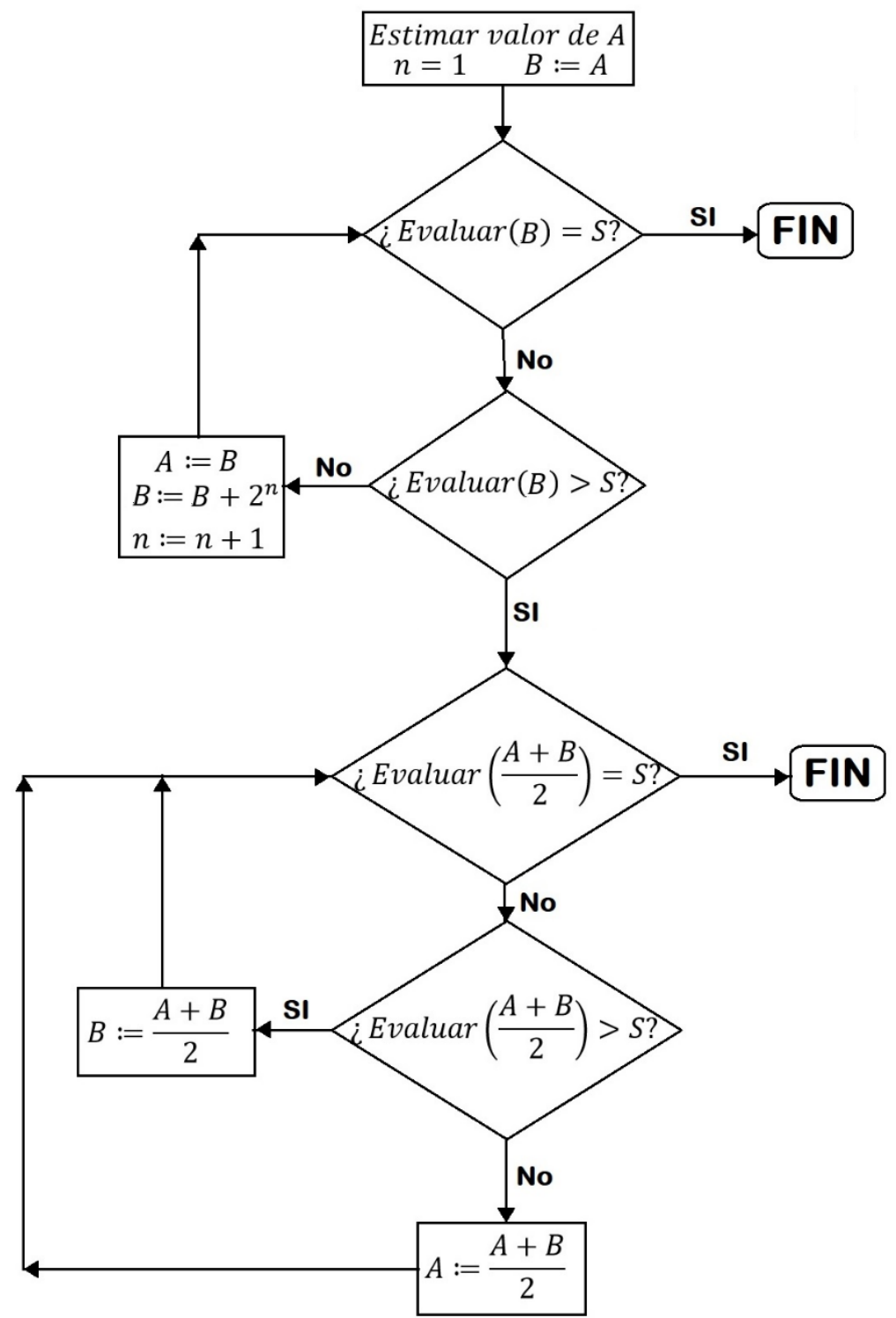

Figura 13. Algoritmo equivalente a la Regla Media de Andrés Puig 


\section{ANEXO VII. Maravillas de Ventallol}

Antes de nada, expliquemos brevemente la terminología que usa. Usa el término advenimiento. El advenimiento de dos números es el cociente obtenido al sumarlos y dividirlos por uno de ellos. Entonces, con dos números se producen dos advenimientos, uno es al dividir la suma entre uno de los números y el otro al dividirla entre el otro. Entonces, si los números por ejemplo son $a$ y $b$ sus advenimientos son $\frac{a+b}{a}$ y $\frac{a+b}{b}$.

Para no salirnos en exceso del objeto de nuestro estudio sobre Puig, pondremos aquí el texto original de la primera "maravilla" (Figura 14) y el resto simplemente la identidad que la explica con ojos actuales, ya que Ventallol no hace demostración alguna.

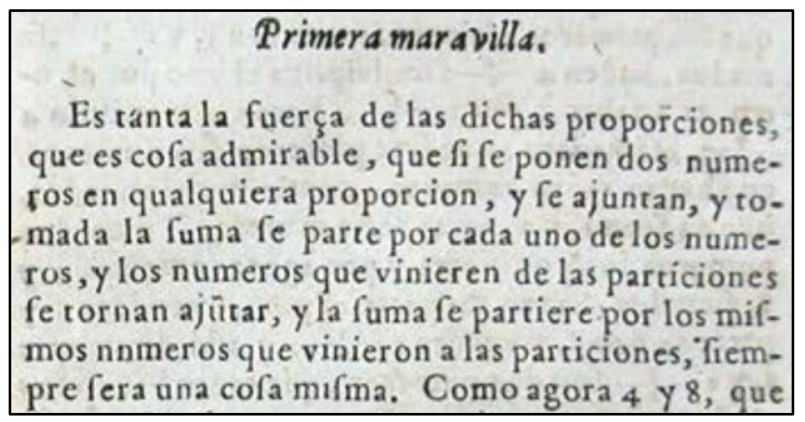

Figura 14. Primera maravilla de Ventallol (Tolrà, 1619, p. 481)

Esto quiere decir que si tenemos dos números cualesquiera (número en el sentido de la época, es decir número racional positivo), $a$ y $b$ se cumplen estas dos identidades:

$$
\left(\frac{a+b}{a}+\frac{a+b}{b}\right): \frac{a+b}{a}=\frac{a+b}{b} \text { y }\left(\frac{a+b}{a}+\frac{a+b}{b}\right): \frac{a+b}{b}=\frac{a+b}{a}
$$

La segunda "maravilla" dice que si dos números son proporcionales con una cierta proporción, sus advenimientos son proporcionales con la misma proporción. Es decir, si $a=k \cdot b \Rightarrow \frac{a+b}{b}=k \cdot \frac{a+b}{a}$.

La tercera "maravilla" dice que respecto dichos números en cualquier proporción, se cumple $\frac{a+b}{a} \cdot \frac{a+b}{b}=\frac{a+b}{a}+\frac{a+b}{b}$.

La cuarta "maravilla" añade una relación entre segundos advenimientos. Y resulta esta identidad: $\frac{\frac{a+b}{a}+\frac{a+b}{b}}{\frac{a+b}{a}}=\frac{a+b}{b}$ y viceversa. Esta "maravilla" se podría deducir de la primera.

La quinta "maravilla" establece esta interesante identidad. Si tenemos dos números en una cierta proporción $a=k \cdot b$, se cumple que $\frac{a+b}{a}+\frac{a+b}{b}=(k+2)+\frac{1}{k}$.

Además, esta misma regla acontece con los segundos advenimientos. 
La sexta "maravilla" (Figura 15) dice algo que podemos interpretar como: sean los dos números proporcionales $a=k \cdot b$. Su primer advenimiento sería $\frac{a+b}{a}=\frac{k b+b}{k b}=$ $\frac{b(k+1)}{k b}=\frac{k+1}{k}$ que evidentemente no puede ser un número entero. Para el otro advenimiento ocurre igual. Veamos ahora para la suma de los dos advenimientos: $\frac{a+b}{a}+$ $\frac{a+b}{b}$ que según la quinta "maravilla" es $(k+2)+\frac{1}{k}$ que tampoco es un número entero.

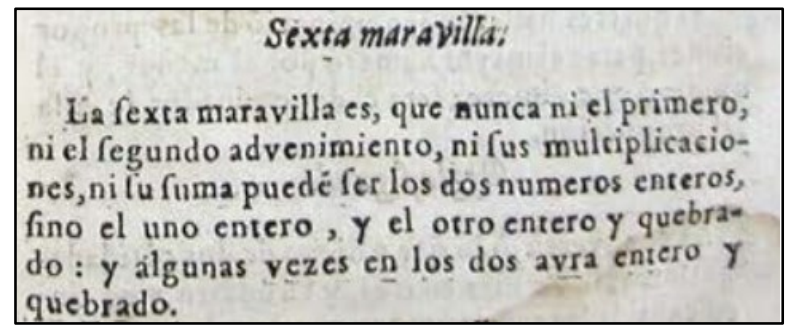

Figura 15. Sexta maravilla de Ventallol (Tolrà, 1619, p. 483)

Y el producto, utilizando la tercera "maravilla", tampoco puede ser un entero.

En la séptima "maravilla", generaliza lo dicho en la quinta además de para enteros, para quebrados.

Quizás el llamarle "maravillas" a estas identidades (al igual que hace Puig con su octava "maravilla") es porque no son tan evidentes. Simplemente se le "demuestra" al lector que son ciertas con ejemplos y de esta forma se les da un halo de misterio. 


\section{ANEXO VIII. Ejemplo de la adición 7}

Un ejemplo sencillo nos puede permitir ver la diferencia entre ambos métodos. Supongamos que queremos calcular el montante de una mercancía compuesta por 25 cargas y 5 quintales a un precio de 26 libras cada carga. Sabemos que 3 quintales es 1 carga.

Haremos primero los cálculos con el método antes de la adición y luego utilizando el método explicado en la adición. Todo en la Figura 16.

\begin{tabular}{|c|c|c|}
\hline & $\begin{array}{l}25 \text { cargas } 5 \text { quintales } \\
26 \text { libras }\end{array}$ & 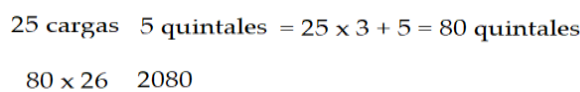 \\
\hline $6 \times 25=150$ & 150 & $\overline{3}=\frac{3}{3}$ \\
\hline $2 \times 25=50$ & 500 & $2080 \operatorname{div} 3=693$ resto 1 \\
\hline $\begin{array}{c}6 \times 5=30 \\
30 \text { div } 3=10 \text { resto } 0\end{array}$ & 10 & $693 \frac{1}{3}$ libras \\
\hline $\begin{array}{c}2 \times 5=10 \\
100 \operatorname{div} 3=33 \text { resto } 1\end{array}$ & $33 \frac{1}{3}$ & \\
\hline & $693 \frac{1}{3}$ libras & \\
\hline
\end{tabular}

Figura 16. Dos maneras de realizar cálculos mercantiles 


\section{ANEXO IX. Problema de los assentistas de la adición 8}

Este problema es equivalente a calcular cuánto se ha prestado a un interés anual del $10 \%$ a 4 años para que al final sean devueltas 1000 libras, más lo mismo para 3 años, para 2 años y para 1 año.

Según el método adicionado por Puig, y que dice que es más correcto que el utilizado antes por los assentistas (pero que él mismo tiene en su libro desde la primera impresión), los cálculos serían estos (según nomenclatura actual).

$$
C_{f}=C_{i} \cdot\left(1+\frac{r \cdot t}{100}\right)=C_{i} \cdot\left(1+\frac{10 \cdot 4}{100}\right)=1^{\prime} 4 \cdot C_{i} \Rightarrow C_{i}=\frac{1000}{1^{\prime} 4}=714 \frac{2}{7}
$$

Es decir, que considera que los intereses ya están incluidos en lo prestado (actualmente no se suele considerar así sino que los intereses se añaden a lo prestado).

Él lo calcula con una regla de tres: “si 140. se baxan á 100. á quantos se baxaràn 1000, sigue la dicha regla de tres, y hallaràs 714. libras, y $\frac{2}{7}$ ", (Puig, 1711, pp. 195-197).

Las siguientes 1000 libras están 3 años, por lo que corresponden a un capital inicial de $\frac{1000}{1 / 3}=769 \frac{3}{13}$. Luego otras tantas a 2 años, que corresponden a $\frac{1000}{1 / 2}=833 \frac{1}{3}$. Y por último $\frac{1000}{1 / 1}=909 \frac{1}{11}$. Y todo suma un capital inicial de $714+\frac{2}{7}+769+\frac{3}{13}+833+\frac{1}{3}+909+$ $\frac{1}{11}=\frac{9687500}{3003}=3225 \frac{2825}{3003}$ libras. Que Puig desglosa en unidades monetarias menores, obteniendo 3225 libras, 15 sueldos y $9 \frac{811}{1001}$ dineros.

Ahora, según el método anterior, el que usan los assentitas y él mismo en la primera impresión. Suma $1+2+3+4=10$, que son las anualidades a pagar, que divide entre el número de años (que son 4), y obtiene que se pagarían a $2 \frac{1}{2}$ de años si se hiciera un solo pago. Y ahora, con una regla de tres: en dos años y medio, al 10\% anual, 100 se convierten en 125. Por lo tanto, “si 125. se baxan à 100. à quantos se baxarán 4000. libras. y se obtienen 3200 libras" (Puig, 1711, pp. 195-197).

Por consiguiente, hay una diferencia entre los dos métodos de más de 25 libras.

Según la lógica y la forma de calcular intereses en la época, es cierto que la manera de los assentistas es incorrecta y que la nueva manera es la más correcta. Ellos tratan cada cuota anual como independiente de las otras cuotas, y según están pendientes de pago más años, les aplican un interés anual correspondiente.

Si nos fijamos en las dos maneras de calcular el interés en Puig, las fórmulas equivalentes serían las de las Figuras 17 y 18. 
$C_{f}=C_{i} \cdot\left(1+\frac{1}{t} \cdot \sum_{i=1}^{t} \frac{r \cdot i}{100}\right)$

Figura 17. Fórmula del interés para los assentistas

$$
C_{f}=C_{i} \cdot\left(\frac{1}{\frac{1}{t} \cdot \sum_{i=1}^{t} \frac{1}{1+\frac{r \cdot i}{100}}}\right)
$$

Figura 18. Fórmula del interés mejorada

Donde $C_{f}$ es el capital total final devuelto, $C_{i}$ es el capital total inicial prestado, $t$ es el plazo de amortización en años y $r$ es el tipo de interés anual. 


\section{ANEXO X. Problema de la adición 9}

El problema que resuelve y explica consiste en que un hombre recibe una renta de 50 libras cada tres meses, pero necesita 732 libras de fondo mínimo, y pide un préstamo a un "negociante". El "negociante" se las presta pero con un interés anticipado cada tres meses del 20\% anual. Puig resuelve el problema de la siguiente manera. Lo primero es que como el hombre necesita sus 732 libras y no tiene aún nada y tiene que devolver 50 libras, necesita pedir algo más de dinero para cuando tenga sus 50 libras, devolverlas y seguir conservando 732. Puig separa el 20\% de interés anual en 4 partes, al 5\% cada una (cada trimestre). Por lo tanto, y con una regla de tres, si a 100 le quitamos 5, obtenemos 95 , por lo que si de 95 salen 100, ¿de dónde saldrán 732 ?. Y calcula que son algo más de 770 libras. Es decir, que el hombre debe pedir prestada esta cantidad para poder devolver en el primer pago las 50 libras que tiene de renta y quedarle aún 732 libras. Luego calcula que de las algo más de 770 libras deberá pagar un 5\% de interés y descontar sus 50 libras que devuelve, por lo que tras el primer trimestre seguirá debiendo algo más de 720 libras. $\mathrm{Y}$ así sigue sucesivamente calculando intereses trimestrales y descontando cuotas de 50 libras. Puig no completa los cálculos pero dice que son 28 cuotas de 50 libras y que se parará el proceso cuando queden menos de 50 libras a deber. Al final quedan según Puig 33 libras, 6 sueldos y 8 dineros. A esta última parte le añade los intereses y esa es la última cuota a pagar por el hombre. Indica Puig que:

En todas las partidas destas sumas, y restas el quebrado, que no á llegado a medio dinero no se ha puesto, y el que ha llegado se ha puesto por entero, por ser cosa de muy poca monta, y ahorrar trabajo. (Puig, 1711, p. 201).

Es decir, que realiza un redondeo a la unidad de dinero. 


\section{ANEXO XI. Lectura analítica aritmética de la adición 10}

Para construir un grafo, partimos de una serie de datos conocidos, representados como nodos en el grafo. Echamos mano de una serie de incógnitas auxiliares, representadas también por nodos. Los datos conocidos se dibujan como puntos cerrados y las incógnitas como cuadrados abiertos. Los nodos están conectados por enlaces que representan las relaciones aritméticas entre los nodos. Luis Puig llama vértices a los nodos y aristas a los enlaces.

Las cantidades encontradas en la lectura analítica son:

- Dato: "La distancia de Barcelona a Madrid" $(d)$

- Dato: "El tiempo que le cuesta al de Barcelona recorrer la distancia B-N" $\left(t_{b}\right)$

- Incógnita auxiliar: "La velocidad del de Barcelona" $\left(v_{b}\right)$

- Dato: "El tiempo que le cuesta al de Madrid recorrer la distancia M-B" $\left(t_{m}\right)$

- Incógnita auxiliar: "La velocidad del de Madrid" $\left(v_{m}\right)$

- Incógnita auxiliar: "El espacio recorrido entre los dos viajeros en un día" $\left(v_{b m}\right)$

- Incógnita: "El tiempo en encontrarse" $\left(t_{e}\right)$

Las relaciones entre ellas encontradas en la lectura analítica son:

$$
t_{b} \cdot v_{b}=d \quad t_{m} \cdot v_{m}=d \quad t_{e} \cdot v_{b m}=d \quad v_{b}+v_{m}=v_{b m}
$$

Éste es el grafo:

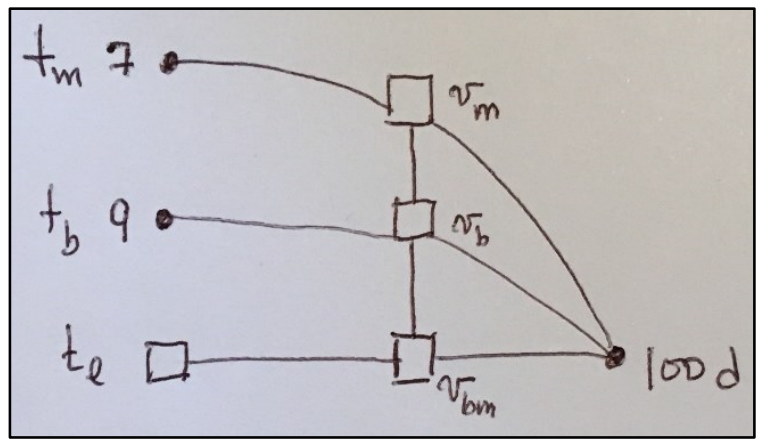

Figura 19. Grafo de la lectura analítica aritmética

El grafo de la Figura 19 nos muestra que la "lectura analítica" del problema permite resolverlo de forma aritmética porque se puede llegar desde los datos a la incógnita del problema haciendo operaciones siempre con datos. Veámoslo.

En la arista $t_{m}, v_{m}, \mathrm{~d}$ hay dos datos, así que podemos calcular la incógnita auxiliar $v_{m}$.

$$
v_{m}=\frac{d}{t_{m}}=\frac{100}{7}
$$

En la arista $t_{b}, v_{b}, d$ hay dos datos, así que podemos calcular la incógnita auxiliar $v_{b}$.

$$
v_{b}=\frac{d}{t_{b}}=\frac{100}{9}
$$

Como ya hemos calculado $\mathrm{v}_{\mathrm{m}} \mathrm{y} \mathrm{v}_{\mathrm{b}}$, en la arista $\mathrm{V}_{\mathrm{m}}, \mathrm{v}_{\mathrm{b}}, \mathrm{v}_{\mathrm{bm}}$ hay dos datos, así que podemos calcular la incógnita auxiliar Vbm. 


$$
v_{b m}=v_{m}+v_{b}=\frac{100}{7}+\frac{100}{9}
$$

Como ya hemos calculado $v_{b m}$, en la arista $t_{e}, v_{b m}, d$ hay dos datos, así que podemos calcular la incógnita del problema $t_{e}$.

$$
t_{e}=\frac{d}{v_{b m}}=\frac{100}{\frac{100}{7}+\frac{100}{9}}=3^{\prime} 9375 \text { días }
$$

Con esta lectura analítica, hemos encontrado una serie de operaciones aritméticas que tienen sentido entre las cantidades del problema, que nos permite solucionarlo.

Puig (1672) muestra otra serie de operaciones aritméticas diferente, carente de sentido pero que ofrece el mismo resultado. Si ambas series de operaciones las escribimos como fórmulas, es fácil pasar de la que acabamos de obtener, en la que todas las operaciones tienen sentido, a la que da como regla Puig (1672), en la que ninguna de las operaciones tiene sentido.

$$
\begin{aligned}
\frac{100}{\frac{100}{7}+\frac{100}{9}}= & \frac{100}{\frac{100 \cdot 9}{7 \cdot 9}+\frac{100 \cdot 7}{7 \cdot 9}}=\frac{100}{\frac{100 \cdot 9+100 \cdot 7}{7 \cdot 9}}=\frac{100}{\frac{100 \cdot(7+9)}{7 \cdot 9}}=\frac{100 \cdot 7 \cdot 9}{100 \cdot(7+9)} \\
& =\frac{7 \cdot 9}{7+9}
\end{aligned}
$$

Para pasar de una a otra todo lo que se hace tiene sentido cuando los números se toman como números abstractos, no como cantidades. 


\section{ANEXO XII. Lectura analítica algebraica de la adición 10}

Las cantidades encontradas en la lectura analítica son:

- Dato: "La distancia de Barcelona a Madrid" $(d)$

- Dato: "El tiempo que le cuesta al de Barcelona recorrer la distancia B-N" $\left(t_{b}\right)$

- Incógnita auxiliar: "Espacio recorrido por el de Barcelona" $\left(e_{b}\right)$

- Incógnita auxiliar: "La velocidad del de Barcelona" $\left(v_{b}\right)$

- Dato: "El tiempo que le cuesta al de Madrid recorrer la distancia M-B" $\left(t_{m}\right)$

- Incógnita auxiliar: "La velocidad del de Madrid" $\left(v_{m}\right)$

- Incógnita auxiliar: "Espacio recorrido por el de Madrid" $\left(e_{m}\right)$

- Incógnita: "El tiempo en encontrarse" $\left(t_{e}\right)$

Las relaciones entre ellas encontradas en la lectura analítica son:

$$
t_{m} \cdot v_{m}=d \quad t_{b} \cdot v_{b}=d \quad t_{e} \cdot v_{m}=e_{m} \quad t_{e} \cdot v_{b}=e_{b} \quad e_{m}+e_{b}=d
$$

Y este es el grafo:

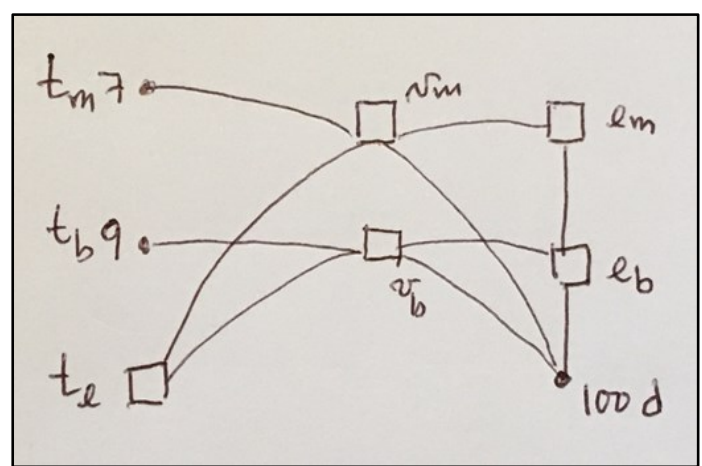

Figura 20. Grafo de una lectura analítica algebraica

Este grafo, el de la Figura 20, muestra que no es posible obtener una solución aritmética con esta lectura analítica, porque no se puede calcular la incógnita haciendo operaciones con datos. En efecto, $v_{m} \mathrm{y} v_{b}$ sí que pueden calcularse a partir de datos, usando las relaciones $t_{m} \cdot v_{m}=d \mathrm{y} t_{b} \cdot v_{b}=d$, ya que en ambas hay dos datos, y convertirlas en nuevos datos, 100/7 y 100/9. Pero una vez hecho esto, no hay en el grafo ninguna otra relación en la que haya dos datos, las tres relaciones que quedan sin utilizar, $t_{e} \cdot v_{m}=e_{m}$, $t_{e} \cdot v_{b}=e_{b}$ y $e_{m}+e_{b}=d$, sólo tienen un dato cada una, con lo que la única manera de seguir haciendo cálculos es asignando una letra, la $x$, a la cantidad $t_{e}$ y usar las relaciones para escribir expresiones algebraicas y una ecuación. Por ejemplo:

Usando $t_{e} \cdot v_{m}=e_{m}$, se obtiene $e_{m}=100 / 7 \cdot x$.

Usando $t_{e} \cdot v_{b}=e_{b}$, se obtiene $e_{b}=100 / 9 \cdot x$

Usando $e_{m}+e_{b}=d$, se obtiene $d=100 / 7 \cdot x+100 / 9 \cdot x$.

Y como $d=100$, se obtiene la ecuación $100 / 7 \cdot x+100 / 9 \cdot x=100$. 
Y la resolución de esa ecuación precisamente nos lleva a que la solución expresada como una fórmula sería $t_{e}=\frac{100}{\frac{100}{9}+\frac{100}{7}}$. 


\section{ANEXO XIII. Demostración de la adición 11}

Puig supone que 20 tiene raíz cuadrada (natural), y sabemos que no es un número cuadrado por supuesto. 4 no puede ser, porque el cuadrado de 4 se queda por debajo de 20, y 5 tampoco porque se queda por encima. Entonces la raíz de 20 debe estar entre 4 y 5. Por lo tanto, si 20 tiene raíz cuadrada no puede ser un número entero (aquí usa ya el término entero, en realidad un número natural) y deberá ser un número compuesto (compuesto de entero y quebrado). Pero esto no puede ser verdad porque del producto por sí mismo de un número compuesto no puede salir más que otro número compuesto, por lo que 20 no puede tener raíz cuadrada (natural). Y dice que a lo más que se puede hacer es a aproximar el valor de la raíz cuadrada tanto como se quiera. Y aproxima la raíz cuadrada de 20 por medio de un algoritmo de aproximación que utiliza para el cálculo de ecuaciones (se trata del método explicado en el epígrafe "Método general de cálculo de raíces aproximadas").

Y termina diciendo que de lo dicho se infiere que si el lado de un cuadrado es un número (en la manera euclidiana), no se puede "expresar" su diagonal, es decir, que su diagonal no es un número (en la manera euclidiana). Que en términos actuales sería que $\sqrt{2}$ no es un número racional, como ya sabemos. 


\section{ANEXO XIV. Ejemplo de la adición 12}

Imaginemos que queremos buscar tres cuadrados que sumados den otro cuadrado, por ejemplo 900. Utilizamos los artificios de los dos primeros ejemplos para construir cualquier terna de cuadrados que sumen otro cuadrado. Por ejemplo, utilicemos $3^{2}+4^{2}+$ $12^{2}=13^{2}$. Si usamos otra terna, obtendremos otro grupo de cuadrados que sumen 900 (de aquí viene la apreciación de la adición en que dice que hay multitud de ternas posibles). El artificio que utiliza Puig es el siguiente. Sea $(a, b, c ; 30)$ la terna que buscamos que cumpla $a^{2}+b^{2}+c^{2}=900=30^{2}$. Entonces se cumplen estas proporciones:

$$
a: 3:: 30: 13 \quad b: 4:: 30: 13 \quad c: 12:: 30: 13
$$

A partir de esas proporciones podemos obtener esta: $a^{2}+b^{2}+c^{2}: 3^{2}+4^{2}+12^{2}:$ : $30^{2}: 13^{2}$. Ahora aplicamos la regla de la proporcionalidad que nos dice que el producto de la primera y cuarta es igual al de la segunda y tercera, con lo que $\left(a^{2}+b^{2}+c^{2}\right) \cdot 13^{2}=$ $\left(3^{2}+4^{2}+12^{2}\right) \cdot 30^{2}$. Pero sabemos que $3^{2}+4^{2}+12^{2}=13^{2}$, por lo que $\left(a^{2}+b^{2}+c^{2}\right) \cdot 13^{2}=$ $13^{2} \cdot 30^{2}$, con lo que hemos demostrado que $a^{2}+b^{2}+c^{2}=30^{2}$. Y ahora ya podemos calcular $a=3 \cdot \frac{30}{13}=3 \frac{12}{13}, b=4 \cdot \frac{30}{13}=9 \frac{3}{13}$ y $c=12 \cdot \frac{30}{13}=27 \frac{9}{13}$.

Si en vez de usar la terna $(3,4,12 ; 13)$ hubiera usado otra, habría obtenido otros valores para $a, b$ y $c$, lo que ya advierte en la adición. Este artificio está basado en la proposición 24 del libro VIII de los Elementos de Euclides: "Si dos números guardan entre sí la razón que un número cuadrado guarda con un número cuadrado y el primero es cuadrado, el segundo será también cuadrado" (Euclides, 2007, pp. 40-41).

El proceso de obtención de series de cuadrados, a partir de dos, de tres, de cuatro, etc, lo explica Puig mediante ejemplos en el capítulo X del libro cuarto (página 332 y siguientes). Y está basado en algunas aportaciones de los matemáticos griegos. Por ejemplo, en el ejemplo primero, toma un cuadrado impar (el 9). Le quita una unidad (queda 8), toma la mitad (4), hace su cuadrado (16), y concluye que la suma de ambos cuadrados es otro cuadrado $(9+16=25)$.

Veamos lo que ha hecho, utilizando simbología actual: Toma un cuadrado impar, por ejemplo $a^{2}$, le quita uno y lo divide entre dos, $\frac{a^{2}-1}{2}$. Hace el cuadrado de lo obtenido, $\left(\frac{a^{2}-1}{2}\right)^{2}$, y concluye que la suma de ambos cuadrados es otro cuadrado, es decir $a^{2}+$ $\left(\frac{a^{2}-1}{2}\right)^{2}=a^{2}+\frac{a^{4}+1-2 a^{2}}{4}=\frac{4 a^{2}+a^{4}+1-2 a^{2}}{4}=\frac{a^{4}+2 a^{2}+1}{4}=\frac{\left(a^{2}+1\right)^{2}}{4}=\left(\frac{a^{2}+1}{2}\right)^{2}$.

Y con esta identidad podemos construir ternas de cuadrados a partir de una semilla (el número a). Esto mismo lo hace para construir series de 3, 4, o más cuadrados que sumados den otro cuadrado. 


\section{ANEXO XV. Evidencias de la adición 19}

Veamos las identidades (expresadas en álgebra actual y con la simbología anteriormente empleada de razón “":” y proporción “::”). En los casos de proporcionalidad, el orden es de mayor a menor y de izquierda a derecha.

Evidencia 1. $(a+b)+(a-b)=2 a$

$$
(a+b)-(a-b)=2 b
$$

Evidencia 2. $a: b:: a^{2}: a b$

Evidencia 3. $a: b:: a^{3}: a^{2} b$

Evidencia 4. $a^{2}: a:: a: 1$

Evidencia 5. En una progresión aritmética se cumple 1: $\frac{a_{1}+a_{n}}{2}:: n: S_{n}$. Donde $a_{i}$ es el término en la posición $i$ y $S_{n}$ es la suma de los $n$ primeros términos.

Evidencia 6. En una progresión aritmética se cumple 1: $a_{1}+a_{n}:: \frac{n}{2}: S_{n}$

Evidencia 7. En una progresión aritmética se cumple $\frac{a_{1}+a_{n}}{2}: 1:: S_{n}: n$

Evidencia 8. Si $a: b:: c^{2}$ entonces $(a-1) \cdot b+b=d^{2}$. Es decir, si la proporción de dos números es un cuadrado, si al mayor le quitamos la unidad, lo multiplicamos por el menor y le sumamos el menor, el resultado es un número cuadrado.

Evidencia 9. Si $a: b:: c^{2}$ entonces $(a+1) \cdot b-b=d^{2}$

Evidencia 10. En una progresión geométrica se cumple $1: r-1:: S_{n}-a_{n}: a_{n}-a_{1}$. Donde $r$ es la razón de la progresión.

Evidencia 11. La suma de dos cuadrados es un cuadrado.

Evidencia 12. Dados tres números en que los dos primeros están en "sesquicuarta" proporción y los dos últimos en "sesquitercia" proporción, la suma de los cuadrados de los dos menores es un cuadrado y la diferencia entre el cuadrado del mayor y cualquiera de los cuadrados de los otros dos es un cuadrado. Es decir, sean los números $a, b$ y $c$ de forma que $a: b:: 5: 4$ y $b: c:: 4: 3$. Usaremos como ayuda la forma fraccionaria: $\frac{a}{b}=\frac{5}{4} \mathrm{y}$ $\frac{b}{c}=\frac{4}{3}$. La evidencia dice que $b^{2}+c^{2}$ es un cuadrado. Como $b=\frac{4 c}{3}$ entonces $\left(\frac{4 c}{3}\right)^{2}+$ $c^{2}=\frac{4^{2} c^{2}}{3^{2}}+c^{2}=\left(\frac{4^{2}}{3^{2}}+1\right) \cdot c^{2}=\frac{25}{9} \cdot c^{2}=\left(\frac{5 c}{3}\right)^{2}$. Como vemos, lo que aprovecha es que $3^{2}+4^{2}$ es un cuadrado. $\mathrm{Y}$ en la otra parte aprovecha también la relación que hay entre estos tres cuadrados: $3^{2}+4^{2}=5^{2}$.

Evidencia 13. Si $a: b:: b: c$, entonces $a c=b^{2}$

Evidencia 14. Si $a: b:: b: c$, entonces $a: c:: a^{2}: b^{2}$

Evidencia 15. $a: c:: a b: b c$ 
Evidencia 16. $a^{2}-b^{2}=(a-b)^{2}+2 \cdot(a-b) \cdot b$

Evidencia 17. $a^{2}-b^{2}=(a+b) \cdot(a-b)$

Evidencia 18. Si $a: b:: b: c$, entonces $(a-c) \cdot c=b^{2}-c^{2}$

Evidencia 19. Si $a: b:: b: c$, entonces $(a-c) \cdot a=a^{2}-b^{2}$

Evidencia 20. Si $a: b:: b: c$, entonces $a^{2}-b^{2}=(a-c)^{2}+\left(b^{2}-c^{2}\right)$

Evidencia 21. Si $a: b:: b: c$, entonces $(a+c)^{2}=a^{2}+b^{2}+c^{2}+b^{2}$

Evidencia 22. Si $a: b:: b: c$, entonces $(a+c) \cdot b^{2}=\left(b^{2}+c^{2}\right) \cdot a$

Evidencia 23. Si $a: b:: b: c$, entonces $b^{2} \cdot(a+c)=\left(a^{2}+b^{2}\right) \cdot c$

Evidencia 24. Si $a: b:: b: c$, entonces $(a \cdot b+b \cdot c) \cdot(a+c)=(a+c)^{2} \cdot b$

Evidencia 25. $\left(a^{2}-b^{2}\right) \cdot(a-b)=(a+b) \cdot(a-b)^{2}$

Evidencia 26. $(a+b)^{2}=2 \cdot\left(a^{2}+b^{2}\right)-(a-b)^{2}$

Evidencia 27. Si $a=b+1$, entonces $a^{2} \cdot b^{2}+a^{2}+b^{2}$ es un cuadrado.

Evidencia 28. Si $a: b:: c: d$, entonces $a \cdot d=b \cdot c$

Evidencia 29. Si $a: b:: c: d$, entonces $a: d:: a^{3}: b^{3}$

Evidencia 30. Si $a: b:: c: d$, entonces $\frac{b^{2}}{c}=a$ y $\frac{c^{2}}{b}=d$

Evidencia 31. Sea $a=b+c$, entonces $a \cdot b=b^{2}+b \cdot c$

Evidencia 32. Sea $a=b+c$, entonces $a^{2}=b^{2}+c^{2}+2 \cdot b \cdot c$

Evidencia 33. Sea $a=b+c$, entonces $a^{3}=b^{3}+c^{3}+3 \cdot a^{2} \cdot c+3 \cdot b^{2} \cdot c$

Evidencia 34. $\sqrt{a \cdot a+a \cdot b+\left(\frac{b}{2}\right)^{2}}=a+\frac{b}{2}$

Evidencia 35. Sea $a>b$, entonces $\sqrt{a \cdot a-a \cdot b+\left(\frac{b}{2}\right)^{2}}=a-\frac{b}{2}$

Evidencia 36. Sea $a<b$, entonces $\sqrt{\left(\frac{b}{2}\right)^{2}-(a \cdot b-a \cdot a)}=a-\frac{b}{2}$. Añade que hay que tener cuidado porque suele tener dos soluciones diferentes. Esta es precisamente la regla que luego utilizará para resolver un caso concreto de ecuaciones de segundo grado en el que hay dos soluciones positivas, explicado en el Capítulo VI del Libro quinto (Puig, 1672, p. 397).

Evidencia 37. $\sqrt{a^{2} \cdot a+a^{2} \cdot b+\left(\frac{b}{2}\right)^{2}}=a^{2}+\frac{b}{2}$

Evidencia 38. La suma del cuadrado de la diagonal de un rectángulo más el doble de su área es igual al cuadrado de la suma de dos lados que son adyacentes a uno de los ángulos rectos. $d^{2}+2 \cdot A=(a+b)^{2}$ 
Evidencia 39. El cuadrado de la hipotenusa de un triángulo rectángulo más el cuadrado de su área es igual al cuadrado de la suma de los dos lados que son adyacentes al ángulo recto. $h^{2}+4 \cdot A=(a+b)^{2}$ 